Florida International University FIU Digital Commons

\title{
Comparative Evaluation on Human Infants Dietary Mercury Exposure through Consumption of Fish and Rice Products
}

Wenbin Cui

wcui001@fiu.edu

DOI: $10.25148 /$ etd.FIDC001932

Follow this and additional works at: https://digitalcommons.fiu.edu/etd

\section{Recommended Citation}

Cui, Wenbin, "Comparative Evaluation on Human Infants Dietary Mercury Exposure through Consumption of Fish and Rice Products" (2017). FIU Electronic Theses and Dissertations. 3464.

https://digitalcommons.fiu.edu/etd/3464 


\section{FLORIDA INTERNATIONAL UNIVERSITY}

Miami, Florida

\section{COMPARATIVE EVALUATION ON HUMAN INFANTS DIETARY MERCURY EXPOSURE THROUGH CONSUMPTION OF FISH AND RICE PRODUCTS}

A dissertation submitted in partial fulfillment of

the requirements for the degree of

DOCTOR OF PHILOSOPHY

in

CHEMISTRY

by

Wenbin Cui 
To: Dean Michael R. Heithaus

College of Arts, Sciences and Education

This dissertation, written by Wenbin Cui, and entitled Comparative Evaluation on Human Infants Dietary Mercury Exposure through Consumption of Fish and Rice Products, having been approved in respect to style and intellectual content, is referred to you for judgment.

We have read this dissertation and recommend that it be approved.
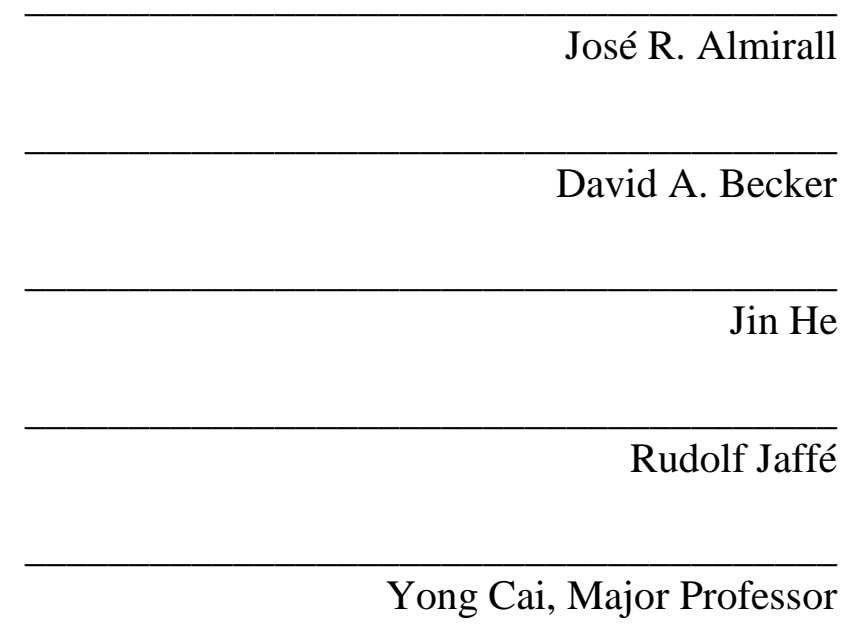

Date of Defense: June 27, 2017

The dissertation of Wenbin Cui is approved.

Dean Michael R. Heithaus College of Arts, Sciences and Education

Andrés G. Gil

Vice President for Research and Economic Development And Dean of the University Graduate School

Florida International University, 2017 
(C) Copyright 2017 by Wenbin Cui

All rights reserved. 


\section{DEDICATION}

I dedicate this work to my wife Jingyi Zhao, my daughter Rachel Cui, my parents Yongchun Cui and Junping Wang. I also dedicate this work and give special thanks to all my lab mates, faculties and staff of Chemistry department. Without their understanding, encouragement, support and help, the completion of this work would not have been possible. 


\section{ACKNOWLEDGMENTS}

I would like to thank all my committee members who were more than generous with their expertise and precious time. A special thanks to Dr. Yong Cai, my major advisor, for his incredible supervision, guidance and the patience through the entire process.

I also would like to acknowledge Dr. Rudolf Jaffé, Dr. Jose Almirall, Dr. Jin He, and Dr. David Becker for agreeing to serve as my committee members. I appreciate their valuable time, insightful advices, and precious suggestions to my research. I would like to express my sincere thanks to Dr. Yanbin Li, Dr. Bo Meng, Dr. Yiqun Xu, Dr. Yongmin Wang, Dr. Ping Jiang, Peter Lorenzo, Mark Kershaw for all helpful suggestions and discussion.

Special thanks go to Dr. Guangliang Liu, whose immeasurable help and guidance in the experiment design and dissertation writing supported me to get through the tough times of my entire research. I would also like to thank Department of Chemistry \& Biochemistry at Florida International University for the Teaching Assistant Fellowship during the five years. I wish to thank my lab mates for their support and patience. I also would like to thank my family for their endless support and love.

Finally, I wish to express my appreciation to those who have helped me in any respect during my study at FIU, as well as expressing my apology that I could not mention personally one by one. 


\title{
ABSTRACT OF THE DISSERTATION \\ COMPARATIVE EVALUATION ON HUMAN INFANTS DIETARY MERCURY \\ EXPOSURE THROUGH CONSUMPTION OF FISH AND RICE PRODUCTS
}

\author{
by \\ Wenbin Cui \\ Florida International University, 2017 \\ Miami, Florida \\ Professor Yong Cai, Major Professor
}

Human exposure to methylmercury (MeHg) through diets (e.g., fish and rice) is a global health concern. Although $\mathrm{MeHg}$ exposure through fish consumption has long been considered the major route of mercury health risks, studies concerning the long-term changes in $\mathrm{MeHg}$ exposure from fish remain lacking. In sharply contrast to the fish $\mathrm{MeHg}$ issue, the presence of $\mathrm{MeHg}$ in rice has only been reported recently and its implications on $\mathrm{MeHg}$ exposure, albeit probably important, are still in infancy. Focusing on the discrepancies in the studies of $\mathrm{MeHg}$ exposure through fish and rice consumption, this study was aimed to assess the $\mathrm{MeHg}$ exposure of human infants through consumption of rice cereals and to evaluate the long-term changes in fish $\mathrm{MeHg}$.

The presence of $\mathrm{MeHg}$ in rice prompted the studies on $\mathrm{MeHg}$ concentrations and bioaccessibility in rice cereals and potential infant dietary exposure to $\mathrm{MeHg}$ through cereal consumption, which is believed to be the first of its kind. The analysis of a variety of infant cereals sampled from the common markets in the United States and China showed that the concentrations of MeHg in the cereals ranged from 0.07 to $13.9 \mu \mathrm{g} / \mathrm{kg}$ with a mean of $1.61 \mu \mathrm{g} / \mathrm{kg}$. On the basis of these $\mathrm{MeHg}$ concentrations, the daily intake 
of $\mathrm{MeHg}$ through rice cereal consumption for infants was estimated to be $4-122 \%$ of the reference dose (RfD). The MeHg bioaccessibility in the cereals, determined using an in vitro digestion method, ranged from 25 to $74 \%$ with a mean of $48 \pm 16 \%$. A further examination on these results, however, revealed the occurrence of $\mathrm{MeHg}$ re-adsorption during extraction steps, which leads to the underestimation of $\mathrm{MeHg}$ bioaccessibility and warrants cautions to be exercised when using these procedures to evaluate bioaccessibility in general.

The long-term changes in fish $\mathrm{MeHg}$ were investigated through conducting a comprehensive data analysis on datasets for the Everglades, a well-studied aquatic ecosystem for $\mathrm{Hg}$ contamination. The results showed a clear decline of $\mathrm{MeHg}$ in mosquitofish in the Everglades during the past two decades, which was probably related to changes in environmental conditions (e.g., periphyton, dissolve organic matter, and sulfate) instead of mercury deposition. 


\section{TABLE OF CONTENTS}

CHAPTER

PAGE

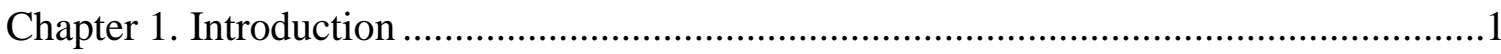

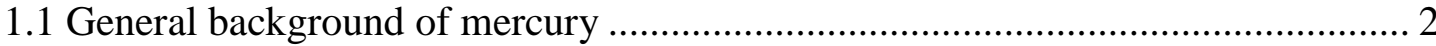

1.1.1 Sources of mercury to the environment ..................................................... 2

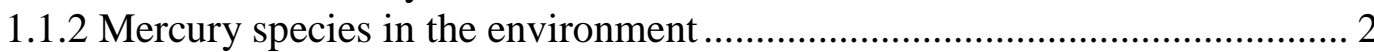

1.1.3 Exposure and toxicological effects of mercury ……................................. 3

1.2 Mercury exposure through fish consumption .................................................... 4

1.2.1 Aquatic mercury cycling and mercury bioaccumulation in fish .................... 4

1.2.2 Mercury concentrations in fish ................................................................. 5

1.3 Mercury exposure through consumption of rice products ...................................... 7

1.3.1 Terrestrial mercury cycling and mercury accumulation in rice ..................... 7

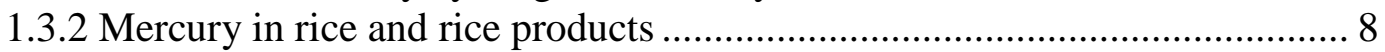

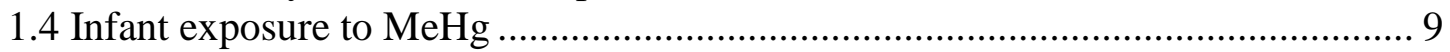

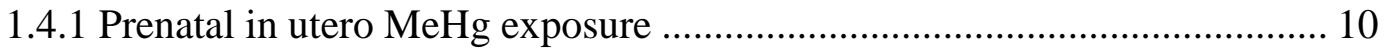

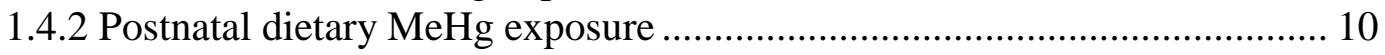

1.5 Bioavailability of $\mathrm{MeHg}$ in diet ................................................................. 12

1.6 Research gaps and objectives of this study ....................................................... 14

Chapter 2. Occurrence of Methylmercury in Rice-based Infant Cereal and Estimation of Daily Dietary Intake of Methylmercury for infants.................................................18

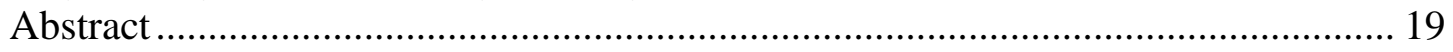

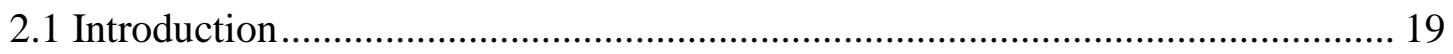

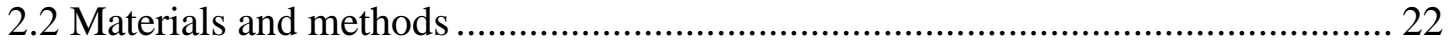

2.2.1 Infant cereal samples and sample classification ........................................ 22

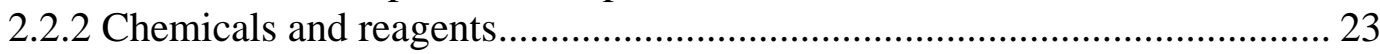

2.2.3 Determination of THg and MeHg in cereals.............................................. 24

2.2.4 Method validation and quality assurance..................................................... 25

2.2.5 Estimation of daily intake of $\mathrm{MeHg}$ from rice-based cereal consumption .. 25

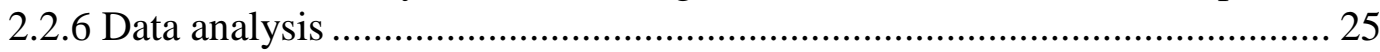

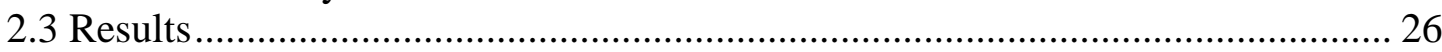

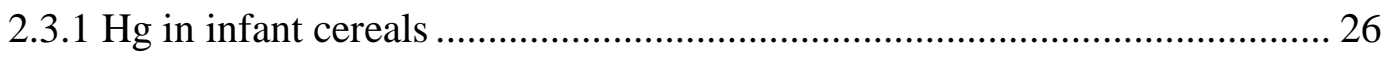

2.3.2 Estimation of daily intake of $\mathrm{MeHg}$ from rice-based cereal consumption .. 31

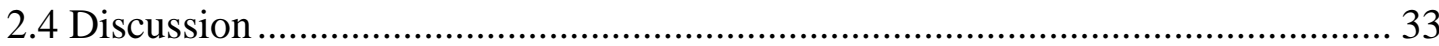

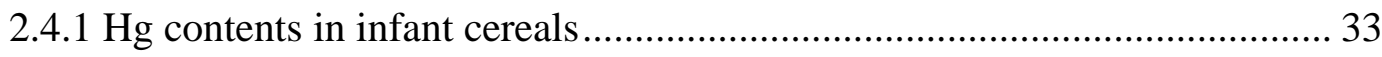

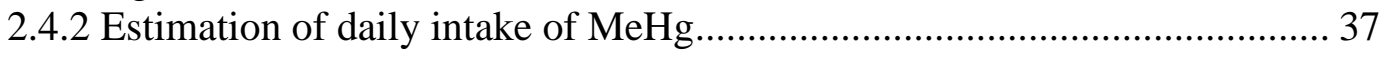

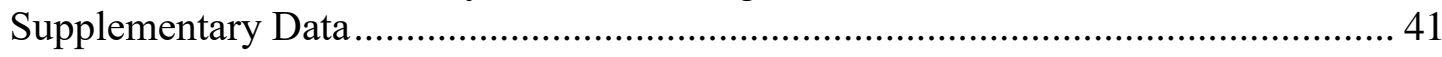

Chapter 3. Determination of Bioaccessibility of Methylmercury in Rice-based Infant

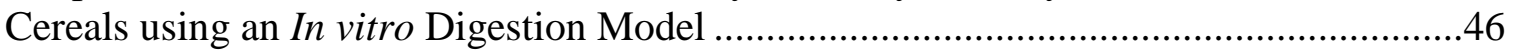

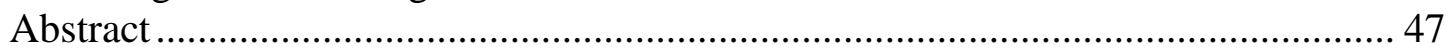

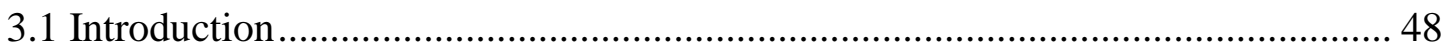

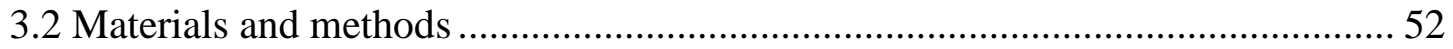




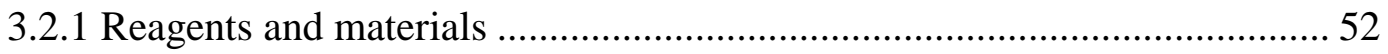

3.2.2 Sampling and preparation of rice cereal and fish samples........................... 53

3.2.3 In vitro artificial gastrointestinal fluid digestion ......................................... 54

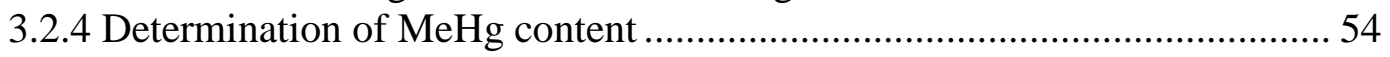

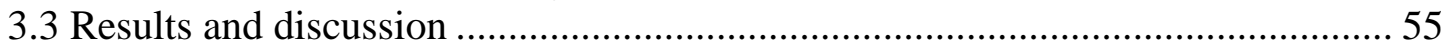

3.3.1 Bioaccessibility of $\mathrm{MeHg}$ in rice cereals and possible affecting factors ..... 55

3.3.2 Effect of re-adsorption on MeHg bioaccessibility .......................................... 61

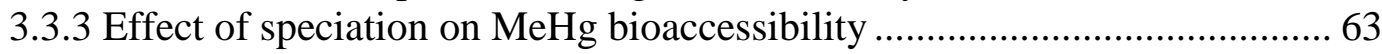

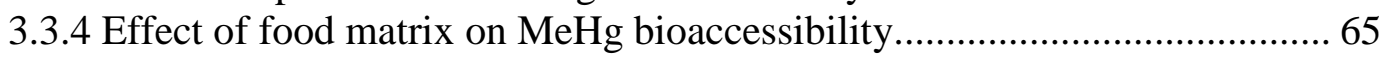

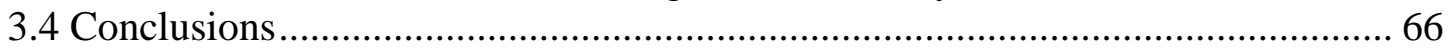

Chapter 4. Decadal Variations of Mercury in Mosquito Fish in the Everglades and Relation to Changes in Atmospheric Hg Deposition and Ecosystem Alteration................68

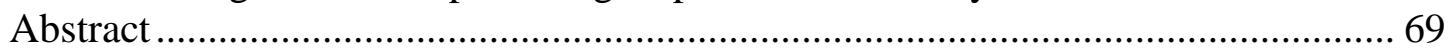

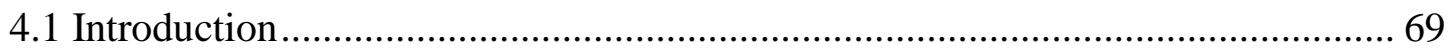

4.2 Materials and methods ............................................................................... 72

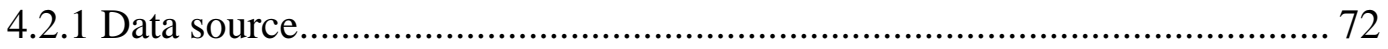

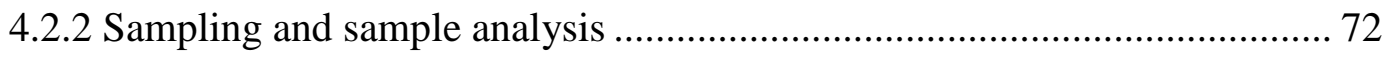

4.2.3 Measurement of MeHg in the porewater of sediment/floc and absorbed

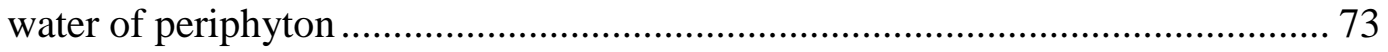

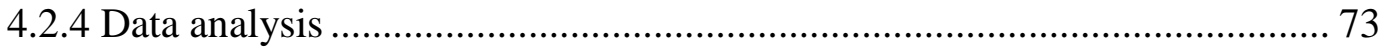

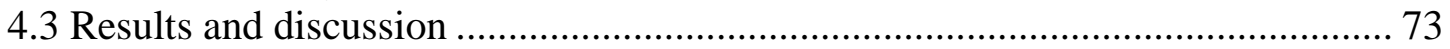

4.3.1 Variation of mercury in Everglades mosquitofish from 1995 to 2014 .........73

4.3.2 Change in $\mathrm{Hg}$ atmospheric deposition into Everglades and its effects on

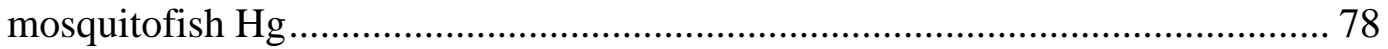

4.3.3 Ecosystem alteration in the Everglades and its effects on mosquitofish $\mathrm{Hg} 80$

4.3.4 Possible reasons of the decrease in periphyton $\mathrm{MeHg}$ from 1995 to 2014.. 84

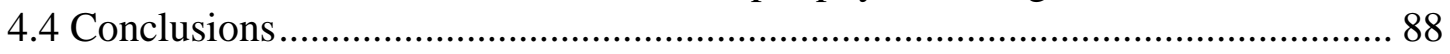

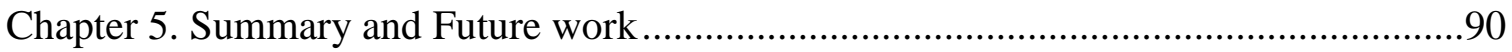

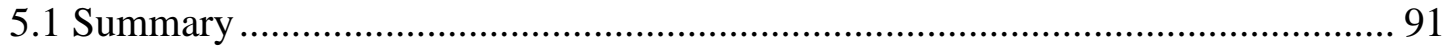

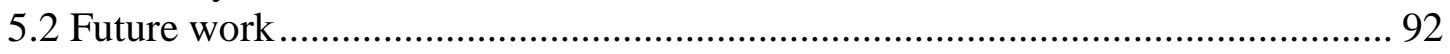

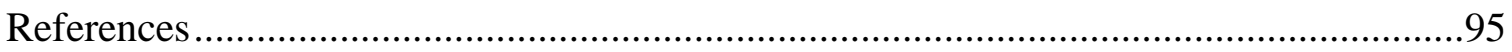

VITA 


\section{LIST OF TABLES}

TABLE

PAGE

Table 1.1 Reported Hg concentration in fish and shellfish.................................6

Table 1.2 Summary of commonly used in vitro digestion model...........................13

Table $2.1 \mathrm{Hg}$ concentrations $(\mu \mathrm{g} / \mathrm{kg})$ and $\mathrm{MeHg} / \mathrm{THg}$ ratios in infant cereals..........26

Table 2.2 General information and mercury levels of the tested cereal samples .......42

Table $3.1 \mathrm{Hg}$ concentrations and bioaccessibilities of infant rice cereals and fish.....56

Table 4.1 Correlation analysis and multiple regression analysis of $\mathrm{Hg}$ in

mosquitofish and $\mathrm{MeHg}$ periphyton with environmental parameters.......................85 


\section{LIST OF FIGURES}

FIGURE

PAGE

Figure 1.1. Mercury cycling pathways in aquatic environments .............................5

Figure 1.2. Mercury cycling in rice paddy field .................................................

Figure 2.1. MeHg and $\mathrm{THg}$ levels in the infant cereal samples tested $(\mu \mathrm{g} / \mathrm{kg}) \ldots \ldots \ldots . .28$

Figure 2.2. $\mathrm{MeHg}$ and $\mathrm{THg}$ content in rice cereals purchased from different cities....29

Figure 2.3. $\mathrm{MeHg}$ and $\mathrm{THg}$ level in different brands of rice cereals ......................... 30

Figure 2.4. Estimation of average dietary $\mathrm{MeHg}$ daily intake from cereal consumption (dot) and breastmilk consumption (diagonal) for first year infants .......32

Figure 2.5. Boxplots of $\mathrm{MeHg} / \mathrm{THg}$ ratios in different types of cereals ..................... 35

Figure 3.1. MeHg levels and bioaccessibilities in infant rice cereal and fish.............58

Figure 3.2. MeHg bioaccessibility in dual step digestion ....................................59

Figure 3.3. $\mathrm{MeHg}$ measured in supernatant and residue of rice cereal samples under different digestion time

Figure 3.4. MeHg bioaccessibility determined using multiple steps extraction

Figure 3.5. Bioaccessible MeHg in supernatant and residue of undigested samples ..64

Figure 4.1. Long-term variation in the mosquito fish $\mathrm{Hg}$ in the Everglades, and WCA 1, WCA 2, WCA 3 and ENP parts of the Everglades from 1995-2014 (EPAREMAP data)

Figure 4.2. Long-term variation in the mosquito fish $\mathrm{Hg}$ from 1995-2014 (data obtained from SFWD DBHYDRO data) 76

Figure 4.3. Long-term variation in the large bass and sunfish $\mathrm{Hg}$ from 1999-2015....77

Figure 4.4. Wet deposition of $\mathrm{Hg}$ into the Florida Everglades and $\mathrm{THg}$ in

Everglades sediment and water.

Figure 4.5. Long-term variation in $\mathrm{MeHg}$ in Everglades water, sediment, and periphyton from 1995-2014 (EPA-REMAP data).

Figure 4.6. PCA and $\mathrm{CA}$ analyses of $\mathrm{Hg}$ in fish with $\mathrm{Hg}$ in other matrices (a, floc included, b, floc not included) and $\mathrm{MeHg}$ in periphyton with environmental factors. 82 
Figure 4.7. MeHg concentrations in Everglades soil/floc porewater, periphyton

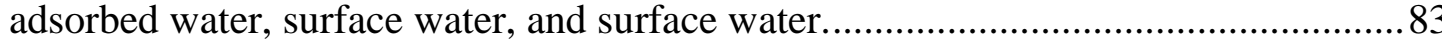

Figure 4.8. Long-term variation in Everglades periphyton $\mathrm{THg}$, and $\mathrm{TP}, \mathrm{SO}_{4}^{2-}$, TOC, $\mathrm{H}_{2} \mathrm{~S}$, water depth in Everglades water from 1995-2014 (EPA-REMAP data). . 87 


\section{ABBREVIATIONS AND ACRONYMS}

\begin{tabular}{|c|c|}
\hline Chl-a & Chlorophyll a \\
\hline CV-GCAFS & Cold vaper gas chromatography atomic florescence spectrometry \\
\hline EDI & Estimated daily intake \\
\hline GI & Gastrointestinal \\
\hline $\mathrm{Hg}$ & Mercury \\
\hline $\mathrm{Hg}^{0}$ & Elemental mercury \\
\hline $\mathrm{Hg}^{2+}$ & Mercuric mercury \\
\hline $\mathrm{IHg}$ & Inorganic mercury \\
\hline IQ & Intelligence quotient \\
\hline LMB & Largemouth bass \\
\hline $\mathrm{MeHg}$ & Methylmercury \\
\hline NOM & Natural organic matter \\
\hline $\mathrm{ppm} / \mathrm{ppb}$ & Parts per million/billion \\
\hline Rfd & Reference dose \\
\hline SRB & Sulfate reducing bacteria \\
\hline USEPA & United States Environmental Protection Agency \\
\hline USFDA & United States Food and Drug Administration \\
\hline
\end{tabular}


Chapter 1. Introduction 


\subsection{General background of mercury}

\subsubsection{Sources of mercury to the environment}

Mercury (Hg), a heavy metal, is a highly toxic element that is introduced into the environment both naturally and anthropogenically. ${ }^{1}$ Natural sources of $\mathrm{Hg}$ may include geologic activities such as volcanic and geothermal emissions, volatilization of $\mathrm{Hg}$ in marine environments, and emission of $\mathrm{Hg}$ from terrestrial environments. Anthropogenic emissions of mercury can result from a variety of activities, including coal burning, waste incineration, and mining. Previous studies suggested that the annual mercury emissions from natural processes were approximately $5,207 \mathrm{Mg}$, while the anthropogenic emissions were estimated to be $2,035 \mathrm{Mg}$. It should be borne in mind that high uncertainties are present for the estimation of $\mathrm{Hg}$ emissions from both natural and anthropogenic sources, resulting in large variation in the relative importance of these two sources reported in the literature. ${ }^{2,3}$ Once released into the environment, mercury can be transported over a long distance in the atmosphere (and hence it is a global contaminant), undergo complicated biogeochemical processes in the environment, accumulate in the food web, and consequently pose severe adverse effects on human and ecosystem health. ${ }^{4,5}$ Mercury contamination in various ecosystems has been a global concern for decades. ${ }^{6-9}$

\subsubsection{Mercury species in the environment}

Mercury can exist in the environment in different forms at three oxidation states, $\mathrm{Hg}^{0}$ (metallic), $\mathrm{Hg}^{2+}$ (mercuric), and $\mathrm{Hg}^{+}$(mercurous), with the last one being rare because of its instability. ${ }^{10-13}$ In pure form, it is known alternatively as "elemental" or "metallic" mercury and usually expressed as $\mathrm{Hg}^{0}$. Elemental $\mathrm{Hg}$ can be transformed into many inorganic and organic mercury species by undergoing a variety of processes in the 
environment. ${ }^{12}$ Major inorganic Hg species include mercuric sulfide (HgS), mercuric oxide $(\mathrm{HgO})$, and other mercury salts such as mercuric chloride $\left(\mathrm{HgCl}_{2}\right)$. In the environment, inorganic mercury may be converted into organic forms such as methylmercury (MeHg). Methylmercury is the most toxic and common organic mercury compound in the biogeochemical cycling of $\mathrm{Hg}$. Methylmercury is primarily formed in the environment by microbial processes in the presence of sulfate reducing or iron reducing bacteria, although abiotic processes, such as chemical methylation of inorganic Hg species, could produce MeHg. ${ }^{10,11,14}$. Other organomercury species occurring in the environment include ethylmercury (EtHg) and phenylmercury (PhHg) and dimethylmercury (DMHg). The occurrence of EtHg in the environment has been reported, suggesting that EtHg could be an important species during $\mathrm{Hg}$ biogeochemical cycling, although how EtHg occurs in the environment remains unclear. ${ }^{15}$ The cause of $\mathrm{PhHg}$ occurrence in the environment is considered to be related to historical discharge. ${ }^{16}$

\subsubsection{Exposure and toxicological effects of mercury}

All $\mathrm{Hg}$ species are toxic, and the toxicological effects of mercury exposure are dependent on the forms of ingested $\mathrm{Hg}$, among other factors. Of the common $\mathrm{Hg}$ species, elemental $\mathrm{Hg}$ can cross the membranes of cells and enter the circulatory system, then pose adverse effects on the blood cells, the central nervous system, and kidneys. At the same time, elemental $\mathrm{Hg}$ also can cross the placenta and accumulate in fetus, affecting the development of nervous system of fetus. The mercuric mercury $\left(\mathrm{Hg}^{2+}\right)$ usually affects amino acid transfer and accumulates in kidneys and may cause renal damage. Methylmercury, once entering the body, inhibits the formation of microtubule and synthesis of protein in neurons, affects membrane activities, and causes DNA damage. 
Severe kidney damage is also the result of MeHg poisoning. ${ }^{17-19}$ More importantly, ingested MeHg in pregnant women can be almost completely (95\%) absorbed and readily cross the placenta and blood-brain barriers, hence posing severe health risks to fetus. ${ }^{20}$

Historically incidental, acute mercury exposure, e.g., in Iraq and Minamata, Japan, has occurred. Both incidents were the results of consumption of $\mathrm{Hg}$ contaminated food, where in Iraq grain treated with $\mathrm{MeHg}$ as a fungicide was used to make bread and in Japan seafood in the Minamata Bay contaminated by MeHg from a chemical plant discharge was consumed. The MeHg poisoning occurred in Iraq caused 6530 patients being admitted to hospital and 459 of them died eventually. ${ }^{21-23}$ While 2252 patients were officially diagnosed as Minamata disease, 1043 of them died in the tragedy that occured in Minamata city, Japan. ${ }^{24-27}$ Nowadays acute MeHg poisoning incidents are rare. Instead, human mercury exposure occurs mainly through consumption of food, in particular fish/shellfish.

\subsection{Mercury exposure through fish consumption}

\subsubsection{Aquatic mercury cycling and mercury bioaccumulation in fish}

The major source of $\mathrm{Hg}$ in aquatic system is atmospheric $\mathrm{Hg}$ deposition. ${ }^{28}$ Once entering aquatic ecosystems, $\mathrm{Hg}$ exists in different forms and undergoes various chemical and physical transformations.(Figure 1.1) ${ }^{29}$ In aquatic system, dissolved $\mathrm{Hg}^{2+}$ can be reduced to $\mathrm{Hg}^{0}$ with the involvement of aquatic microorganism activities or abiotic processes. The formed $\mathrm{Hg}^{0}$ can then be emitted back to the atmospheric phase of $\mathrm{Hg}$ cycling. More importantly and relevant to $\mathrm{Hg}$ bioaccumulation and subsequent human exposure, the dissolved $\mathrm{Hg}$ can be methylated to $\mathrm{MeHg}$ in the aquatic environment, which is mainly driven by the microbial activities with sulfate (and iron) reducing 
bacteria (SRB) being considered as the major contributor. The formed $\mathrm{MeHg}$ can be readily taken up by aquatic organisms and then bioaccumulated through aquatic food chains. ${ }^{29}$ Studies have shown that Mercury in aquatic environment can be transferred into fish through food web, and around 50\% ingested methylmercury accumulate in fish muscle tissue. ${ }^{30,31}$ By undergoing bioaccumulation, the concentration of MeHg in large predatory fish could reach $\mathrm{mg} / \mathrm{kg}(\mathrm{ppm}$ ) levels, leading to human $\mathrm{Hg}$ exposure from fish consumption.

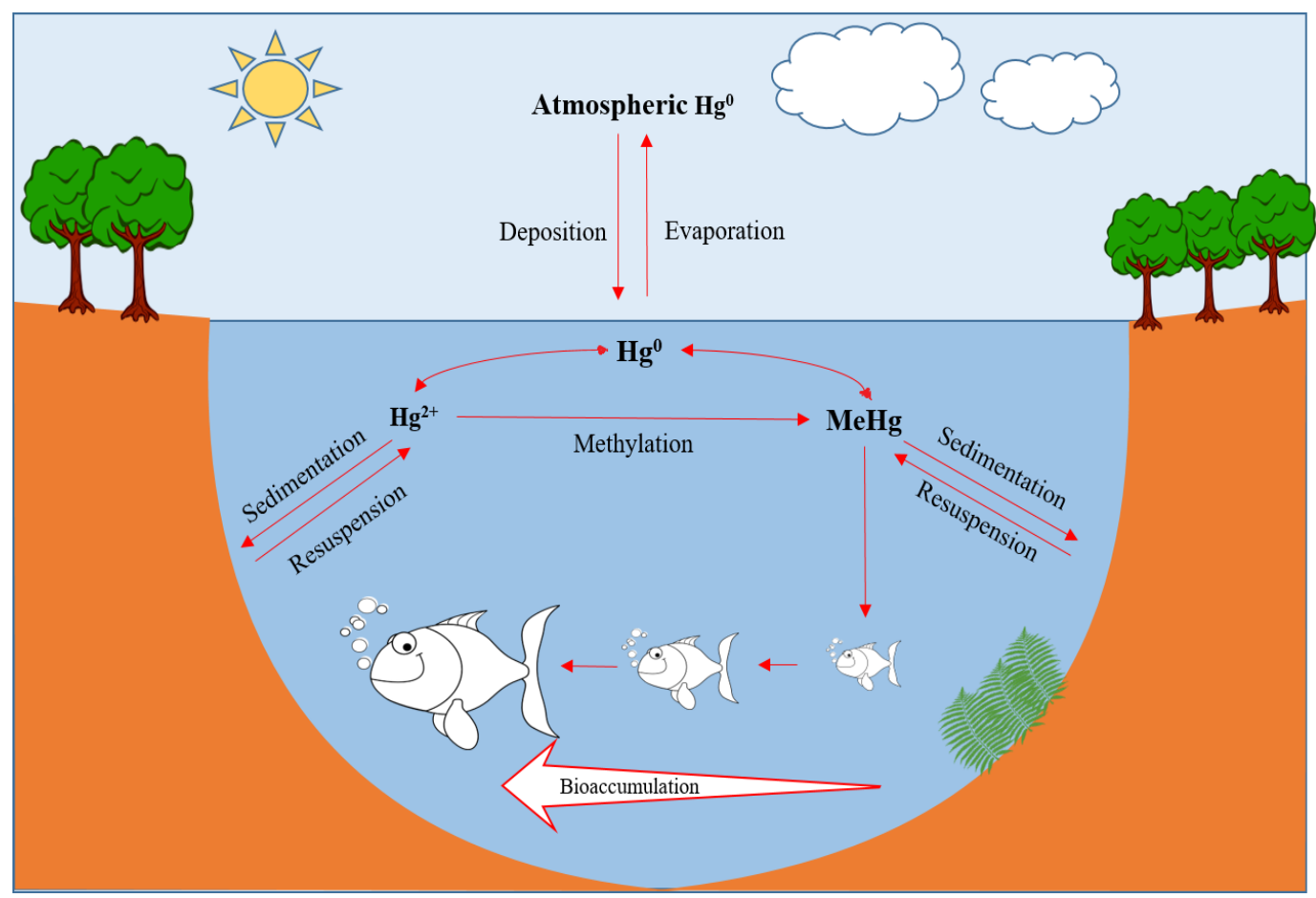

Figure 1.1. Mercury cycling pathways in aquatic environments ${ }^{28,29}$

\subsubsection{Mercury concentrations in fish}

Typically, as MeHg accumulates in fish tissue, human beings can be exposed to MeHg mainly via fish consumption. According to the United States Environmental Protection Agency (USEPA) nearly all methylmercury exposures in the U.S. occur 
through eating fish and shellfish that contain high levels of methylmercury. ${ }^{32}$ Some communities eat significantly more quantities of fish than the general population, and thus may be exposed to much greater mercury contamination than the general population. Hence the USEPA suggests issuing a fish consumption advisory when concentrations of $\mathrm{MeHg}$ in fish exceed a specific value. The concentrations of $\mathrm{Hg}$ in some common fish and shellfish reported by United States Food and Drug Administration are summarized in Table $1.1 .^{33}$

Table 1.1. Reported Hg concentration in fish and shellfish ${ }^{33}$

\begin{tabular}{|c|c|c|c|c|c|}
\hline Species & $\begin{array}{c}\text { Mercury } \\
\text { concentration } \\
\text { Mean } \\
(\mathrm{mg} / \mathrm{kg})\end{array}$ & $\begin{array}{c}\text { Mercury } \\
\text { concentration } \\
\text {, Median } \\
(\mathrm{mg} / \mathrm{kg})\end{array}$ & $\begin{array}{c}\text { Mercury } \\
\text { concentratio } \\
\mathrm{n}, \text { Min } \\
(\mathrm{mg} / \mathrm{kg})\end{array}$ & $\begin{array}{c}\text { Mercury } \\
\text { concentration } \\
, \text { Max } \\
(\mathrm{mg} / \mathrm{kg})\end{array}$ & $\begin{array}{c}\text { Number } \\
\text { of } \\
\text { samples }\end{array}$ \\
\hline Carp & 0.11 & 0.134 & ND & 0.271 & 14 \\
\hline Catfish & 0.024 & 0.005 & ND & 0.314 & 59 \\
\hline Marlin & 0.485 & 0.39 & 0.1 & 0.92 & 16 \\
\hline Oyster & 0.012 & ND & ND & 0.25 & 61 \\
\hline Salmon & 0.022 & 0.015 & ND & 0.19 & 94 \\
\hline Tilapia & 0.013 & 0.004 & ND & 0.084 & 32 \\
\hline Tuna & 0.358 & 0.36 & ND & 0.82 & 43 \\
\hline Shark & 0.979 & 0.811 & ND & 4.54 & 356 \\
\hline Snapper & 0.166 & 0.113 & ND & 1.366 & 67 \\
\hline Swordfish & 0.995 & 0.87 & ND & 3.22 & 636 \\
\hline Bass & 0.354 & 0.303 & ND & 2.18 & 74 \\
\hline Bluefish & 0.368 & 0.305 & 0.089 & 1.452 & 94 \\
\hline Clam & 0.009 & 0.002 & ND & 0.028 & 15 \\
\hline
\end{tabular}

$* \mathrm{ND}=$ Not determined

Because of the health risk caused by MeHg intake through eating fish, a great deal of efforts has been made to investigate distribution and magnitude of $\mathrm{Hg}$ in fish worldwide during the last few decades. The sources of $\mathrm{Hg}, \mathrm{Hg}$ accumulation process, concentrations of $\mathrm{Hg}, \mathrm{MeHg} / \mathrm{Hg}$ ratios, and $\mathrm{Hg}$ species in fish have been studied by different research groups. ${ }^{34-42}$ The MeHg uptake through consumption of fish has been evaluated and 
quantified, including the establishment of daily intake dose by governmental and international agencies, with the USEPA reference dose (RfD) of MeHg of $0.1 \mu \mathrm{g} / \mathrm{kg}$ bw/day being widely used. ${ }^{43}$

\subsection{Mercury exposure through consumption of rice products}

\subsubsection{Terrestrial mercury cycling and mercury accumulation in rice}

In addition to aquatic cycling and bioaccumulation, terrestrial cycling of $\mathrm{Hg}$, in particular in rice paddy fields, could also result in the production and accumulation of MeHg. Atmospheric $\mathrm{Hg}$ can be transferred to terrestrial environments via wet and dry depositions. ${ }^{44}$ The reactive gaseous mercury and a portion of $\mathrm{Hg}$ on the surface of soil can rapidly volatilize back into the atmosphere, ${ }^{29}$ while a large portion of $\mathrm{Hg}$ remains in the soil with long retention times. ${ }^{45}$

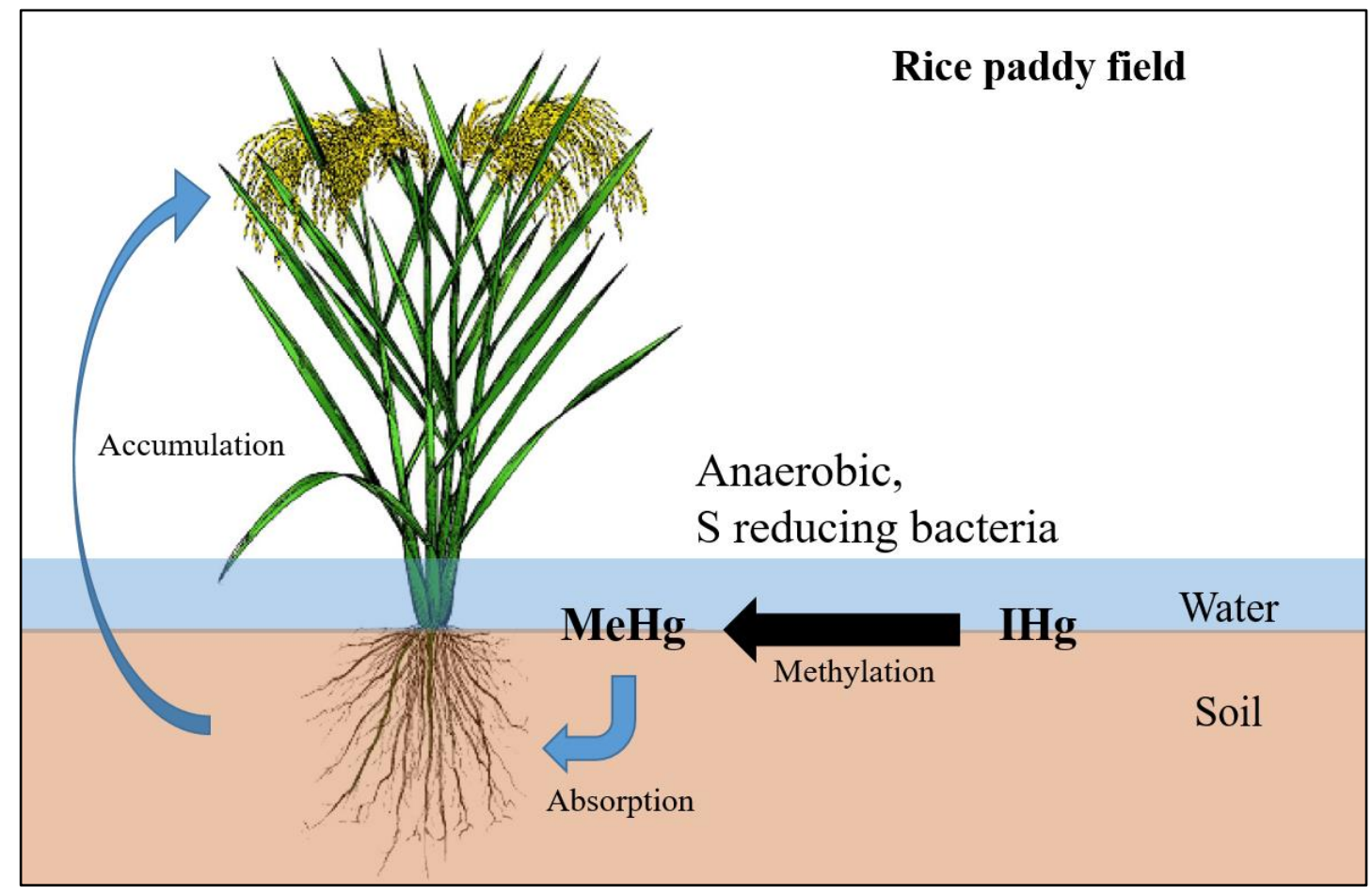

Figure 1.2. Mercury cycling in rice paddy field $28-29,45-51$ 
The $\mathrm{Hg}$ that remains in soil are mainly bound or associated with minerals and organic matter. ${ }^{46}$ While some of $\mathrm{Hg}$ in soil still can get back to the atmosphere by forming volatile $\mathrm{Hg}^{0}$ through reduction of $\mathrm{Hg}^{28}$ in soil, some $\mathrm{Hg}$ could be methylated to form $\mathrm{MeHg}$. The process is especially important for rice paddy fields where the conditions are inductive for $\mathrm{Hg}$ methylation, resulting in $\mathrm{MeHg}$ production and accumulation in rice. Rice paddy is the dominant agricultural land used for rice plantation, and rice paddy fields also have been considered as important sites for the methylation of $\mathrm{Hg}$ in terrestrial ecosystems. ${ }^{47-51}$ As the rice paddy has temporarily flooded soil, the methylation of $\mathrm{Hg}$ in soil is greatly facilitated in the presence of sulfate reducing bacteria in anaerobic conditions. The formed $\mathrm{MeHg}$ can be absorbed by the root and then bioaccumulated through rice plant during the growing season. During the ripening season of rice, $\mathrm{MeHg}$ would be readily transferred and accumulated in rice grains.

\subsubsection{Mercury in rice and rice products}

Although consumption of fish was considered as the only major pathway of $\mathrm{MeHg}$ exposure to human beings for decades, recent studies have shown that rice consumption could also be a main pathway of $\mathrm{MeHg}$ exposure to human, e.g., in $\mathrm{Hg}$ mining areas and in certain inland areas in Southwestern China. ${ }^{52-54}$ Over the last decade, studies have confirmed the occurrence of $\mathrm{MeHg}$ in rice grain, ${ }^{47,52,55,56}$ and found that concentration of $\mathrm{MeHg}$ and ratios of $\mathrm{MeHg} / \mathrm{THg}$ in rice grains are usually much higher than in other plants grown in the same area. ${ }^{49,57}$ On the basis of the data reported, the estimated average concentrations of $\mathrm{THg}$ and $\mathrm{MeHg}$ in rice grains are 8.2 and $2.5 \mu \mathrm{g} / \mathrm{kg}$ for nonpolluted sites and 65 and $16 \mu \mathrm{g} / \mathrm{kg}$ for polluted areas (e.g., mercury or gold mining areas), respectively. 
The findings of elevated levels of MeHg in rice in certain areas suggest that consumption rice could be a potential MeHg exposure pathway to human which warrants further studies on this potential health risk issue, since rice is one of the most consumed staple food in human diet, sustaining approximately 3 billion people around the world. ${ }^{58}$ According to the data obtained so far, the MeHg concentration in rice produced in the US as reported in a few studies are close to that from non-polluted areas. ${ }^{52}$ Considering that the MeHg level is relatively low and the average rice ingestion in the US is generally lower than in countries living on rice, the calculation of daily intake of $\mathrm{MeHg}$ through consumption of US produced rice indicates that the occurrence of MeHg in rice is probably not a serious concern to adult health. However, great differences in adults and infants must be considered while assessing the potential human exposure to $\mathrm{MeHg}$ (see below about infant MeHg exposure).

\subsection{Infant exposure to MeHg}

When it comes to assess MeHg exposure and potential health risks, adults and infants should be treated differently, as the exposure pathways and the toxicological effects of $\mathrm{MeHg}$ are different for them. In fact, infants are much more sensitive to the adverse effects of MeHg exposure because of their high exposure/body weight ratio, and as a result the health risks of $\mathrm{MeHg}$ have been predominantly focused on children, infants, and pregnant women. ${ }^{59}$ Methylmercury exposure has been previously linked to loss of IQ points, delayed speech and decreased performance in memory function because of the most devastating effects of $\mathrm{MeHg}$ are on the developing central nervous system. ${ }^{60}$ The MeHg exposure for infants could be through prenatal in utero exposure to 
maternal MeHg or from postnatal diets, with the former being heavily focused whereas the latter largely overlooked in infant $\mathrm{MeHg}$ exposure studies.

\subsubsection{Prenatal in utero MeHg exposure}

Traditionally, prenatal exposure was considered as the main source of accumulation of $\mathrm{MeHg}$ in infants. As mentioned above, once being ingested by pregnant women through the consumption of fish, the $\mathrm{MeHg}$ can be easily absorbed and readily cross the placenta then transferred to fetus through cord blood. Currently, USEPA has set the reference dose of $\mathrm{MeHg}$ as $0.1 \mu \mathrm{g} / \mathrm{kg}$ bw/day, since high level of prenatal $\mathrm{MeHg}$ exposure to fetus may cause the cerebral, mental retardation, low birth weight, and early sensorimotor dysfunction. ${ }^{61}$ Hence, the best way to prevent fetus being exposed to $\mathrm{MeHg}$ seems to be the abandon of consumption of fish containing high levels of $\mathrm{MeHg}$.

\subsubsection{Postnatal dietary MeHg exposure}

The postnatal pathway for infant $\mathrm{MeHg}$ exposure was poorly studied, and only limited information can be found. In previous studies, postnatal exposure was considered primarily related to consumption of breast milk and fish-based food. ${ }^{62-66}$ The average concentrations of $\mathrm{MeHg}$ in breast milk were found to be $0.17 \mu \mathrm{g} / \mathrm{L}(\mathrm{n}=182)$ in Italy, 0.68 $\mu \mathrm{g} / \mathrm{L}(\mathrm{n}=11)$ in Slovenia, and $0.45 \mu \mathrm{g} / \mathrm{L}(\mathrm{n}=27)$ in Japan. ${ }^{63-67}$ The mean concentration of $\mathrm{MeHg}$ in fish-based infant food reported was $6.1 \mu \mathrm{g} / \mathrm{kg} .{ }^{68}$

Rice cereals have been largely overlooked when considering infant $\mathrm{MeHg}$ through diets, probably because of limited information on $\mathrm{Hg}$ and $\mathrm{MeHg}$ in rice and rice products. Considering the recently reported presence of $\mathrm{MeHg}$ in rice, even at elevated levels in some cases, it is intuitive to assume that the $\mathrm{MeHg}$ in rice could be transferred to the rice cereals resulting in the occurrence of $\mathrm{MeHg}$ in infant cereals. Although there have been 
no studies on the presence and concentrations of $\mathrm{MeHg}$ in infant rice cereals, previous studies have confirmed the occurrence of varying levels of THg in rice-based baby cereals. On the basis of the results of two studies conducted, the median concentrations of THg in different types of infant cereals sold in Portugal and Spain were reported to be $0.50(\mathrm{n}=26) \mu \mathrm{g} / \mathrm{kg}$, ranging from 0.15 to $2.90 \mu \mathrm{g} / \mathrm{kg}^{69}$ and $2.61 \mu \mathrm{g} / \mathrm{kg}(\mathrm{n}=91)$, from 0.66 to $5.13 \mu \mathrm{g} / \mathrm{kg}$, respectively. ${ }^{70}$ Hence, the existence of MeHg in rice-based baby cereals should be expected, as a consequence of the $\mathrm{MeHg}$ in rice made into cereals. Considering that the reported $\mathrm{MeHg}$ concentrations in rice are much higher than those in breast milk and comparable to (for unpolluted areas) or higher than (for polluted areas) MeHg fish-based infant food, it appears necessary to include rice cereals in assessment of infant $\mathrm{MeHg}$ exposure.

The increasingly popular rice cereals consumption in the infant diets further warrants the necessity of investigating the extent of $\mathrm{MeHg}$ contamination in rice-based baby cereals and the potential exposure of infants to $\mathrm{MeHg}$ through cereal consumption. Rice-based cereals have become a vital part of infant diet, as nearly all of infants in US are fed with infant rice cereals. ${ }^{72}$ During the last few decades, the bland taste, hypoallergenic properties of rice and presence of easily digested carbohydrates in rice, ${ }^{71}$ have made rice increasingly popular in production of baby foods, especially the ready-to-eat infant cereals, which are the most common first solid food being introduced to American infants. ${ }^{72}$ Approximately $81 \%$ of infants in the US are introduced to cereals by six months old. ${ }^{73}$ Because of the high prevalence of celiac disease (1 in 144) in US, ricebased food became the most safe first solid food fed to infants. ${ }^{74}$ The high intake of rice made food is distinct difference between infant and adult diets. Comparing to adults' diet, 
infants may consume much higher fractions of rice-based food, ${ }^{75}$ which could put infants at higher risks of $\mathrm{MeHg}$ exposure than adults. However, the $\mathrm{MeHg}$ exposure through consumption of rice cereals, which can be regarded as a new pathway for infants to be exposed to $\mathrm{MeHg}$, has drawn little attention.

Furthermore, although the RfD of MeHg has been established, the RfD set by USEPA only focused on the prenatal MeHg exposure, while the exposure mechanisms of prenatal and postnatal exposure are completely different. Hence, the usage of RfD in assessment of health risk caused by $\mathrm{MeHg}$ postnatal exposure may lead to misleading result. However, the postnatal dietary $\mathrm{MeHg}$ exposure are severely understudied currently, some of the critical information, for instant, the concentrations, bioaccessibilities, bioavailabilities of $\mathrm{MeHg}$ in different types of food except fish, are still missing.

\subsection{Bioavailability of MeHg in diet}

To estimate human infant's dietary exposure to $\mathrm{MeHg}$, not only $\mathrm{MeHg}$ concentration but also the bioavailability, which is presently defined as the proportion of an administer dose that reaches the systemic circulation, ${ }^{76}$ of $\mathrm{MeHg}$ in diet is needed, since only a fraction of ingested $\mathrm{Hg}$ could be released from digested food and then be absorbed eventually by human body. In vivo approaches are most commonly used method to determine the bioavailability of contaminant in food. It can provide the most direct data about how much $\mathrm{MeHg}$ in different matrices can get into human body. However, considering the complicacy and the high cost of in vivo bioavailability assessments, the in vitro gastrointestinal (GI) digestion models were developed for the evaluation the bioaccessibility of $\mathrm{MeHg}$, which defined as the fraction of ingested $\mathrm{MeHg}$ that is released 
and soluble in GI fluid. ${ }^{77}$ The in vitro GI digestion model is an easily controlled, reproductive method that simulates the digestion process occurred in digestive track, and then provides the information about how much and where the $\mathrm{MeHg}$ in food is solubilized. At present, there is no standard method, hence various models with different experimental designs exist. Some of commonly used methods were summarized in Table $1.2 .^{78-80}$

Table 1.2. Summary of commonly used in vitro digestion model ${ }^{78-80}$

\begin{tabular}{|c|c|c|c|}
\hline Method & Oral digestion & Stomach digestion & Intestine digestion \\
\hline $\begin{array}{c}\text { Simple } \\
\text { Bioaccessibility } \\
\text { extraction (SBET) }\end{array}$ & No & $\mathrm{pH} 1.5 \mathrm{HCl}, 1 \mathrm{~h}$ & No \\
\hline $\begin{array}{l}\text { In vitro digestion } \\
\text { model (RIVM) }\end{array}$ & $\begin{array}{c}\text { pH } 6.5 \\
\text { Artificial } \\
\text { Saliva, 5min } \\
\end{array}$ & $\begin{array}{l}\mathrm{pH} 2 \text { Artificial } \\
\text { gastric juice, } 2 \mathrm{~h}\end{array}$ & $\begin{array}{c}\text { pH } 7 \text { Artificial } \\
\text { intestinal juice, } 2 \mathrm{~h}\end{array}$ \\
\hline $\begin{array}{c}\text { Simulator of Human } \\
\text { Intestinal Microbial } \\
\text { Ecosystem of infants } \\
\text { (SHIME) }\end{array}$ & No & $\begin{array}{c}\text { pH } 4 \text { Artificial } \\
\text { gastric juice, } 3 \mathrm{~h}\end{array}$ & $\begin{array}{l}\mathrm{pH} 6.5 \text { Artificial } \\
\text { intestinal juice, } 5 \mathrm{~h}\end{array}$ \\
\hline $\begin{array}{l}\text { TNO gastrointestinal } \\
\text { Model (TIM) }\end{array}$ & $\begin{array}{l}\text { pH } 5 \text { Artificial } \\
\text { Saliva, } 5 \mathrm{~min}\end{array}$ & $\begin{array}{l}\text { Initial pH } 5 \text { Artificial } \\
\text { gastric juice, } \\
\text { decreasing to } \mathrm{pH} 3.5, \\
2.5,2 \text {, after } 30,60, \\
90 \mathrm{~min}\end{array}$ & $\begin{array}{l}\text { pH } 7 \text { Artificial } \\
\text { intestinal juice, } \\
\text { duodenal secretion } \\
\text { at } 1 \mathrm{ml} / \mathrm{min}, 6 \mathrm{~h}\end{array}$ \\
\hline
\end{tabular}

All the models were designed according to the residence time of food and properties of GI track, such as $\mathrm{pH}$ and chemical component in GI track. Efforts have been made to obtain the bioaccessibilities of $\mathrm{MeHg}$ in different types of seafood using various in vitro digestive models. The results of previous in vitro studies indicated that the bioaccessibilities of $\mathrm{MeHg}$ in seafood varied dramatically, ranging from 2 to $100 \% .^{78-83}$ Studies on assessment of $\mathrm{MeHg}$ bioaccessibility in rice and rice products remain lacking. 


\subsection{Research gaps and objectives of this study}

It can be seen from the aforementioned previous studies, the two major $\mathrm{MeHg}$ exposure pathways are at different stages of research maturity, with $\mathrm{MeHg}$ exposure through fish consumption being studied extensively but exposure from rice and rice products receiving much less attention. Nonetheless, important research gaps are still present for these $\mathrm{MeHg}$ exposure pathways, as discussed below.

Studies on $\mathrm{MeHg}$ in rice and rice products and the related $\mathrm{MeHg}$ exposure are still at the early stage, and little quantitative information is available for dietary mercury exposure through consumption of rice and rice products. The relative contribution and importance of mercury exposure through consumption of rice and rice products, in comparison to fish and shellfish, is not clear. On the basis of the limited available data, ${ }^{52,70,84}$ we assume that even the $\mathrm{MeHg}$ level in rice is lower than MeHg level in fish, rice and rice products still could create health risk to certain people, like infants. To assess the health hazard that may be caused by rice and rice products containing $\mathrm{MeHg}$, more data such as concentrations of $\mathrm{MeHg}$ in rice and rice products and daily intake from them are required. In particular, no studies have reported the concentrations of $\mathrm{MeHg}$ in infant rice cereals yet, to our best knowledge.

While bioaccessibility of MeHg in fish has been evaluated, no studies have attempted to assess the bioaccessibility of $\mathrm{MeHg}$ in rice and rice products.

Bioaccessibility should be considered when evaluating human dietary mercury exposure through food consumption, as mercury species are different in different foods and hence so is bioabsorption. The previously determined bioaccessibility of fish MeHg may not be applicable to the $\mathrm{MeHg}$ in rice and related products. Moreover, the results of $\mathrm{MeHg}$ 
bioaccessibility in seafood obtained from different studies varied within a wide range.

Even for the same type of fish, the bioaccessible $\mathrm{MeHg}$ could be largely different in interand intra-studies, with no real rational explanations being given. ${ }^{50,80,82,85,86}$. Therefore, to solve the concerns related to potentially misleading information on $\mathrm{MeHg}$ bioaccessibility, studies need to be conducted to more accurately evaluate the bioaccessibility of $\mathrm{MeHg}$ in different types of food.

In addition, the established Rfd for daily MeHg intake were all on the basis of epidemiologic studies where fish consumption was the primary MeHg exposure pathway. However, there are two factors, which may lead to MeHg Rfd for fish consumers not applicable for rice consumers, have been ignored. First, the contents in fish and rice are very different, as rice is rich in starch and fish is rich in protein, thus resulting in varying release and absorption efficiency of MeHg in GI track. Second, the MeHg Rfd was set on the basis of the assumption that MeHg may only get into infants through cord blood, which is a totally different exposure pathway than dietary $\mathrm{MeHg}$ exposure. The applicability and implications of using previously determined RfD to evaluate the $\mathrm{MeHg}$ exposure and the subsequent health risks need to be carefully examined.

As for $\mathrm{Hg}$ exposure through fish consumption, extensive studies have been conducted, but what remains lacking is a comprehensive analysis utilizing the databases that have been generated to examine the long-term changes of $\mathrm{MeHg}$ in fish and the possible environmental and ecological causes for these changes. Such a comprehensive data analysis on the changes of fish $\mathrm{MeHg}$ and exposure requires long-term and largescale studies on mercury biogeochemical cycling in typical ecosystems. The ecosystemwide mercury, geochemical, and ecological studies conducted in the Florida Everglades 
since 1980s provide an opportunity to examine the changes in fish $\mathrm{MeHg}$ and related controlling factors.

The Everglades is one of the largest freshwater wetlands in the world, ${ }^{87}$ and it is a subtropical ecosystem located in south Florida. As the input of $\mathrm{Hg}$ to the ecosystem is mainly from atmospheric deposition with only limited anthropogenic interferences involved, the studies on $\mathrm{Hg}$ in such an ecosystem would be representative. Elevated levels of $\mathrm{Hg}$ have been frequently detected in fish of the Everglades since 1980s, making it one of "hot spots" for $\mathrm{Hg}$ study. The long-term $\mathrm{Hg}$ studies in this system would help to obtain related information to investigate the $\mathrm{MeHg}$ level changes and explain the relationship between the $\mathrm{MeHg}$ in fish and environmental factors. The Everglades Regional Ecosystem Monitoring and Assessment Program (REMAP), a comprehensive monitoring and research project led by USEPA, ${ }^{29}$ was initiated in 1993 to study the source and biogeochemical cycling of $\mathrm{Hg}$ in the Everglades. Up to date, four phases have been completed (1995-96, 1999, 2005, 2014), involving approximately 1300 sampling stations. In addition to REMAP, several agencies have also conducted studies dealing with atmospheric mercury deposition, $\mathrm{Hg}$ transport and transformation, and $\mathrm{Hg}$ concentrations in game fish, wading birds and other large predators. These studies provide timely and critical information needed for a better understanding of the cycling of $\mathrm{Hg}$ in the Everglades. A comprehensive analysis on the data produced by these programs will reveal the changes of fish $\mathrm{MeHg}$ during the past years and provide information of great importance for a better understanding of the $\mathrm{MeHg}$ cycling, transport, transformation, and bioaccumulation in the ecosystem. 
Focusing on these research gaps as identified above, the objectives of this study were set for $\mathrm{MeHg}$ in rice products and potential $\mathrm{MeHg}$ exposure as follows: 1) To determine the levels of both $\mathrm{THg}$ and $\mathrm{MeHg}$ in common infant cereals representative of different regions of the US and China, two large markets in infant cereal usage; 2) To estimate the daily intake of $\mathrm{MeHg}$ through consumption of rice cereals and assess the potential health risks associated with $\mathrm{MeHg}$ ingestion through diets for infants; and 3) To investigate the bioaccessibility of $\mathrm{MeHg}$ in various infant rice cereal samples and fish that are commonly available on the market by using an in vitro digestion model and explore the possible reasons causing variations in $\mathrm{MeHg}$ bioaccessibility.

For the $\mathrm{Hg}$ in fish study, the objectives were to 1) elucidate the temporal $\mathrm{Hg}$ trend in mosquitofish in the past two decades; 2) evaluate the contributions of atmospheric deposition, climate change and ecosystem alteration to these changes; and 3) investigate how $\mathrm{Hg}$ in mosquitofish affect the $\mathrm{Hg}$ in lager fish at higher trophic level in the Everglades. 
Chapter 2. Occurrence of Methylmercury in Rice-based Infant Cereal and Estimation of Daily Dietary Intake of Methylmercury for infants

The work described in this chapter has been submitted to the Environmental Science \& Technology 


\begin{abstract}
Recent reports of elevated levels of methylmercury $(\mathrm{MeHg})$ in rice prompted us to reason that the $\mathrm{MeHg}$ in rice may be transferred to infant cereals, leading to potential $\mathrm{MeHg}$ exposure and health risks of infant cereal consumption. Hence, we determined total mercury (THg) and MeHg levels in 119 infant cereal samples commonly marketed in U.S. and China and estimated daily MeHg intake through cereal consumption to evaluate potential health risks. Concentrations of $\mathrm{THg}$ and $\mathrm{MeHg}$ in the tested cereal samples ranged from 0.35 to $15.9 \mu \mathrm{g} / \mathrm{kg}$ and from 0.07 to $13.9 \mu \mathrm{g} / \mathrm{kg}$ with means being 2.86 and $1.61 \mu \mathrm{g} / \mathrm{kg}$, respectively. Rice-based cereals contained significantly higher THg and $\mathrm{MeHg}$ than non-rice cereals, indicating that elevated levels of $\mathrm{MeHg}$ in rice could indeed be detected in rice cereals. Cereal consumption could be a potential pathway of $\mathrm{MeHg}$ exposure for infants, as the estimated $\mathrm{MeHg}$ daily intake through cereal consumption amounted to $4-122 \%$ of $\mathrm{MeHg}$ reference dose (RfD). This postnatal MeHg exposure through cereal consumption, a different pathway than prenatal exposure adopted for RfD calculations, should be further evaluated for its potential health risks.
\end{abstract}

\title{
2.1 Introduction
}

Mercury $(\mathrm{Hg})$ is a highly toxic element that occurs naturally in the environment and can be present as the result of human activities, such as combustion of fossil fuels. Mercury can exist in the environment in different forms, among which methylmercury (MeHg) is known as the most toxic $\mathrm{Hg}$ species produced mainly from microbial methylation of inorganic $\mathrm{Hg}$ ( $\mathrm{IHg}$ ) in sediment and soil. ${ }^{88}$ Methylmercury has been of 
particular interest because of its high neurotoxicity and capability of bioaccumulation through the food chain. ${ }^{1,89-91}$

Methylmercury accumulated in marine and freshwater fish is considered to be the major source of $\mathrm{MeHg}$ exposure to human, as $\mathrm{MeHg}$ may bio-magnify through food webs and reach $\mathrm{mg} / \mathrm{kg}$ levels in large predatory fish which are high enough to cause health risks to humans upon consumption. ${ }^{1,24,92}$ According to the United States Environmental Protection Agency ${ }^{29}$, nearly all human MeHg exposures in the US occur through consumption of fish and shellfish containing high concentrations of MeHg. ${ }^{32}$ For particular groups of people, such as fishermen or island residents who eat significantly more fish than general population, they may be exposed to high levels of MeHg.

Research conducted in southwestern China has shown that rice consumption could also be an important pathway of human exposure to $\mathrm{MeHg}$ in $\mathrm{Hg}$ mining areas as well as in certain inland areas in Southwestern China, where the amount of fish consumption is limited. ${ }^{48,93}$ The studies conducted worldwide confirmed the occurrence of MeHg in rice grains. ${ }^{52}$ The elevated levels of MeHg in rice are likely because of the enhanced methylation of inorganic $\mathrm{Hg}$ under the floored conditions in the rice paddy field. Rice preferably accumulates $\mathrm{MeHg}$ in its grains in comparison to inorganic $\mathrm{Hg}$, and concentration of $\mathrm{MeHg}$ in rice grains are usually much higher than in other plants grown in the same area. ${ }^{54,57}$ The finding that rice grain is possibly a pathway for human exposure to $\mathrm{MeHg}$ triggers the alarm and interest in further studies on this potential issue, since rice is one of the most important staple foods in human diets, sustaining approximately 3 billion people around the world.$^{58}$ Over the last decade, studies have investigated total $\mathrm{Hg}$ (THg) and MeHg levels in rice around the world. ${ }^{52,56,94}$ On the basis 
of the data reported, the estimated average concentrations of $\mathrm{THg}$ and $\mathrm{MeHg}$ in rice grains are 8.2 and $2.5 \mu \mathrm{g} / \mathrm{kg}$ for non-polluted sites and 65 and $16 \mu \mathrm{g} / \mathrm{kg}$ for polluted areas (e.g., mercury or gold mining areas), respectively. The $\mathrm{Hg}$ levels in rice produced in the US as reported in few studies are close to that from non-polluted areas, ${ }^{52}$ and it seems that the occurrence of $\mathrm{MeHg}$ in rice is probably not a serious concern to adult health, as the average rice ingestion in the US is generally lower than for people in countries that consume rice as the main part of the diet.

However, as far as risk assessment of the potential human exposure to $\mathrm{MeHg}$ is concerned, great differences in adults and children (in particular infants) must be considered. First, because of its bland taste, hypo-allergenic properties and presence of easily digested carbohydrates, ${ }^{71}$ rice has been increasingly used in production of baby foods, especially ready-to-eat infant cereals, which are the most common first solid food being fed to American infants. ${ }^{72}$ Approximately $81 \%$ of infants in the US are introduced to cereals by six months of age, ${ }^{73}$ and the high prevalence of celiac disease ( 1 in 144) also makes the rice-based food the most safe first solid food being fed to infants. ${ }^{74}$ Second, compared to adults' diet, infants may consume much higher fractions of rice-based food, ${ }^{75}$ which could put infants at higher risks of $\mathrm{MeHg}$ exposure than adults. Moreover, infants are much more sensitive to $\mathrm{MeHg}$ exposure because of their high exposure/body weight ratio. ${ }^{59}$ Since $\mathrm{MeHg}$ exposure has been previously linked to loss of IQ points, delayed speech, and decreased performance in memory function because of the most devastating effects of $\mathrm{MeHg}$ on the developing central nervous system, ${ }^{60}$ increasingly popular rice cereals consumption may lead to $\mathrm{MeHg}$ exposure and potential health risks 
in infants, which, as a new pathway for infants to be exposed to $\mathrm{MeHg}$, has drawn little attention.

Traditionally, prenatal exposure was considered as the main source of accumulation of $\mathrm{MeHg}$ in infants, while postnatal exposure was primarily related to consumption of breast milk and fish-based food. ${ }^{62-66}$ However, as a vital part of infant diet, rice-based cereals have been largely neglected because of the perception of low $\mathrm{Hg}$ in rice and rice

products. As elevated $\mathrm{MeHg}$ has been observed in rice and rice-based cereals, ${ }^{95}$ it is necessary to investigate the extent of $\mathrm{MeHg}$ contamination in rice-based baby cereals and the potential exposure of infants to $\mathrm{MeHg}$ through cereal consumption. Therefore, the objectives of this study were to 1) determine the levels of both $\mathrm{THg}$ and $\mathrm{MeHg}$ in common infant cereals representative of different regions of the US and China, two large markets in infant cereal usage, and 2) estimate the daily intake of $\mathrm{MeHg}$ through consumption of rice cereals and assess the potential health risks associated with $\mathrm{MeHg}$ ingestion through diets for infants.

\subsection{Materials and methods}

\subsubsection{Infant cereal samples and sample classification}

In this study, a total of 119 infant cereal samples were purchased, among which 58 samples were from four big cities in different regions of the U.S. (Miami, FL; New York, NY; San Jose, CA; and Chicago, IL) and 61 samples from four different cities in China (Beijing, Wuhan, Nanjing, and Qingdao). These cities are located geographically in different areas, representing possible rice derived food sources that infants would be exposed to in these two countries. Cereal samples were purchased in local grocery stores 
or online and then kept in a cabinet inside a Class 100 clean room (with inlet air purified by gold-coated sand to remove $\mathrm{Hg}$ ) to avoid contamination.

The cereal samples used here include common brands available in the market, and they were supplied in tin cans, cardboard boxes or plastic containers. The product information provided by the manufacturers about the products includes total fat, carbohydrate and protein amount per serving. The information is used in sample classification and data interpretation without further validation. The contents of carbohydrates, fat and proteins in these samples were in the range of $28.0-86.7 \%, 0.0-$ $12.6 \%$ and $1.9-15 \%$, respectively. For the convenience of discussion, the studied samples were grouped by the type of grain used to make cereals, including rice based (rice only, $\mathrm{n}$ = 79), multigrain based (mixture of rice and oat, wheat, corn, rye or quinoa, $n=9$ ) and other grain based (no rice at all, $\mathrm{n}=31$ ) cereals according to the ingredients given by the manufacturers. Rice-base cereals were further divided into different subgroups according to manufacturers, including brands A ( $\mathrm{n}=10), \mathrm{B}(\mathrm{n}=5), \mathrm{C}(\mathrm{n}=8), \mathrm{D}(\mathrm{n}=2), \mathrm{E}(\mathrm{n}=2)$, $F(n=2), G(n=3), H(n=6), I(n=10), J(n=10), K(n=2), L(n=4)$, and M ( $n=3)$. There are 12 other brands with one sample for each brand, they were classified as group $\mathrm{N}$. These samples were also classified by the locations, including Miami (MIA, $n=15$ ), New York (NY, $n=4)$, Saint Jose (SJ, $n=4)$, Chicago (CHI, $n=3)$, Beijing (BJ, $n=13)$, Qingdao (QD, $\mathrm{n}=13)$, Nanjing $(\mathrm{NJ}, \mathrm{n}=6)$ and Wuhan $(\mathrm{WH}, \mathrm{n}=21)$.

\subsubsection{Chemicals and reagents}

Ultrapure deionized water produced by a Barnstead Nanopure Diamond water purification system with resistivity of $18 \mathrm{M} \Omega \cdot \mathrm{cm}$ was used for preparing all solutions. American Chemical Society certified grade reagents, such as sulfuric acid, potassium 
hydroxide, hydrogen peroxide, copper sulfate, potassium bromide, methylene chloride, and tin chloride, and TraceMetal grade nitric acid and hydrochloric acid were used to minimize the blank problem. All chemicals were supplied by Fisher Scientific, unless otherwise specified. All glassware was soaked in $10 \%(\mathrm{v} / \mathrm{v})$ nitric acid for overnight, then rinsed with ultrapure deionized water, and baked at $500{ }^{\circ} \mathrm{C}$ in a muffle furnace for $5 \mathrm{~h}$ before use.

The acidic potassium bromide solution used for $\mathrm{MeHg}$ extraction was prepared by dissolving $180 \mathrm{~g}$ of $\mathrm{KBr}$ in $250 \mathrm{ml}$ water containing $50 \mathrm{ml}$ concentrated sulfuric acid, and the solutions were mixed up and made up to $1 \mathrm{~L}$ using water after cooling down to ambient temperature. Copper sulfate solution (1 M) and citric buffer (1 M) were prepared by adding appropriate amounts of salts in water. Ethylation reagent was prepared by

dissolving $1 \mathrm{~g}$ of sodium tetraethylborate ( $\mathrm{NaBEt}_{4}$, Sigma-Aldrich) in $100 \mathrm{ml}$ of $2 \%$ (w/w) potassium hydroxide. And $40 \mathrm{~g}$ of tin chloride was dissolved in $2 \mathrm{~L} 1 \%(\mathrm{v} / \mathrm{v})$ hydrochloric acid to obtain reductant solution used in $\mathrm{THg}$ analysis.

Certified $1000 \mathrm{mg} / \mathrm{L} \mathrm{Hg}$ and $10 \mathrm{mg} / \mathrm{L} \mathrm{MeHg}$ standard solutions were used for quantification during THg and MeHg analysis. Certified reference materials, GBW10043 (IGGE) rice flour and DORM-2 (National Research Council of Canada), were used for quality control and validation of $\mathrm{THg}$ and $\mathrm{MeHg}$ determination methods.

\subsubsection{Determination of $\mathrm{THg}$ and $\mathrm{MeHg}$ in cereals}

Concentration of THg was analyzed by using the slightly modified method described by Horvat et al., ${ }^{96}$ and $\mathrm{MeHg}$ levels in cereal samples were measured using a gas chromatography-atomic fluorescence spectrometry (GC-AFS) (Brooks Rand Automated 
MERX) MeHg System, following a extraction method reported previously. ${ }^{97}$ The details of sample preparation and analysis methods can be found in supplementary material.

\subsubsection{Method validation and quality assurance}

Quality control (QC) and quality assurance (QA) were performed following the established procedures. ${ }^{96}$ Limit of detection (LOD) of THg and MeHg analysis, estimated by three times standard deviation of 6 replicates of a blank sample, were $0.18 \mu \mathrm{g} / \mathrm{kg}$ and $0.05 \mu \mathrm{g} / \mathrm{kg}$, respectively. The accuracy of methods was evaluated by spiking reference standard solutions into samples and by analysis of certified reference materials. The mean recoveries of matrix-spiked standards for $\mathrm{MeHg}$ and $\mathrm{THg}$ analysis were $100.8 \pm 30.3 \%$ (n $=15)$ and $102.6 \pm 12.7 \%(\mathrm{n}=13)$, respectively. The mean recoveries of DORM-2 (Fish protein CRM certified for trace metals) and GBW10043 (rice flour CRM certified for metals) used in MeHg and THg determination were $90.5 \pm 27.7 \%(n=6)$ and $96.5 \pm$ $18.2 \%(n=6)$.

\subsubsection{Estimation of daily intake of MeHg from rice-based cereal consumption}

The daily intake of $\mathrm{MeHg}$ was calculated on the basis of the $\mathrm{MeHg}$ concentration in food, daily food consumption and body weight (bw) of infants. The equation 2.1 was used in calculation of estimated MeHg daily intake (EDI):

$$
\mathrm{EDI}=\frac{\sum\left(\mathrm{C}_{\mathrm{MeHg}} \times \mathrm{IR}\right)}{\mathrm{bw}}
$$

Where EDI is given in micrograms per kilogram of body weight per day; $\mathrm{C}$ is the concentration of $\mathrm{MeHg}(\mu \mathrm{g} / \mathrm{kg})$ and IR is intake rate $(\mathrm{g} / \mathrm{day})$.

\subsubsection{Data analysis}

All data were analyzed using JMP 10.0.0 software (SAS institute Inc., Cary, NC, USA) and Excel 2013 (Microsoft corp., WA, USA). General linear fit, one-way ANOVA, 
and box plot were used to identify significant differences $(\mathrm{p}<0.05)$ between data from two different groups of samples.

\subsection{Results}

\subsubsection{Hg in infant cereals}

The data of $\mathrm{Hg}$ levels in rice cereals studied were listed in Table 2.1. Detailed information about all cereal samples, including types of cereals (rice, other grain, and multi grain), concentrations of $\mathrm{THg}$ and $\mathrm{MeHg}$, locations purchased, and marketing brands are summarized in Table 2.2.

Table 2.1. Hg concentrations $(\mu \mathrm{g} / \mathrm{kg})$ and $\mathrm{MeHg} / \mathrm{THg}$ ratios in infant cereals.

\begin{tabular}{|c|c|c|c|c|c|c|}
\hline Type & $\mathrm{n}$ & $\mathrm{THg}^{\mathrm{a}}(\mu \mathrm{g} / \mathrm{kg})$ & $\mathrm{STD}$ & $\mathrm{MeHg}^{\mathrm{a}}(\mu \mathrm{g} / \mathrm{kg})$ & $\mathrm{STD}$ & $\mathrm{MeHg} / \mathrm{THg}^{\mathrm{b}}(\%)$ \\
\hline Rice & 79 & $\begin{array}{c}3.82(1.47- \\
15.88)\end{array}$ & 2.83 & $\begin{array}{c}2.29(0.57- \\
13.94)\end{array}$ & 2.46 & $57(16-96)$ \\
\hline $\begin{array}{c}\text { Multi- } \\
\text { grain }\end{array}$ & 9 & $\begin{array}{c}1.38(0.94- \\
2.91)\end{array}$ & 0.60 & $\begin{array}{c}0.70(0.27- \\
1.64)\end{array}$ & 0.44 & $51(23-80)$ \\
\hline $\begin{array}{c}\text { Other } \\
\text { grain }\end{array}$ & 30 & $\begin{array}{c}0.78(0.35- \\
1.14)\end{array}$ & 0.20 & $\begin{array}{c}0.12(\mathrm{BDL}- \\
0.26)\end{array}$ & 0.06 & $15(3-40)$ \\
\hline
\end{tabular}

${ }^{a}$ Mercury concentration in different types of cereal, means and ranges were presented ${ }^{b} \mathrm{MeHg} / \mathrm{THg}$ ratio (w/w) in different types of cereal, means and ranges were presented

The concentrations of $\mathrm{THg}$ and $\mathrm{MeHg}$ were presented for each group of cereals (ricebased, multigrain, and non-rice) in Fig. 2.1 (within group samples were ranked from high to low on the basis of $\mathrm{Hg}$ concentrations). For the group of rice-based cereal samples, the concentrations of $\mathrm{THg}$ and $\mathrm{MeHg}$ ranged from 1.47 to $15.9 \mu \mathrm{g} / \mathrm{kg}$ with a mean value of $3.81 \mu \mathrm{g} / \mathrm{kg}$ and from 0.51 to $13.9 \mu \mathrm{g} / \mathrm{kg}$ with a mean of $2.28 \mu \mathrm{g} / \mathrm{kg}$, respectively. For the multi-grain cereal samples, $\mathrm{THg}$ and $\mathrm{MeHg}$ concentrations were in the ranges of 0.94 - 
$2.91 \mu \mathrm{g} / \mathrm{kg}$ and $0.27-1.64 \mu \mathrm{g} / \mathrm{kg}$ with mean concentrations of 1.37 and $0.70 \mu \mathrm{g} / \mathrm{kg}$, respectively.
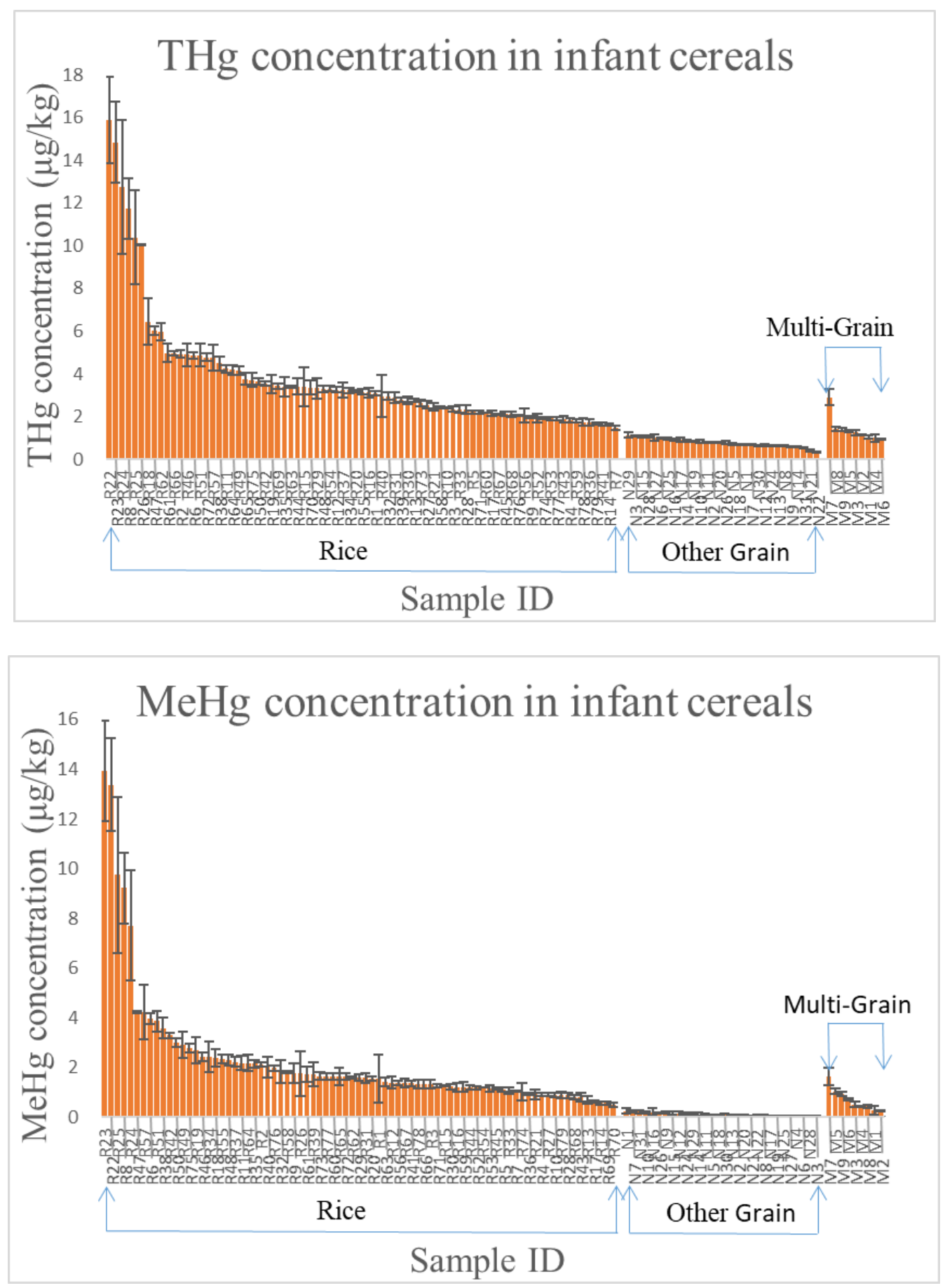

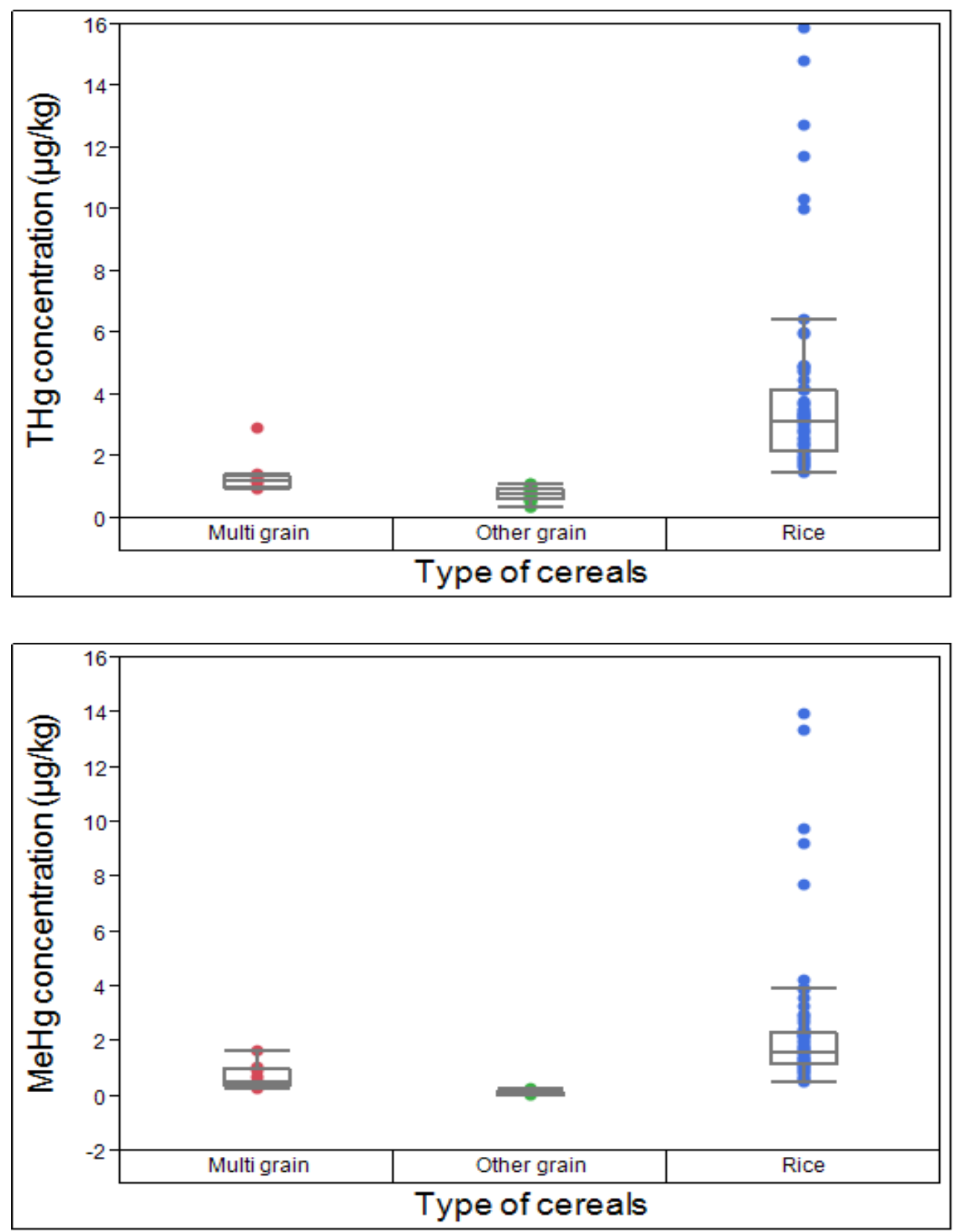

Figure 2.1. MeHg and THg levels in the infant cereal samples tested $(\mu \mathrm{g} / \mathrm{kg})$

The concentration ranges of $\mathrm{THg}$ and $\mathrm{MeHg}$ in no rice samples were $0.35-1.14 \mu \mathrm{g} / \mathrm{kg}$ and $0.03-0.26 \mu \mathrm{g} / \mathrm{kg}$ with mean values of 0.78 and $0.11 \mu \mathrm{g} / \mathrm{kg}$, respectively. Turkey's test on results of $\mathrm{Hg}$ determination suggests that $\mathrm{THg}$ concentrations in rice-based cereal 
samples were significantly higher than those in cereals contain no rice ( $\mathrm{p}<0.0001)$, and multi-grain cereals $(\mathrm{p}=0.0103)$. While the $\mathrm{MeHg}$ concentrations in rice cereal were only significantly higher than those in non-rice grain cereal samples $(\mathrm{p}<0.0001)$.
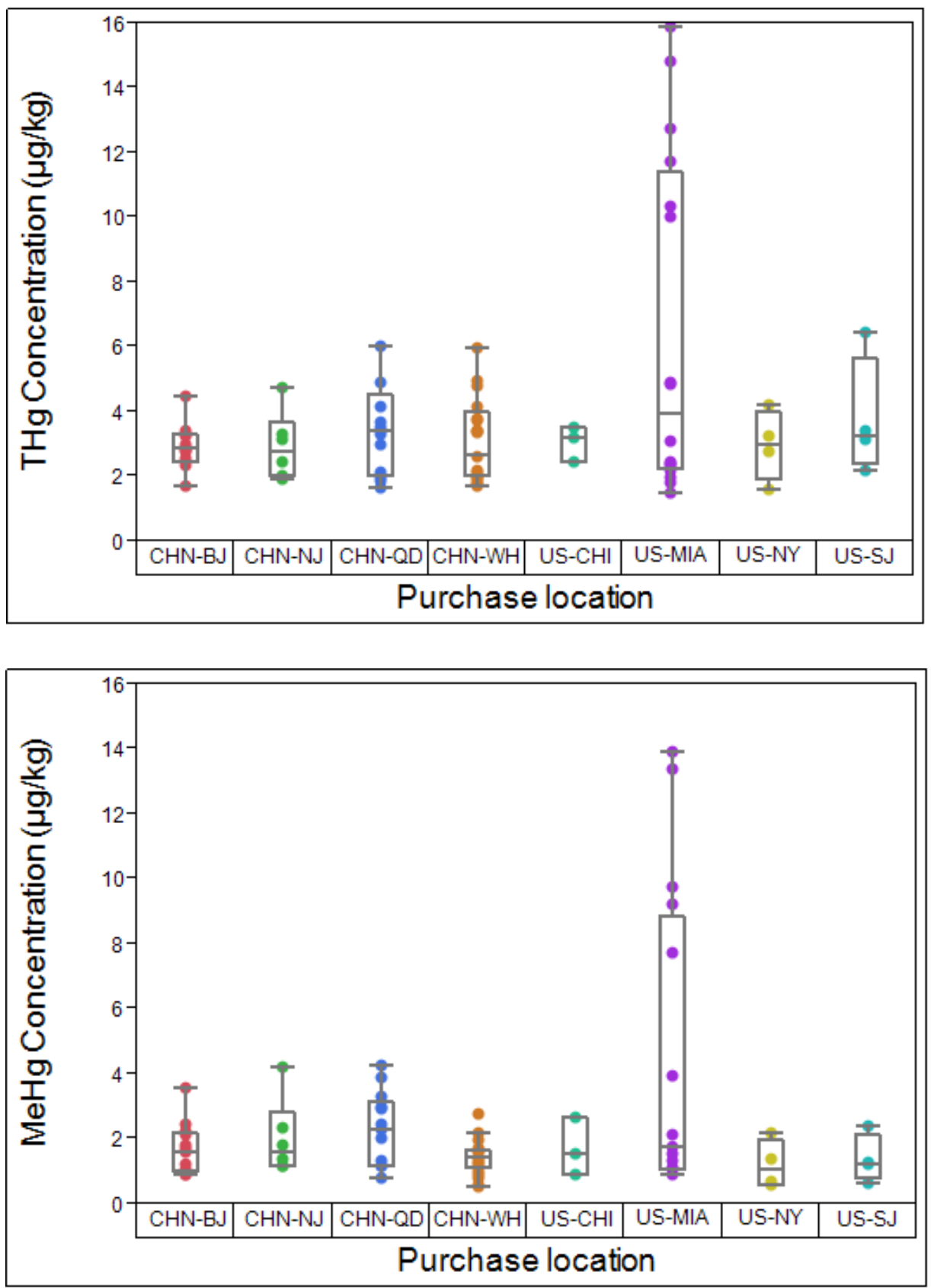

Figure 2.2. MeHg and THg content in rice cereals purchased from different cities 

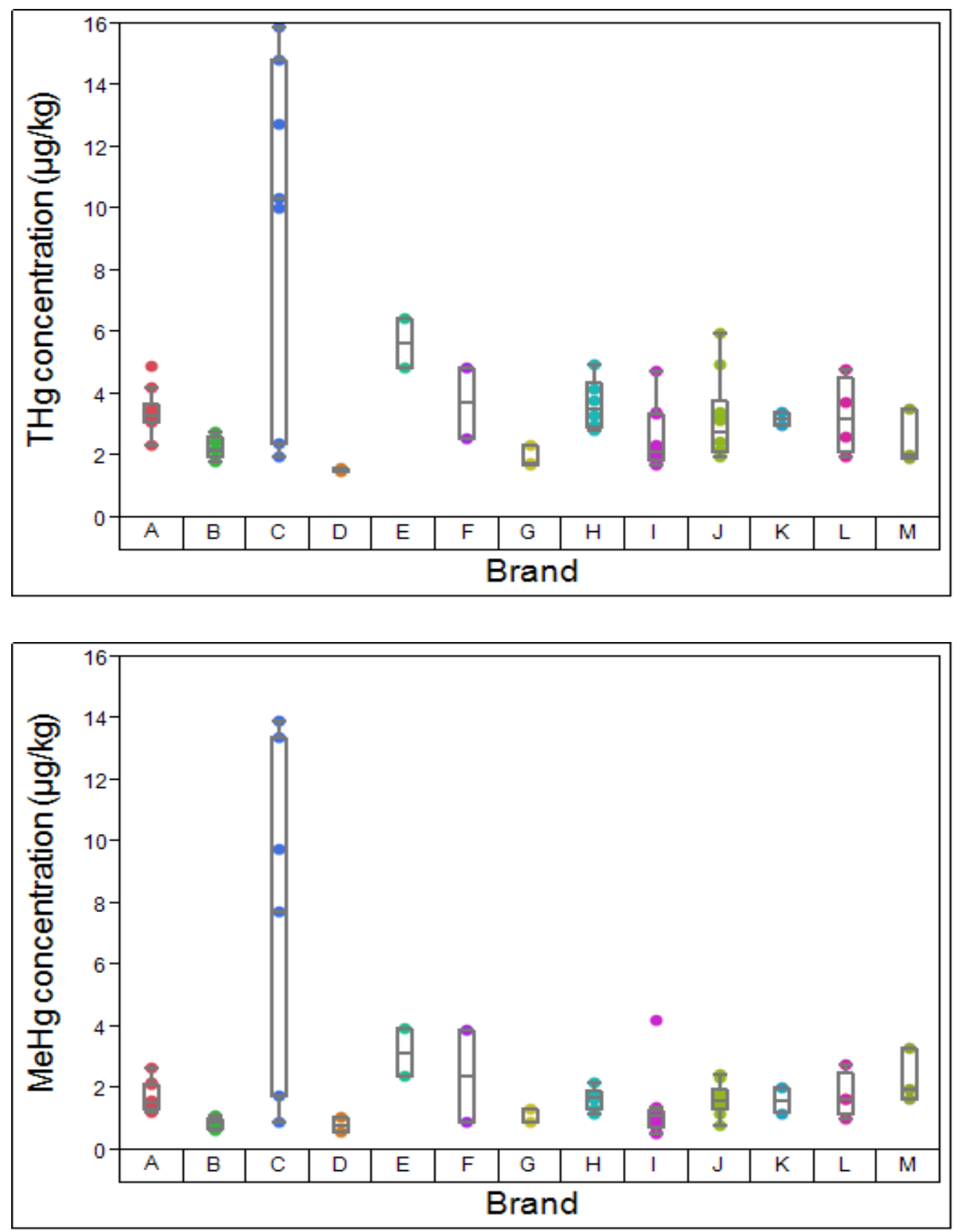

Figure 2.3. MeHg and THg level in different brands of rice cereals

For the group of rice-based cereal samples, statistical analysis was performed to examine the relationship between $\mathrm{Hg}$ concentrations and the locations where the samples were purchased (Fig. 2.2). Significant differences were not observed for both $\mathrm{MeHg}$ and 
THg contents in all cities in both USA and China except Miami ( $\mathrm{p}=0.32$ for $\mathrm{MeHg}$ and $\mathrm{p}=0.85$ for $\mathrm{THg}$ ). Five samples from Miami, including 3 samples purchased online (with warehouse locations around Miami), contained distinctly high concentrations of both $\mathrm{THg}(10.3-15.9 \mu \mathrm{g} / \mathrm{kg})$ and $\mathrm{MeHg}(7.72-13.9 \mu \mathrm{g} / \mathrm{kg})$, resulting in overall mean concentrations $(6.44 \mu \mathrm{g} / \mathrm{kg}$ for $\mathrm{THg}, 4.47 \mu \mathrm{g} / \mathrm{kg}$ for $\mathrm{MeHg})$ being significantly higher than those from other cities $(3.14 \mu \mathrm{g} / \mathrm{kg}$ for $\mathrm{THg}, 1.72 \mu \mathrm{g} / \mathrm{kg}$ for $\mathrm{MeHg}$ ). Similar statistical analysis was conducted against the samples grouped according to the manufacturers (Fig. 2.3), and lower concentration of both $\mathrm{THg}$ and $\mathrm{MeHg}$ were observed in rice cereal samples made by manufactures $\mathrm{B}, \mathrm{D}$, and $\mathrm{G}$.

\subsubsection{Estimation of daily intake of $\mathrm{MeHg}$ from rice-based cereal consumption}

The dietary intake of $\mathrm{MeHg}$ via rice-based cereals was estimated using concentration of $\mathrm{MeHg}$ determined in the infant cereal, on the basis of the recommended daily dose of infant cereal for the various stages of infancy (4-5 months: $46.5 \mathrm{~g} / \mathrm{day}, 6-8$ months: 67.5 g/day, and 9-11months: 84 g/day) and median value of weight-for-age of infants, which was calculated by averaging the weight-for-age of boys and girls (4-5 months: $5.19 \mathrm{~kg}$, 6-

8 months: $8.11 \mathrm{~kg}, 9-11$ months: $8.96 \mathrm{~kg}$ and $12-24$ months: $10 \mathrm{~kg}) .{ }^{75,98}$ Figure 2.4 presents the estimated dietary intake of $\mathrm{MeHg}$ for infants fed on the studied infant cereals with a red line showing the reference daily dose (RfD), which is $0.1 \mu \mathrm{g} / \mathrm{kg} / \mathrm{day}$, set by USEPA. The estimated intake of MeHg of these cereals ranged between 0.004 and 0.123 $\mu \mathrm{g} / \mathrm{kg} /$ day with a mean of $0.020 \mu \mathrm{g} / \mathrm{kg} /$ day 

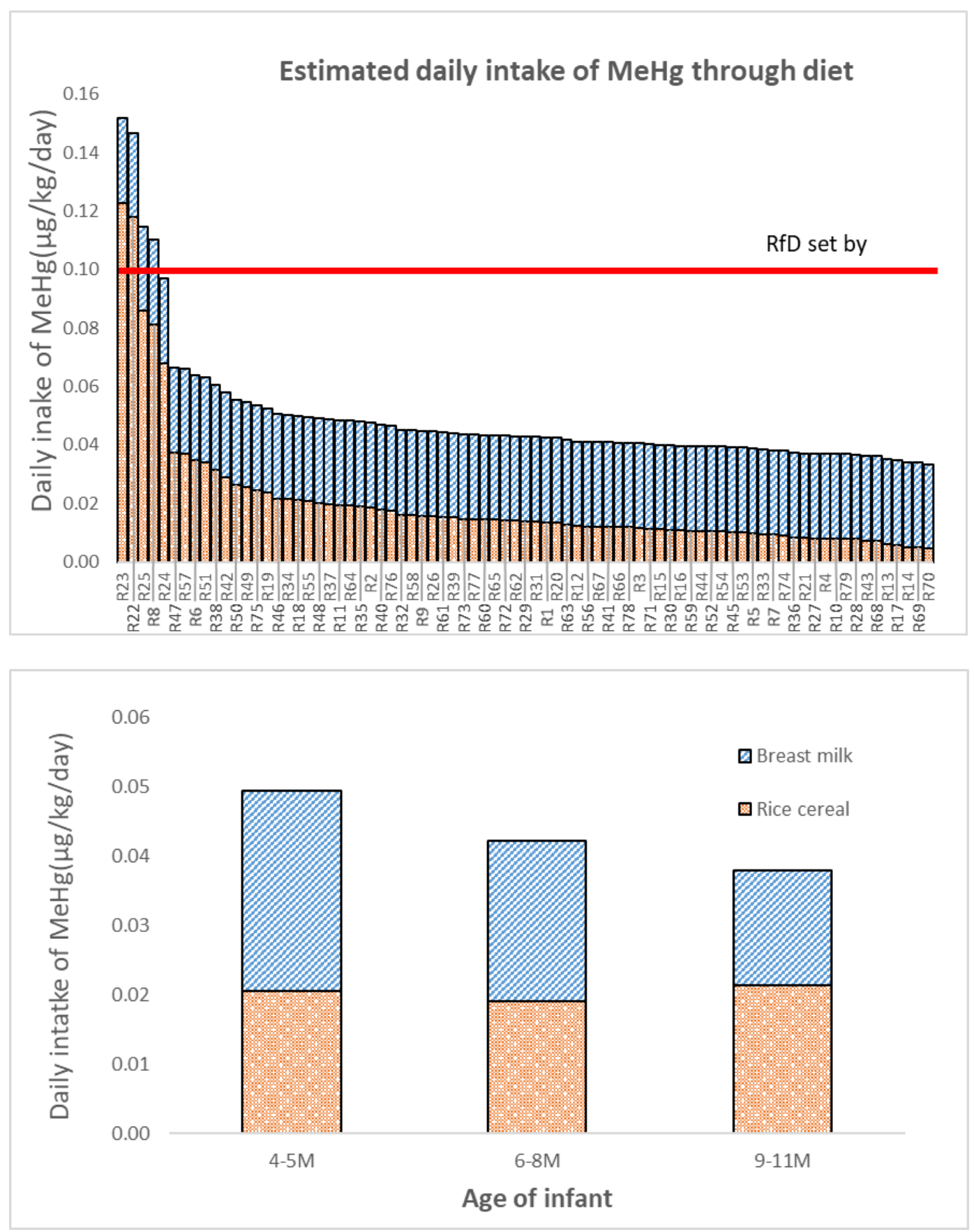

Figure 2.4. Estimation of average dietary MeHg daily intake from cereal consumption (dot) and breastmilk consumption (diagonal) for first year infants 


\subsection{Discussion}

\subsubsection{Hg contents in infant cereals}

Infant cereal is the traditional choice of the first solid food for infants. It is often mixed with infant formula or breast milk to give a slurry consistency and constitute a basic integral part of an infant diet during the first year of life. Because of the recent finding of elevated $\mathrm{MeHg}$ in rice, infant cereals might be potentially considered as a main source of $\mathrm{MeHg}$ intake for infants. In this study, mean concentrations of $2.86 \pm 2.69$ $\mu \mathrm{g} / \mathrm{kg}$ for $\mathrm{THg}$ and $1.61 \pm 2.23 \mu \mathrm{g} / \mathrm{kg}$ for $\mathrm{MeHg}$ were found in the cereal samples analyzed. Our THg results seem to agree with previous studies where median concentrations of THg in different types of infant cereals sold in Portugal and Spain were reported to be $0.50(\mathrm{n}=26) \mu \mathrm{g} / \mathrm{kg}$, ranging from 0.15 to $2.90 \mu \mathrm{g} / \mathrm{kg}^{69}$ and $2.61 \mu \mathrm{g} / \mathrm{kg}(\mathrm{n}=$ 91), from 0.66 to $5.13 \mu \mathrm{g} / \mathrm{kg}$, respectively ${ }^{70}$. As for $\mathrm{MeHg}$, the results could not be compared to the literature, since no previous study has reported the concentrations of $\mathrm{MeHg}$ in rice-based infant cereals, to the best of our knowledge.

The potential sources of $\mathrm{Hg}$, especially $\mathrm{MeHg}$, present in the infant cereals may mainly include the raw materials used and the manufacture processes where $\mathrm{Hg}$ could be introduced as a contaminant. Although infant cereals may be made from a variety of materials including rice, wheat, oat, corn, rye and quinoa, rice is the most widely used food material for the production of infant cereals and has been used in a large quantity. ${ }^{99}$ In comparison to other grains, rice contains higher $\mathrm{Hg}$ concentration possibly because of its higher ability to accumulate inorganic $\mathrm{Hg}$ as well as MeHg. ${ }^{50,54,100,101}$ Recent studies have demonstrated the presence of elevated $\mathrm{MeHg}$ in rice grains because of the bioaccumulation of $\mathrm{Hg}$, MeHg in particular, in rice grain. ${ }^{49,54,102}$ The $\mathrm{MeHg}$ accumulated 
in rice grains may end up in the infant cereals when the rice is used for cereal production, resulting higher concentrations of $\mathrm{Hg}$ in rice-based cereals compared to other grain based cereals.

The comparison among three groups of cereals (rice-based, non-rice, and multigrains) showed that THg contents in rice-based cereals were significantly higher than that in cereals containing no rice (Fig. 2.1 and Table 2.1). For multi-grains in which several grains were normally supplemented in addition to rice, $\mathrm{THg}$ was also less than that in rice-based cereals, but this difference was not significant. These results indicate that the elevated THg in infant cereals is likely from the rice used for cereal production. Support for this notion came from a line of evidence. First, the determined THg and $\mathrm{MeHg}$ contents in rice-based infant cereals in this study are comparable to reported $\mathrm{Hg}$ levels in rice samples ${ }^{48,51,52,95}$ suggesting that the source of $\mathrm{Hg}$ in cereals could be rice. Second, MeHg levels in rice-based cereals were significantly higher than in cereals containing no rice ( $\mathrm{p}<0.0001)$, as indicated by comparisons using Turkey's test. The result is strongly indicative of rice being the source of $\mathrm{Hg}$ in cereals. Third, the significantly higher $\mathrm{MeHg} / \mathrm{THg}$ ratios in rice-based cereals (57\%) than in non-rice cereals (15\%) provided further evidence that rice is the main source of MeHg in infant cereals (Fig. 2.5).

Previous studies have shown that rice plants preferably accumulate $\mathrm{MeHg}$ in comparison to inorganic $\mathrm{Hg}$, resulting in higher $\mathrm{MeHg} / \mathrm{THg}$ ratios in rice grains,${ }^{49,54}$ whereas this selective accumulation has not been reported in other plants/grains. ${ }^{102}$ The high $\mathrm{MeHg} / \mathrm{THg}$ ratio also could be the result of removing hull and bran while producing the white rice which was generally used to make rice cereal. Since around 70-80\% of inorganic $\mathrm{Hg}$ in rice is present in the hull and bran, and this portion of $\mathrm{IHg}$ would be 
eliminated during the polishing process, ${ }^{50}$ whereas $\mathrm{MeHg}$ in rice, mainly present in grain, would remain in polished rice. As a result, the $\mathrm{MeHg} / \mathrm{THg}$ ratio would be higher in white rice and this higher $\mathrm{MeHg} / \mathrm{THg}$ ratio would be transferred to cereals during cereal production. ${ }^{50}$ The loss of IHg during grain processing might also explain large variations in THg contents in cereals observed in this study, as around half of rice based cereal samples have similar levels of THg with multi grain and non-rice cereals.

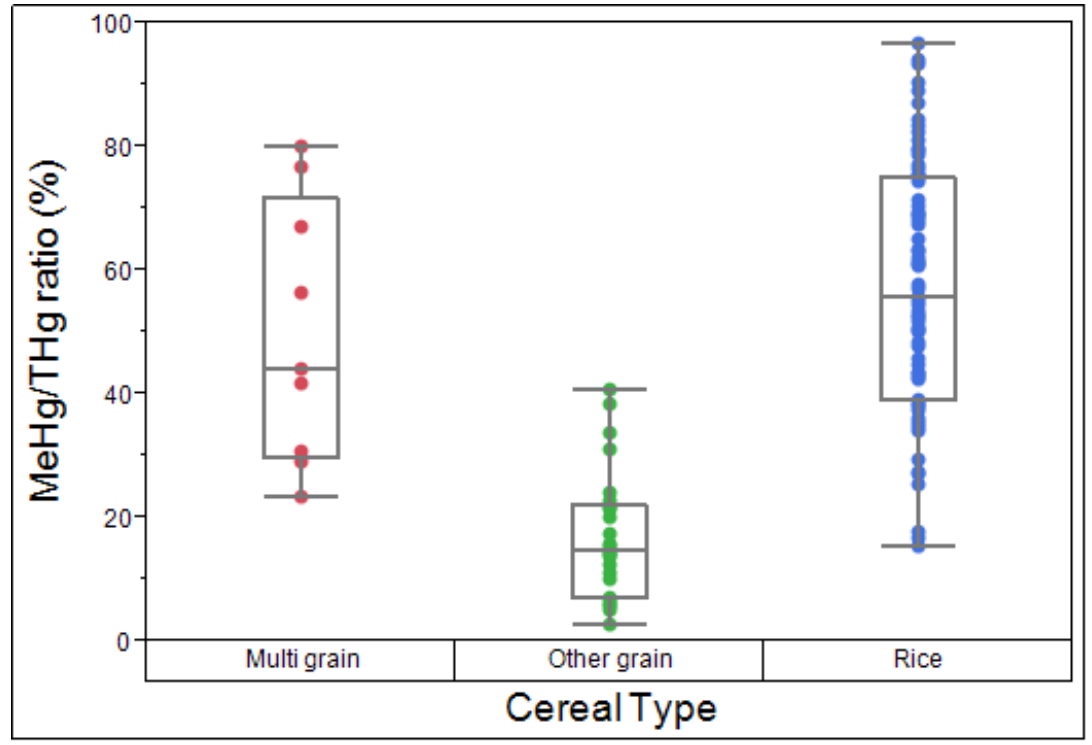

Figure 2.5. Boxplots of $\mathrm{MeHg} / \mathrm{THg}$ ratios in different types of cereals

Significant differences were not observed while comparing both $\mathrm{THg}$ and $\mathrm{MeHg}$ contents in the cereal samples purchased from different areas. The result was not unexpected since the locations of purchase are probably not directly linked to the sources of rice grains used for cereal production. It was found that sometimes cereal samples purchased from different cities had the same manufacture product lot numbers. It should be pointed out that 5 of the 15 rice cereal samples from Miami showed distinctly high concentrations of $\mathrm{THg}$ and $\mathrm{MeHg}$ in comparison with the rest samples from Miami and 
from the other cities (R26 was high in $\mathrm{THg}$ but low in $\mathrm{MeHg}$ ) (Fig. 2.2). These 5 samples, produced by the same manufacturer and only were purchased in Miami, were labeled as hot-cereal, meaning that they need to be boiled before serving. These samples were obtained through repeated sampling of this specific type of cereal in the Miami market at different times, and thus they were unlikely manufactured in the same production batch (as indicated by different product lot numbers on the labels). Although the reason why these hot-cereals contain much more $\mathrm{MeHg}$ from this manufacturer is unclear, the high $\mathrm{Hg}$ contents in all these 5 samples could suggest that this specific type of cereals from this manufacturer could be produced from rice with high levels of $\mathrm{Hg}$ and/or be related to manufacturing process.

Comparing the contents of $\mathrm{Hg}$ in rice cereals from different manufacturers, no significant differences were found among the most common brands, including brand A with around $80 \%$ market share in USA, and brand $\mathrm{H}$, I and $\mathrm{J}$ with a combined $75 \%$ market share in China, ${ }^{103,104}$ while $\mathrm{THg}$ and $\mathrm{MeHg}$ levels showed significant differences among some brands with small market shares (Fig. 2.3). Several brands, such as B, D, and $\mathrm{G}$, contained lower levels of $\mathrm{MeHg}$, while brand $\mathrm{C}$ contained significantly higher concentrations of both $\mathrm{THg}$ and $\mathrm{MeHg}$, probably because of varying $\mathrm{THg}$ and $\mathrm{MeHg}$ levels in the rice used for cereals production and the effect of manufacturing processes. Unfortunately, as we were not able to obtain the rice used for production of cereals from manufacturers, it is difficult to evaluate the effects of manufacturing processes on the MeHg in cereal products. However, as previous studies have shown that cooking processes had limited impact on the MeHg concentration in different types of food, ${ }^{79,83}$ the cereal manufacturing processes, mainly the cooking not packing process, may not be 
a major factor affecting $\mathrm{MeHg}$ in the cereal products. The rice that is used for the cereal production should be considered as a crucial factor, as the source of $\mathrm{Hg}$ in rice-based infant cereals could be attributed to rice as discussed previously. Therefore, differences in the $\mathrm{Hg}$ contents found among various brands were indicative of the differences in origin of rice used.

\subsubsection{Estimation of daily intake of MeHg}

The estimated daily intake values of $\mathrm{MeHg}$ in this study were compared to the EPA $\operatorname{RfD}(0.1 \mu \mathrm{g} / \mathrm{kg} / \mathrm{day})^{43}$ to evaluate the health risks associated with consumption of ricebased infant cereals (Fig. 2.4). The calculated daily intake of $\mathrm{MeHg}$ ranged from 0.004 to $0.122 \mu \mathrm{g} / \mathrm{kg} / \mathrm{day}$, accounting for $4-122 \%$ of the RfD, with a mean of $20 \%$. Two of the 79 rice-based infant cereals exceeded the $\mathrm{MeHg} \mathrm{RfD}$, suggesting potential $\mathrm{MeHg}$ exposure of infants through cereal diet. Considering that cereal diet is not the only MeHg exposure pathway for infants and that breast milk has been regarded as an important source of $\mathrm{MeHg}$ in infants, ${ }^{63,66}$ we further estimated the $\mathrm{MeHg}$ daily intake through both cereals and breastfeeding. The concentrations of $\mathrm{MeHg}$ in breast milk were found to be 0.17 $\mu \mathrm{g} / \mathrm{L}(\mathrm{n}=182)$ in Italy, $0.68 \mu \mathrm{g} / \mathrm{L}(\mathrm{n}=11)$ in Slovenia, and $0.45 \mu \mathrm{g} / \mathrm{L}(\mathrm{n}=27)$ in Japan. ${ }^{63-}$

${ }^{67}$ On the basis of these reported concentrations and sample sizes we calculated a mean concentration of $0.23 \mu \mathrm{g} / \mathrm{L}$ for $\mathrm{MeHg}$ in breast milk. Using the recommended daily intake of human milk according to the EPA handbook for various stages (4-5 months: 126 ml/kg/day, 6-8 months: $101 \mathrm{ml} / \mathrm{kg} /$ day, and 9-11 months: $72 \mathrm{ml} / \mathrm{kg} / \mathrm{day}),{ }^{105}$ we estimated $\mathrm{MeHg}$ daily intake through breast milk and the overall dietary $\mathrm{MeHg}$ intake. The dietary $\mathrm{MeHg}$ daily intake through breast milk for infants less than one-year-old ranged from 0.037 to $0.049 \mu \mathrm{g} / \mathrm{kg} /$ day with a mean of $0.043 \mu \mathrm{g} / \mathrm{kg} / \mathrm{day}$, which is $37-49 \%$ of the $\mathrm{MeHg}$ 
RfD (Fig. 2.4). When combining MeHg daily intake through both breast milk and rice cereal, approximately half of calculated daily intake values exceeded $50 \%$ of the EPA RfD, while for 5 cereal samples the MeHg intake could be over or close to the RfD value. The daily intake of $\mathrm{MeHg}$ through breast milk and cereals for infants seemed to decrease with age (Fig. 2.4), but this should not be interpreted as a decrease in dietary $\mathrm{MeHg}$ exposure. For infants of 8-10 months old, fish-based infant food, which have been proven to be higher in $\mathrm{MeHg},{ }^{68}$ may be introduced to the diet, leading to increases in $\mathrm{MeHg}$ daily intake.

Although we compared the estimated $\mathrm{MeHg}$ daily intake of infants through cereal diet to the EPA RfD for evaluation of potential exposure and health risks, it should be borne in mind that there are differences in the calculation of RfD and the scenario of infant exposure to $\mathrm{MeHg}$ through ingestion of cereal diet. The RfD was developed on the basis of the evaluation of the neurodevelopmental effects of prenatal $\mathrm{MeHg}$ exposure resulting from maternal fish consumption which would expose fetuses to $\mathrm{MeHg}$ in utero. In establishing the RfD, a benchmark dose level of $11 \mathrm{ppm}$ of $\mathrm{Hg}$ in hair was calculated as the lower limit of the $95 \%$ confidence interval for the maternal-hair concentration corresponding to a $10 \%$ extra risk level. ${ }^{106}$ A ratio of $250: 1$ was used to convert the maternal hair $\mathrm{Hg}$ concentration to cord blood $\mathrm{Hg}$ concentration, which is $44 \mu \mathrm{g} / \mathrm{L}$. The benchmark dose level (BMDL) for daily intake of $\mathrm{MeHg}$ was calculated as $1.1 \mu \mathrm{g} / \mathrm{kg}$ according to Equation 2.2.

$$
\mathrm{BMDL}=\frac{\mathrm{C} \times \mathrm{b} \times \mathrm{V}}{\mathrm{A} \times \mathrm{f} \times \mathrm{bw}}
$$


Where $\mathrm{C}=$ concentration in cord blood $(44 \mu \mathrm{g} / \mathrm{L}) ; \mathrm{b}=$ elimination constant $\left(0.014\right.$ day $\left.^{-1}\right)$; $\mathrm{V}=$ volume of blood in body $(5 \mathrm{~L}) ; \mathrm{A}=$ absorption factor $(0.95) ; \mathrm{F}=$ fraction of daily intake taken up by blood (0.05); bw= body-weight $(60 \mathrm{~kg})$

An uncertainty factor of 10 was then used to calculate RfD. ${ }^{107}$

$$
\mathrm{RfD}=\frac{\mathrm{BMDL}}{\mathrm{UF}}=\frac{1.1 \mu \mathrm{g} / \mathrm{kg} / \mathrm{day}}{10}=0.1 \mu \mathrm{g} / \mathrm{kg} / \mathrm{day}
$$

The development of RfD did use neurodevelopmental effects of fetus and infant as the sensitive end point for MeHg toxicity, but the RfD was on the basis of maternal intake of $\mathrm{MeHg}$ (e.g., through fish consumption) which would be transferred to fetuses in utero via cord blood. This is different than postnatal exposure of infants to $\mathrm{MeHg}$ through cereal diet, where infant bodies are exposed to $\mathrm{MeHg}$ by digesting the food and taking up the $\mathrm{MeHg}$ contained in the cereals. As fish consumption was assumed to be a major pathway of $\mathrm{MeHg}$ exposure for establishing the $\mathrm{RfD},{ }^{43}$ the bioaccessibility and bioavailability of MeHg in rice-based cereals could be different than that in fish because of the different composition of these two types of food. In addition, the elimination rate of $\mathrm{MeHg}$ is directly related to exposure frequency, ${ }^{108}$ and thus for population group like infants who are exposed to $\mathrm{MeHg}$ through diet (breast milk and rice cereal) everyday, a lower elimination rate likely needs to be considered when evaluating health risks. Animal experiments have in fact shown that infants may not be able to eliminate $\mathrm{MeHg}$ from their body because of the lack of de-methylation bacteria in gut. ${ }^{109}$ All factors mentioned above may greatly influence the RfD calculation.

Considering the difference between the EPA RfD and the postnatal MeHg exposure through cereal diet, caution should be exercised when evaluating the health risks 
associated with infant exposure to MeHg in cereals, and simply comparing to the RfD might not provide accurate health risk information. While prenatal MeHg exposure has been extensively studied for its adverse effects on the developing nervous system during fetal, infant, and even childhood stages, postnatal $\mathrm{MeHg}$ exposure through diets for children of early ages and the related toxicological effects have received less attention. In a US-based study on 24-month-old children, better Bayley Mental Developmental Index ${ }^{21}$ scores were associated with $\mathrm{Hg}$ concentration (albeit non-significantly), while increased risk of delayed fine motor skill on the Denver Developmental Screening Test was marginally correlated with higher 3-month postpartum infant hair $\mathrm{Hg}$ levels for 26month-old children in an Italian study. ${ }^{110,111}$ As the EPA RfD might not be able to accurately reflect the exposure levels and health risks when infants are exposed to $\mathrm{MeHg}$ through diets after birth, it might be informative to compare the results to animal studies when evaluating the health effects of postnatal MeHg exposure. Since MeHg exposure could produce similar neurodevelopmental effects in monkeys and in humans, animal studies using monkeys are particularly relevant in this regard. ${ }^{112,113}$ Studies in a cohort of monkeys revealed sensory system impairment and evidence of delayed neurotoxicity, when they were dosed beginning in utero and continuing until 4 years of age. ${ }^{113-115}$ Reference doses were then derived from these data to evaluate the effects of prenatal and postnatal $\mathrm{Hg}$ exposure, suggesting that, for combined in utero and postnatal exposure, reference does ranging from 0.01 to $0.05 \mu \mathrm{g} / \mathrm{kg} / \mathrm{day}$ could be obtained when an uncertainty factor of 10 was used for extrapolation from animals to humans. ${ }^{113-115}$ These results again suggest that the exposure and health effects of postnatal MeHg exposure through diets (e.g., rice cereals, which have received little attention previously) are 
probably not evaluated properly if simply comparing to the EPA RfD. Further studies considering the specific characteristics in uptake, metabolism, and excretion of $\mathrm{MeHg}$ for infants and children at different ages are warranted for a more precise evaluation on the effects of postnatal diet $\mathrm{MeHg}$ exposure during infancy and childhood.

\section{Supplementary Data}

\section{Details of Sample preparation and analysis of $\mathrm{THg}$ and $\mathrm{MeHg}$ in cereals}

Digestion of cereal samples for THg analysis was performed using a hot block at 140 ${ }^{\circ} \mathrm{C}$ for $4 \mathrm{~h}$, following addition of $0.2 \mathrm{~g}$ sample to a premixed acid composed of concentrated nitric acid $(8 \mathrm{ml})$ and sulfuric acid $(2 \mathrm{ml})$ in a pre-cleaned $50 \mathrm{ml}$ glass digestion tube. After cooling down, $2 \mathrm{ml}$ of hydrogen peroxide was added into the digestion tubes and the tubes were heated at $95^{\circ} \mathrm{C}$ for $1 \mathrm{~h}$. Five to ten folds dilution was applied with ultrapure deionized water before the samples were analyzed by using a PSA Mercury Analyzer (P S Analytical) in the purge and gold-trap preconcentration mode. $\mathrm{Hg}$ concentration was expressed in $\mu \mathrm{g} / \mathrm{kg} \mathrm{Hg}$ in dry weight.

For MeHg determination, briefly, $0.5 \mathrm{~g}$ of cereal sample was digested with $6 \mathrm{ml}$ of $\mathrm{KBr} / \mathrm{H}_{2} \mathrm{SO}_{4} / \mathrm{CuSO}_{4}$ solution and the $\mathrm{MeHg}$ present in the digest was extracted into $10 \mathrm{ml}$ of $\mathrm{CH}_{2} \mathrm{Cl}_{2}$. Then, 0.1 to $1 \mathrm{ml}$ of $\mathrm{CH}_{2} \mathrm{Cl}_{2}$ extract was pipetted into a $40 \mathrm{ml}$ amber glass vial containing $30 \mathrm{ml}$ of ultrapure deionized water. The vial was purged with $\mathrm{N}_{2}$ to completely volatilize the $\mathrm{CH}_{2} \mathrm{Cl}_{2}$, leaving $\mathrm{MeHg}$ in the aqueous solution. $\mathrm{MeHg}$ in the aqueous solution was then derivatized with $150 \mu \mathrm{l}$ of $1 \%(\mathrm{w} / \mathrm{v}) \mathrm{NaBEt}_{4}$ to convert $\mathrm{MeHg}$ to volatile methylethylmercury which was then purged and trapped on a Tenax trap followed by analysis on GC-CVAFS MeHg system. 
Table 2.2. General information and mercury levels of the cereal samples

\begin{tabular}{|c|c|c|c|c|c|c|c|c|c|}
\hline ID & Brand & Location $^{*}$ & Type ${ }^{* *}$ & $\mathrm{THg}(\mu \mathrm{g} / \mathrm{kg})$ & $\operatorname{MeHg}(\mu \mathrm{g} / \mathrm{kg})$ & $\begin{array}{c}\mathrm{MeHg} / \mathrm{THg} \\
(\%)\end{array}$ & Fat $\%$ & Protein $\%$ & Carb\% \\
\hline $\mathrm{R} 1$ & A & MIA & $\mathrm{R}$ & $3.07 \pm 0.46$ & $1.55 \pm 0.98$ & 50.5 & 3.33 & 6.67 & 80.0 \\
\hline $\mathrm{R} 2$ & $\mathrm{~A}$ & MIA & $\mathrm{R}$ & $4.92 \pm 0.25$ & $2.13 \pm 0.09$ & 43.3 & 3.33 & 6.67 & 80.0 \\
\hline $\mathrm{R} 3$ & A & MIA & $\mathrm{R}$ & $2.35 \pm 0.37$ & $1.34 \pm 0.17$ & 57.0 & 3.33 & 6.67 & 80.0 \\
\hline $\mathrm{R} 4$ & $\mathrm{~B}$ & MIA & $\mathrm{R}$ & $1.82 \pm 0.05$ & $0.92 \pm 0.05$ & 50.5 & 0.00 & 6.67 & 80.0 \\
\hline R5 & B & MIA & $\mathrm{R}$ & $2.21 \pm 0.22$ & $1.12 \pm 0.10$ & 50.7 & 0.00 & 6.67 & 80.0 \\
\hline R6 & $\mathrm{E}$ & MIA & $\mathrm{R}$ & $4.87 \pm 0.18$ & $3.95 \pm 0.22$ & 81.1 & 3.13 & 6.25 & 81.3 \\
\hline R7 & $\mathrm{D}$ & MIA & $\mathrm{R}$ & $1.47 \pm 0.29$ & $1.05 \pm 0.01$ & 71.4 & 7.14 & 7.14 & 78.6 \\
\hline $\mathrm{R} 8$ & $\mathrm{C}$ & MIA & $\mathrm{R}$ & $11.74 \pm 1.48$ & $9.23 \pm 1.43$ & 78.6 & 4.76 & 9.52 & 76.2 \\
\hline R9 & $\mathrm{C}$ & MIA & $\mathrm{R}$ & $1.97 \pm 0.41$ & $1.78 \pm 0.38$ & 90.4 & 4.76 & 9.52 & 81.0 \\
\hline $\mathrm{R} 10$ & $\mathrm{C}$ & MIA & $\mathrm{R}$ & $2.39 \pm 0.04$ & $0.91 \pm 0.08$ & 38.1 & 3.57 & 7.14 & 71.4 \\
\hline R11 & $\mathrm{A}$ & NY & $\mathrm{R}$ & $4.23 \pm 0.37$ & $2.19 \pm 0.27$ & 51.8 & 3.00 & 7.30 & 77.8 \\
\hline R12 & $\mathrm{A}$ & $\mathrm{NY}$ & $\mathrm{R}$ & $3.25 \pm 0.06$ & $1.39 \pm 0.25$ & 42.8 & 10.00 & 6.00 & 60.0 \\
\hline R13 & $\mathrm{B}$ & $\mathrm{NY}$ & $\mathrm{R}$ & $2.76 \pm 0.67$ & $0.70 \pm 0.15$ & 25.4 & 8.00 & 5.00 & 67.0 \\
\hline R14 & $\mathrm{D}$ & NY & $\mathrm{R}$ & $1.62 \pm 0.27$ & $0.57 \pm 0.08$ & 35.2 & 7.10 & 7.10 & 71.4 \\
\hline R15 & A & SJ & $\mathrm{R}$ & $3.39 \pm 0.08$ & $1.26 \pm 0.02$ & 37.2 & 3.33 & 6.67 & 80.0 \\
\hline R16 & A & SJ & $\mathrm{R}$ & $3.12 \pm 0.80$ & $1.22 \pm 0.18$ & 39.1 & 3.33 & 6.67 & 80.0 \\
\hline R17 & B & SJ & $\mathrm{R}$ & $2.17 \pm 0.10$ & $0.64 \pm 0.05$ & 29.5 & 0.00 & 6.67 & 80.0 \\
\hline R18 & $\mathrm{E}$ & SJ & $\mathrm{R}$ & $6.43 \pm 0.32$ & $2.39 \pm 0.34$ & 37.2 & 3.13 & 6.25 & 81.3 \\
\hline R19 & $\mathrm{A}$ & $\mathrm{CHI}$ & $\mathrm{R}$ & $3.51 \pm 0.26$ & $2.68 \pm 0.53$ & 76.4 & 3.33 & 6.67 & 80.0 \\
\hline R20 & A & $\mathrm{CHI}$ & $\mathrm{R}$ & $3.2 \pm 0.51$ & $1.55 \pm 0.10$ & 48.4 & 3.33 & 6.67 & 86.7 \\
\hline R21 & $\mathrm{B}$ & $\mathrm{CHI}$ & $\mathrm{R}$ & $2.44 \pm 0.28$ & $0.93 \pm 0.20$ & 38.1 & 0.00 & 6.67 & 80.0 \\
\hline R22 & $\mathrm{C}$ & MIA & $\mathrm{R}$ & $15.88 \pm 2.17$ & $13.38 \pm 1.88$ & 84.3 & 4.76 & 9.52 & 76.2 \\
\hline R23 & $\mathrm{C}$ & MIA & $\mathrm{R}$ & $14.84 \pm 2.19$ & $13.94 \pm 2.02$ & 93.9 & 4.76 & 9.52 & 76.2 \\
\hline R24 & $\mathrm{C}$ & MIA & $\mathrm{R}$ & $12.73 \pm 1.67$ & $7.72 \pm 2.20$ & 60.6 & 4.76 & 9.52 & 76.2 \\
\hline $\mathrm{R} 25$ & $\mathrm{C}$ & MIA & $\mathrm{R}$ & $10.37 \pm 1.45$ & $9.75 \pm 3.13$ & 94.0 & 4.76 & 9.52 & 76.2 \\
\hline R26 & $\mathrm{C}$ & MIA & $\mathrm{R}$ & $10.03 \pm 0.63$ & $1.77 \pm 0.90$ & 17.6 & 4.76 & 9.52 & 81.0 \\
\hline R27 & $\mathrm{F}$ & $\mathrm{BJ}$ & $\mathrm{R}$ & $2.55 \pm 0.23$ & $0.92 \pm 0.08$ & 36.1 & 8.00 & 5.00 & 67.0 \\
\hline R28 & $\mathrm{G}$ & $\mathrm{BJ}$ & $\mathrm{R}$ & $2.34 \pm 0.18$ & $0.89 \pm 0.11$ & 38.0 & 12.50 & 6.45 & 57.8 \\
\hline R29 & $\mathrm{A}$ & $\mathrm{BJ}$ & $\mathrm{R}$ & $3.33 \pm 0.12$ & $1.59 \pm 0.14$ & 47.7 & 1.90 & 6.40 & 84.5 \\
\hline R30 & $\mathrm{N}$ & $\mathrm{BJ}$ & $\mathrm{R}$ & $2.76 \pm 0.07$ & $1.23 \pm 0.11$ & 44.6 & 2.80 & 8.00 & 86.8 \\
\hline R31 & $\mathrm{N}$ & BJ & $\mathrm{R}$ & $2.9 \pm 0.06$ & $1.58 \pm 0.21$ & 54.5 & 11.60 & 8.00 & 77.0 \\
\hline R32 & $\mathrm{H}$ & $\mathrm{BJ}$ & $\mathrm{R}$ & $2.96 \pm 0.18$ & $1.84 \pm 0.46$ & 62.2 & 6.50 & 1.90 & 81.5 \\
\hline R33 & $\mathrm{I}$ & $\mathrm{BJ}$ & $\mathrm{R}$ & $2.34 \pm 0.18$ & $1.07 \pm 0.14$ & 45.7 & 5.00 & 5.38 & 85.0 \\
\hline R34 & $\mathrm{J}$ & $\mathrm{BJ}$ & $\mathrm{R}$ & $3.22 \pm 0.14$ & $2.43 \pm 0.62$ & 75.5 & 6.00 & 11.00 & 79.5 \\
\hline R35 & $\mathrm{N}$ & $\mathrm{BJ}$ & $\mathrm{R}$ & $3.41 \pm 0.23$ & $2.16 \pm 0.15$ & 63.3 & 10.00 & 5.00 & 60.0 \\
\hline R36 & $\mathrm{I}$ & BJ & $\mathrm{R}$ & $1.71 \pm 0.18$ & $0.95 \pm 0.04$ & 55.6 & 5.00 & 5.38 & 85.0 \\
\hline R37 & $\mathrm{N}$ & $\mathrm{BJ}$ & $\mathrm{R}$ & $3.23 \pm 0.06$ & $2.23 \pm 0.20$ & 69.0 & 10.00 & 5.00 & 28.0 \\
\hline
\end{tabular}




\begin{tabular}{|c|c|c|c|c|c|c|c|c|c|}
\hline \multicolumn{10}{|c|}{ Table 2.2 (continued) } \\
\hline R38 & $\mathrm{N}$ & BJ & $\mathrm{R}$ & $4.49 \pm 0.32$ & $3.58 \pm 0.42$ & 79.7 & 2.00 & 9.00 & 81.0 \\
\hline R39 & $\mathrm{H}$ & $\mathrm{BJ}$ & $\mathrm{R}$ & $2.80 \pm 0.10$ & $1.72 \pm 0.49$ & 61.4 & 1.90 & 6.20 & 84.6 \\
\hline R40 & K & QD & $\mathrm{R}$ & $2.96 \pm 0.35$ & $2.03 \pm 0.42$ & 68.6 & 0.60 & 6.00 & 85.2 \\
\hline $\mathrm{R} 41$ & $\mathrm{~N}$ & QD & $\mathrm{R}$ & $1.63 \pm 0.04$ & $1.36 \pm 0.09$ & 83.4 & 1.00 & 5.70 & 76.3 \\
\hline R42 & $\mathrm{M}$ & QD & $\mathrm{R}$ & $3.54 \pm 0.31$ & $3.30 \pm 0.12$ & 93.2 & 1.55 & 7.50 & 85.0 \\
\hline R43 & $\mathrm{I}$ & QD & $\mathrm{R}$ & $1.87 \pm 0.02$ & $0.81 \pm 0.18$ & 43.3 & 5.00 & 5.38 & 85.0 \\
\hline R44 & $\mathrm{K}$ & QD & $\mathrm{R}$ & $3.40 \pm 0.88$ & $1.20 \pm 0.09$ & 35.3 & 0.60 & 6.00 & 85.2 \\
\hline R45 & $\mathrm{N}$ & QD & $\mathrm{R}$ & $2.11 \pm 0.11$ & $1.16 \pm 0.04$ & 55.0 & 5.00 & 5.50 & 68.0 \\
\hline R46 & $\mathrm{N}$ & QD & $\mathrm{R}$ & $4.89 \pm 0.66$ & $2.45 \pm 0.17$ & 50.1 & 3.00 & 7.30 & 77.8 \\
\hline R47 & $\mathrm{N}$ & QD & $\mathrm{R}$ & $6.02 \pm 0.13$ & $4.24 \pm 0.03$ & 70.4 & 8.20 & 15.00 & 67.0 \\
\hline R48 & $\mathrm{N}$ & QD & $\mathrm{R}$ & $3.30 \pm 0.25$ & $2.29 \pm 0.21$ & 69.4 & 10.00 & 6.00 & 60.0 \\
\hline R49 & $\mathrm{N}$ & QD & $\mathrm{R}$ & $4.15 \pm 0.25$ & $2.92 \pm 0.53$ & 70.4 & 5.00 & 7.00 & 87.0 \\
\hline R50 & $\mathrm{N}$ & QD & $\mathrm{R}$ & $3.66 \pm 0.12$ & $3.01 \pm 0.17$ & 82.2 & 10.00 & 5.00 & 28.0 \\
\hline R51 & $\mathrm{F}$ & QD & $\mathrm{R}$ & $4.87 \pm 0.30$ & $3.87 \pm 0.41$ & 79.5 & 8.00 & 5.00 & 67.0 \\
\hline R52 & $\mathrm{J}$ & QD & $\mathrm{R}$ & $1.95 \pm 0.20$ & $1.19 \pm 0.07$ & 61.0 & 6.00 & 8.00 & 82.5 \\
\hline R53 & $\mathrm{I}$ & $\mathrm{NJ}$ & $\mathrm{R}$ & $1.91 \pm 0.01$ & $1.16 \pm 0.12$ & 60.7 & 5.00 & 5.38 & 85.0 \\
\hline R54 & $\mathrm{H}$ & $\mathrm{NJ}$ & $\mathrm{R}$ & $3.30 \pm 0.42$ & $1.19 \pm 0.00$ & 36.1 & 6.50 & 1.90 & 81.5 \\
\hline R55 & $\mathrm{J}$ & $\mathrm{NJ}$ & $\mathrm{R}$ & $3.16 \pm 0.20$ & $2.35 \pm 0.19$ & 74.4 & 6.00 & 11.00 & 79.5 \\
\hline R56 & I & $\mathrm{NJ}$ & $\mathrm{R}$ & $2.03 \pm 0.30$ & $1.38 \pm 0.09$ & 68.0 & 5.00 & 5.38 & 85.0 \\
\hline R57 & I & NJ & $\mathrm{R}$ & $4.75 \pm 0.11$ & $4.22 \pm 1.09$ & 88.8 & 5.00 & 12.00 & 80.0 \\
\hline R58 & $\mathrm{J}$ & $\mathrm{NJ}$ & $\mathrm{R}$ & $2.43 \pm 0.34$ & $1.83 \pm 0.05$ & 75.3 & 5.00 & 12.00 & 80.0 \\
\hline R59 & $\mathrm{I}$ & WH & $\mathrm{R}$ & $1.80 \pm 0.27$ & $1.21 \pm 0.20$ & 67.2 & 5.00 & 5.38 & 85.0 \\
\hline R60 & $\mathrm{J}$ & WH & $\mathrm{R}$ & $2.18 \pm 0.06$ & $1.64 \pm 0.13$ & 75.2 & 6.00 & 6.00 & 84.5 \\
\hline R61 & $\mathrm{J}$ & WH & $\mathrm{R}$ & $4.98 \pm 0.52$ & $1.73 \pm 0.32$ & 34.7 & 6.00 & 6.00 & 84.5 \\
\hline R62 & $\mathrm{J}$ & WH & $\mathrm{R}$ & $5.96 \pm 0.14$ & $1.60 \pm 0.05$ & 26.8 & 6.00 & 6.00 & 84.5 \\
\hline R63 & $\mathrm{J}$ & WH & $\mathrm{R}$ & $3.40 \pm 0.35$ & $1.44 \pm 0.17$ & 42.4 & 4.00 & 5.50 & 86.0 \\
\hline R64 & $\mathrm{H}$ & WH & $\mathrm{R}$ & $4.18 \pm 0.23$ & $2.19 \pm 0.34$ & 52.4 & 1.90 & 6.20 & 84.6 \\
\hline R65 & $\mathrm{H}$ & WH & $\mathrm{R}$ & $3.77 \pm 0.25$ & $1.64 \pm 0.36$ & 43.5 & 1.90 & 6.20 & 84.6 \\
\hline R66 & $\mathrm{H}$ & $\mathrm{WH}$ & $\mathrm{R}$ & $4.96 \pm 0.17$ & $1.35 \pm 0.18$ & 27.2 & 1.90 & 6.40 & 84.4 \\
\hline R67 & $\mathrm{J}$ & WH & $\mathrm{R}$ & $2.11 \pm 0.31$ & $1.37 \pm 0.17$ & 64.9 & 6.00 & 6.00 & 84.5 \\
\hline R68 & $\mathrm{J}$ & WH & $\mathrm{R}$ & $2.11 \pm 0.04$ & $0.81 \pm 0.07$ & 38.4 & 6.00 & 13.00 & 75.0 \\
\hline R69 & $\mathrm{I}$ & WH & $\mathrm{R}$ & $3.43 \pm 0.05$ & $0.57 \pm 0.07$ & 16.6 & 5.00 & 12.00 & 80.0 \\
\hline R70 & $\mathrm{I}$ & WH & $\mathrm{R}$ & $3.36 \pm 0.12$ & $0.51 \pm 0.08$ & 15.2 & 5.00 & 12.50 & 79.0 \\
\hline R71 & $\mathrm{I}$ & WH & $\mathrm{R}$ & $2.20 \pm 0.30$ & $1.27 \pm 0.07$ & 57.7 & 5.00 & 5.38 & 85.0 \\
\hline R72 & $\mathrm{L}$ & WH & $\mathrm{R}$ & $4.78 \pm 0.41$ & $1.63 \pm 0.13$ & 34.1 & 0.50 & 8.50 & 78.2 \\
\hline R73 & $\mathrm{L}$ & WH & $\mathrm{R}$ & $2.64 \pm 0.22$ & $1.66 \pm 0.16$ & 62.9 & 0.50 & 8.10 & 79.8 \\
\hline R74 & $\mathrm{L}$ & WH & $\mathrm{R}$ & $1.95 \pm 0.22$ & $1.03 \pm 0.33$ & 52.8 & 0.60 & 8.80 & 81.3 \\
\hline R75 & $\mathrm{L}$ & WH & $\mathrm{R}$ & $3.71 \pm 0.31$ & $2.78 \pm 0.16$ & 74.9 & 0.60 & 9.00 & 80.0 \\
\hline R76 & $\mathrm{M}$ & WH & $\mathrm{R}$ & $2.05 \pm 0.11$ & $1.98 \pm 0.12$ & 96.6 & 1.55 & 7.50 & 85.0 \\
\hline
\end{tabular}




\begin{tabular}{|c|c|c|c|c|c|c|c|c|c|}
\hline \multicolumn{10}{|c|}{ Table 2.2 (continued) } \\
\hline R77 & M & WH & $\mathrm{R}$ & $1.90 \pm 0.08$ & $1.65 \pm 0.13$ & 86.8 & 1.55 & 7.50 & 85.0 \\
\hline R78 & $\mathrm{G}$ & $\mathrm{WH}$ & $\mathrm{R}$ & $1.75 \pm 0.19$ & $1.35 \pm 0.17$ & 77.1 & 12.50 & 6.45 & 57.8 \\
\hline R79 & G & WH & $\mathrm{R}$ & $1.69 \pm 0.10$ & $0.90 \pm 0.15$ & 53.3 & 12.50 & 6.45 & 57.8 \\
\hline M1 & $\mathrm{A}$ & MIA & $\mathrm{M}$ & $1.04 \pm 0.12$ & $0.30 \pm 0.17$ & 28.8 & 6.67 & 6.67 & 80.0 \\
\hline M2 & A & SJ & $\mathrm{M}$ & $1.15 \pm 0.07$ & $0.27 \pm 0.03$ & 23.5 & 6.67 & 6.67 & 80.0 \\
\hline M3 & A & $\mathrm{NY}$ & $\mathrm{M}$ & $1.25 \pm 0.05$ & $0.52 \pm 0.11$ & 41.6 & 6.67 & 6.67 & 80.0 \\
\hline M4 & A & $\mathrm{CHI}$ & $\mathrm{M}$ & $1.00 \pm 0.00$ & $0.44 \pm 0.03$ & 44.0 & 6.67 & 6.67 & 80.0 \\
\hline M5 & $\mathrm{G}$ & $\mathrm{BJ}$ & $\mathrm{M}$ & $1.30 \pm 0.09$ & $1.04 \pm 0.11$ & 80.0 & 12.50 & 6.78 & 57.7 \\
\hline M6 & $\mathrm{H}$ & $\mathrm{NJ}$ & $\mathrm{M}$ & $0.94 \pm 0.00$ & $0.72 \pm 0.05$ & 76.6 & 1.50 & 9.40 & 80.2 \\
\hline M7 & $\mathrm{H}$ & $\mathrm{WH}$ & $\mathrm{M}$ & $2.91 \pm 0.20$ & $1.64 \pm 0.36$ & 56.4 & 1.50 & 9.50 & 80.6 \\
\hline M8 & I & $\mathrm{WH}$ & $\mathrm{M}$ & $1.43 \pm 0.03$ & $0.44 \pm 0.08$ & 30.8 & 12.50 & 6.78 & 57.7 \\
\hline M9 & $\mathrm{G}$ & WH & $\mathrm{M}$ & $1.39 \pm 0.10$ & $0.93 \pm 0.08$ & 66.9 & 5.00 & 13.00 & 79.0 \\
\hline N1 & $\mathrm{A}$ & MIA & $\mathrm{O}$ & $0.68 \pm 0.06$ & $0.26 \pm 0.12$ & 38.2 & 6.67 & 13.33 & 66.7 \\
\hline $\mathrm{N} 2$ & A & MIA & $\mathrm{O}$ & $0.80 \pm 0.09$ & $0.08 \pm 0.01$ & 10.0 & 3.33 & 6.67 & 80.0 \\
\hline N3 & A & MIA & $\mathrm{O}$ & $1.10 \pm 0.29$ & $0.03 \pm 0.02$ & 2.7 & 6.67 & 6.67 & 73.3 \\
\hline N4 & $\mathrm{A}$ & MIA & $\mathrm{O}$ & $0.88 \pm 0.11$ & $0.05 \pm 0.03$ & 5.7 & 6.67 & 6.67 & 80.0 \\
\hline N5 & A & MIA & $\mathrm{O}$ & $0.72 \pm 0.04$ & $0.11 \pm 0.01$ & 15.3 & 6.67 & 6.67 & 80.0 \\
\hline N6 & A & MIA & $\mathrm{O}$ & $1.00 \pm 0.08$ & $0.05 \pm 0.01$ & 5.0 & 6.67 & 6.67 & 73.3 \\
\hline N7 & $\mathrm{C}$ & MIA & $\mathrm{O}$ & $0.68 \pm 0.03$ & $0.23 \pm 0.04$ & 33.8 & 7.14 & 14.29 & 64.3 \\
\hline N8 & $\mathrm{E}$ & MIA & $\mathrm{O}$ & $0.63 \pm 0.00$ & $0.07 \pm 0.05$ & 11.1 & 6.67 & 13.33 & 66.7 \\
\hline N9 & $\mathrm{D}$ & MIA & $\mathrm{O}$ & $0.61 \pm 0.06$ & $0.19 \pm 0.05$ & 31.1 & 7.14 & 14.29 & 64.3 \\
\hline N10 & $\mathrm{C}$ & MIA & $\mathrm{O}$ & $0.83 \pm 0.04$ & $0.20 \pm 0.05$ & 24.1 & 4.76 & 9.52 & 76.2 \\
\hline $\mathrm{N} 11$ & A & NY & $\mathrm{O}$ & $0.81 \pm 0.02$ & $0.11 \pm 0.03$ & 13.6 & 3.33 & 6.67 & 80.0 \\
\hline N12 & A & NY & $\mathrm{O}$ & $0.65 \pm 0.02$ & $0.14 \pm 0.10$ & 21.5 & 6.67 & 13.33 & 66.7 \\
\hline N13 & $\mathrm{C}$ & NY & $\mathrm{O}$ & $0.65 \pm 0.02$ & $0.09 \pm 0.04$ & 13.8 & 7.14 & 14.29 & 64.3 \\
\hline N14 & $\mathrm{D}$ & NY & $\mathrm{O}$ & $0.57 \pm 0.04$ & $0.13 \pm 0.08$ & 22.8 & 7.14 & 14.29 & 64.3 \\
\hline N15 & A & SJ & $\mathrm{O}$ & $1.08 \pm 0.04$ & $0.17 \pm 0.05$ & 15.7 & 6.67 & 6.67 & 80.0 \\
\hline N16 & $\mathrm{A}$ & SJ & $\mathrm{O}$ & $0.94 \pm 0.06$ & $0.20 \pm 0.15$ & 21.3 & 6.67 & 6.67 & 80.0 \\
\hline N17 & $\mathrm{A}$ & SJ & $\mathrm{O}$ & $0.90 \pm 0.10$ & $0.06 \pm 0.02$ & 6.7 & 6.67 & 6.67 & 73.3 \\
\hline N18 & $\mathrm{A}$ & SJ & $\mathrm{O}$ & $0.70 \pm 0.06$ & $0.10 \pm 0.02$ & 14.3 & 3.33 & 6.67 & 80.0 \\
\hline N19 & $\mathrm{A}$ & SJ & $\mathrm{O}$ & $0.84 \pm 0.06$ & $0.06 \pm 0.02$ & 7.1 & 6.67 & 6.67 & 73.3 \\
\hline $\mathrm{N} 20$ & $\mathrm{~B}$ & SJ & $\mathrm{O}$ & $0.80 \pm 0.15$ & $0.08 \pm 0.02$ & 10.0 & 6.67 & 13.33 & 73.3 \\
\hline $\mathrm{N} 21$ & $\mathrm{E}$ & SJ & $\mathrm{O}$ & $0.40 \pm 0.09$ & $0.07 \pm 0.01$ & 17.5 & 6.67 & 13.33 & 66.7 \\
\hline N22 & $\mathrm{C}$ & SJ & $\mathrm{O}$ & $0.35 \pm 0.01$ & $0.07 \pm 0.02$ & 20.0 & 7.14 & 14.29 & 64.3 \\
\hline $\mathrm{N} 24$ & A & $\mathrm{CHI}$ & $\mathrm{O}$ & $0.65 \pm 0.04$ & $0.14 \pm 0.05$ & 21.5 & 6.67 & 13.33 & 66.7 \\
\hline $\mathrm{N} 25$ & $\mathrm{~B}$ & $\mathrm{CHI}$ & $\mathrm{O}$ & $0.98 \pm 0.12$ & $0.06 \pm 0.02$ & 6.1 & 6.67 & 13.33 & 73.3 \\
\hline $\mathrm{N} 26$ & $\mathrm{C}$ & $\mathrm{CHI}$ & $\mathrm{O}$ & $0.79 \pm 0.19$ & $0.19 \pm 0.02$ & 24.1 & 7.14 & 14.29 & 64.3 \\
\hline N27 & $\mathrm{C}$ & $\mathrm{CHI}$ & $\mathrm{O}$ & $1.04 \pm 0.19$ & $0.06 \pm 0.01$ & 5.8 & 3.57 & 14.29 & 71.4 \\
\hline
\end{tabular}




\begin{tabular}{|c|c|c|c|c|c|c|c|c|c|}
\hline \multicolumn{10}{|c|}{ Table 2.2 (continued) } \\
\hline N28 & D & CHI & O & $1.08 \pm 0.09$ & $0.03 \pm 0.05$ & 2.8 & 7.14 & 14.29 & 64.3 \\
\hline N29 & N & BJ & O & $1.14 \pm 0.03$ & $0.14 \pm 0.04$ & 12.3 & 6.30 & 13.30 & 71.0 \\
\hline N30 & N & BJ & O & $0.66 \pm 0.10$ & $0.10 \pm 0.07$ & 15.2 & 5.30 & 8.60 & 79.4 \\
\hline N31 & G & WH & O & $0.54 \pm 0.00$ & $0.22 \pm 0.06$ & 40.7 & 12.60 & 7.12 & 57.5 \\
\hline
\end{tabular}

"Sampling location: MIA = Miami, NY = New York, SJ = Saint Jose, CHI = Chicago, BJ = Beijing, QD = Qingdao, $\mathbf{N J}=$ Nanjing, $\mathbf{W H}=$ Wuhan .

**:Type: $\mathbf{R}=$ Rice, $M=$ Multi-grain, $\mathbf{O}=$ Other-grain 
Chapter 3. Determination of Bioaccessibility of Methylmercury in Rice-based Infant Cereals using an In vitro Digestion Model 


\begin{abstract}
Considerable levels of methylmercury $(\mathrm{MeHg})$ has been found in rice for over a decade. Studies conducted in our group have suggested that elevated levels of MeHg exist in rice products, hence consumption of rice products may pose a potential health risk to human beings, especially human infants who consume abundant rice cereals and are much more sensitive to the toxic effect of MeHg. Effort was made to assess the potential risk caused by consuming rice cereals for infants, however the crucial information, such as bioavailability or bioaccessibility of $\mathrm{MeHg}$ in rice cereals was still missing. The present study used an in vitro gastrointestinal extraction method to determine the bioaccessibility of $\mathrm{MeHg}$ in rice-based infant cereals and to examine the factors controlling the $\mathrm{MeHg}$ bioaccessibility. The bioaccessibilities of $\mathrm{MeHg}$ in studied rice cereals ranged from $25 \%$ to $74 \%$. Compared to the bioaccessibilities of MeHg in different types of cooked fish, which was traditionally considered as the main $\mathrm{MeHg}$ exposure pathway to human beings, no significant differences were observed. Further experiments were conducted to identify the factors influence $\mathrm{MeHg}$ bioaccessibility in individual sample. The results indicated the re-adsorption of bioaccessible $\mathrm{MeHg}$ in digestive juice was mainly responsible for the variety of $\mathrm{MeHg}$ bioaccessibility in food samples. After taking the portion of re-adsorbed $\mathrm{MeHg}$ into account, the bioaccessibility of $\mathrm{MeHg}$ in all measured rice cereal and fish samples were close to $100 \%$. The finding of this study suggested that we may have been misled by the results from previous studies, which may lead to the neglect of the potential risk of $\mathrm{MeHg}$ exposure through the consumption of rice products.
\end{abstract}




\subsection{Introduction}

Methylmercury $(\mathrm{MeHg})$ is known as a highly neurotoxic contaminant. Upon entering the human body, MeHg will be absorbed rapidly in gastrointestinal (GI) track, then distributed through the body. It can cross the blood-brain barrier, to affect the brain, which will result in severe health problems including loss of IQ, delayed speech and

decreased performance in memory function and even death at high dose of $\mathrm{MeHg}{ }^{60,116}$ Traditionally, fish consumption was considered as the major pathway of $\mathrm{MeHg}$ exposure to human beings since $\mathrm{MeHg}$ could be readily bioaccumulated along the aquatic food chain resulting in high levels of MeHg present in fish. ${ }^{117}$ The well-known Minamata disease, which is a fetal neurological disorder, is one of the most notorious examples of mercury poisoning resulting from the consumption of fish and shellfish containing high levels of MeHg. ${ }^{24}$ Although nowadays incidents involving extremely high $\mathrm{MeHg}$ exposure like in Minamata disease are rare, the $\mathrm{MeHg}$ levels present in a variety of fishes grown in many natural environments are still a worldwide health concern. The chronic exposure of human beings to $\mathrm{MeHg}$ through consumption of fish and shellfish has been the major health risks associated with $\mathrm{MeHg}$, in particular to pregnant women and children.

Recently, scientists worldwide continued to report the occurrence of $\mathrm{MeHg}$ in rice, even at elevated levels in some cases, while the concentrations of $\mathrm{MeHg}$ in other grains such as wheat and oatmeal were almost undetectable. ${ }^{49,52,94,118}$ The finding of elevated level of MeHg in rice is because the physicochemical condition of rice paddy has been proven to be able to facilitate methylation of inorganic $\mathrm{Hg}(\mathrm{IHg})$ in paddy water and soil. Rothenberg et al. summarized the results of previous studies, which have shown that the 
average concentrations of $\mathrm{MeHg}$ in rice grains are $2.5 \mu \mathrm{g} / \mathrm{kg}$ for non-polluted sites and 16 $\mu \mathrm{g} / \mathrm{kg}$ for polluted areas (e.g., mercury or gold mining areas), respectively. The findings of $\mathrm{MeHg}$ occurrence in rice have raised the issue of rice consumption being an exposure pathway of $\mathrm{MeHg}$, in addition to fish consumption, in particular in the inland areas where fish consumption is limited and/or rice and soil are heavily contaminated by $\mathrm{Hg}$. It also should be noted that the $\mathrm{MeHg}$ concentrations in rice produced in most studied areas are close to that from non-polluted areas, ${ }^{52}$ and it seems that the occurrence of such levels of MeHg in rice probably has limited impact on adult's health, especially if rice is not overwhelmingly consumed as the predominant diet.

When assessing the potential human exposure to $\mathrm{MeHg}$ and the associated health risks, differences in adults and infants must be considered since they have different susceptibility to MeHg toxicity and different diets. In fact, the exposure of infants to $\mathrm{MeHg}$ has been of particular concern with regard to $\mathrm{MeHg}$ health issue, as developing nervous system is a more sensitive target organ than the adult brain and $\mathrm{MeHg}$ exposure could lead to various adverse health effects to infant development. ${ }^{116}$ Traditionally, prenatal exposure was considered as the main source of occurrence of MeHg in infants. Methylmercury accumulated in human infants was mainly considered being transferred from pregnant women to fetus via cord blood during the pregnancy after intake of seafood containing MeHg by expectant mother. Postnatal MeHg exposure through diets is also a potential pathway for infants, albeit being understudied, as limited studies have shown that the consumption of breast milk and fish based infant food may related to MeHg exposure to human infants. ${ }^{62-66}$ 
The postnatal MeHg exposure for infants through consumption of rice and rice cereals has been largely overlooked. The recent findings of $\mathrm{MeHg}$ presence in rice may suggest that the $\mathrm{MeHg}$ in rice could be transferred to rice products such as infant cereals and therefore consumption of rice cereals could be a potential pathway for infant $\mathrm{MeHg}$ exposure. A limited number of studies on samples of rice-based baby cereal, which is the most common solid food introduced to human infants, have shown that the concentrations of both $\mathrm{THg}$ and $\mathrm{MeHg}$ in rice-based baby cereals are close to the concentrations of $\mathrm{THg}$ and $\mathrm{MeHg}$ in rice, ${ }^{69,70,95}$ suggesting that the $\mathrm{THg}$ and $\mathrm{MeHg}$ in rice remained in rice cereals after production. The results of our previous work indicated that the concentrations of $\mathrm{MeHg}$ in rice-based baby cereals ranged from 0.51 to $13.9 \mu \mathrm{g} / \mathrm{kg}$ with a mean of $2.28 \mu \mathrm{g} / \mathrm{kg}$. The estimated daily intake of $\mathrm{MeHg}$ for infants through consumption of rice-based baby cereals on the basis of the measured $\mathrm{MeHg}$ level in ricebased baby cereals ranged from $4 \%$ to $123 \%$ of $\mathrm{MeHg}$ reference dose (RfD), which is calculated on the basis of data related to fish consumption, set by United States Environmental Protection Agency (USEPA). ${ }^{29}$

Our previous estimations on infant $\mathrm{MeHg}$ daily intake through consumption of ricebased cereals were on the basis of the total MeHg concentrations determined for the cereals. To accurately assess exposure of $\mathrm{MeHg}$ from rice-based baby cereals, information on bioavailability of $\mathrm{MeHg}$ is needed, as it is possible not all $\mathrm{MeHg}$ is available for absorption. Since the calculated $\mathrm{RfD}$ is directly related to $\mathrm{MeHg}$ bioavailability, while the different properties and contents of two types of foods mean the possible different $\mathrm{MeHg}$ bioaccessibilities in these foods. Usually, In vitro digestion approaches using an enzymatic digestion is a simple, feasible and widely used method for 
assessing bioaccessibility, which is defined as the maximum value of bioavailability. In this method, samples are incubated in artificial gastrointestinal fluid containing enzymes, including amylase, pepsin, pancreatin and bile extract, to simulate the digestion process in human body. Then the $\mathrm{MeHg}$ recovered from the gastrointestinal fluid are identified as the bioaccessible $\mathrm{MeHg}$, while the $\mathrm{MeHg}$ in digestive residue are taken as unbioaccessible. At present, there are various models with different experimental designs exist. In general, an in vitro method is considered valid if the its result matched that obtained from in vivo models. However, high cost and possible ethical dilemma caused by in vivo experiments have limited the its availability of data, hence in the most case, the selection of in vitro digestion models is based on the content of food. Different methods have been used to digest fish and rice samples to evaluate the bioaccessible metal including arsenic, cadmium and lead. ${ }^{18-21}$ Despite various digestion times applied according to purposes of studies, the enzyme used in most case are amylase, pepsin, lipase, pancreatin and bile extract. Efforts have also been made to assess the bioaccessibilities of $\mathrm{MeHg}$ in seafood using in vitro digestive models as well. The results of previous in vitro studies indicated that the overall mean bioaccessibilities of $\mathrm{MeHg}$ in different seafood ranged from $2 \%$ to $100 \% .^{22-27}$

Unfortunately, there is still a knowledge gap in understanding the percentage of bioaccessible $\mathrm{MeHg}$ in infant rice cereals. To our best knowledge, there have been no studies reported on how much $\mathrm{MeHg}$ from rice cereals is released and absorbed by the digestive system. Moreover, the results of $\mathrm{MeHg}$ bioaccessibility in seafood obtained from different studies varied within a wide range. Even the bioaccessible $\mathrm{MeHg}$ in the same type of fish could vary largely in inter-and intra-studies, while no real rational 
explanation was given, suggesting the necessity of investigating MeHg bioaccessibility

and the controlling factors from the food and from the methods used. ${ }^{50,80,82,85,86}$

Therefore, in this study, we focused on investigation of the bioaccessibility of MeHg in various infant rice cereal samples and fish that commonly available on the market by using an in vitro digestion model. Meanwhile, the possible reasons which result in variations in bioaccessibilities of $\mathrm{MeHg}$ in infant rice cereals and fish were investigated. Knowing bioaccessible fraction of $\mathrm{MeHg}$ in rice cereal and fish, together with the controlling factors on variety of MeHg bioaccessibility in those samples, will advance our understanding of the impact of dietary MeHg on infant's health and provide accurate data to perform health risk assessment for infant MeHg exposure.

\subsection{Materials and methods}

\subsubsection{Reagents and materials}

Ultrapure deionized water produced by a Barnstead Nanopure Diamond water purification system with resistivity of $18 \mathrm{M} \Omega \cdot \mathrm{cm}$ was used for preparing all solutions. TraceMetal grade nitric acid, hydrochloric acid and ACS certified grade reagents, including potassium hydroxide, copper sulfate, sulfuric acid, potassium bromide, methylene chloride, hydrogen peroxide, and tin chloride were used in pretreatment and analysis of samples. All chemicals were supplied by Fisher Scientific, unless otherwise specified. Overnight 10\% (v/v) nitric acid soaked and muffle furnace baked glassware were used to get rid of influence of residual $\mathrm{Hg}$ during experiments

The acidic potassium bromide solution used for $\mathrm{MeHg}$ extraction was prepared by dissolving $180 \mathrm{~g}$ of $\mathrm{KBr}$ in $50 \mathrm{ml}$ sulfuric acid in $100 \mathrm{ml}$ water, and the solutions were mixed up and made up to $1 \mathrm{~L}$ using water after cooling to ambient temperature. Copper 
sulfate solution $(1 \mathrm{M})$ and citric buffer $(1 \mathrm{M})$ were prepared by adding appropriate amounts of salts in water. The Ethylation reagent was prepared by dissolving $1 \mathrm{~g}$ of sodium tetraethylborate (NaBEt4, Sigma-Aldrich) in $100 \mathrm{ml}$ of $2 \%$ (w/w) potassium hydroxide. A proper amount of tin chloride was dissolved in $1 \%(\mathrm{v} / \mathrm{v})$ hydrochloric acid to obtain $2 \%(\mathrm{w} / \mathrm{v})$ reductant solution used in $\mathrm{THg}$ analysis. Certified $10 \mathrm{ppm} \mathrm{MeHg}$ standard solutions were used for quantification during $\mathrm{MeHg}$ analysis. Certified reference materials, DORM-2 (National Research Council of Canada), was used for quality control and validation of $\mathrm{MeHg}$ determination methods.

\subsubsection{Sampling and preparation of rice cereal and fish samples}

In this study, a total of 21 infant rice cereal samples were purchased in local grocery stores and then kept in a cabinet inside a Class 100 clean room (with inlet air purified by gold-coated sand to remove $\mathrm{Hg}$ ) to avoid contamination. Three different type of fish samples, including Tuna, Tilapia, and Salmon, were purchased from the local market, and frozen in a freezer at low temperature $\left(-14^{\circ} \mathrm{C}\right)$.

To prepare sample for in vitro digestion, approximately $1.0 \mathrm{~g}$ of rice cereal sample and $4.0 \mathrm{ml}$ of ultra-pure water was placed into a $50-\mathrm{ml}$ centrifuge tube, then was stored in fume hood until digestion. The fish fillets were steam-cooked for 15 minutes using a rice cooker. Then the cooked fish samples were blended using a blender to obtain the homogenized samples. Approximately $1.0 \mathrm{~g}$ of blended fish sample was added into $50 \mathrm{ml}$ centrifuge tube followed by adding $4.0 \mathrm{ml}$ of ultra-pure water, then was stored in fume hood until digestion. 


\subsubsection{In vitro artificial gastrointestinal fluid digestion}

During the experiment, the prepared fish and rice cereal samples were digested using artificial digestive fluid, which contained inorganic and organic salt, and various enzymes. Then the portion of MeHg in liquid phase, which was considered as bioaccessible $\mathrm{MeHg}$, and the $\mathrm{MeHg}$ remained in residue, which was treated as unbioaccessible $\mathrm{MeHg}$, were measured respectively to determine the $\mathrm{MeHg}$ bioaccessibility in samples. The experimental setup of the in vitro digestion approach used has been described previously. ${ }^{122}$ This model has been successfully used in assessment of different contaminant in various types of food. Artificial digestive fluids, including saliva, gastric juice, intestinal juice and bile, were prepared by following the method described by Versantvoort et al. ${ }^{122}$ The extraction was started by adding $6 \mathrm{ml}$ artificial saliva fluid into the prepared rice cereal and fish samples, and the tube was capped and placed in a water bath shaker $\left(37^{\circ} \mathrm{C}, 100 \mathrm{rpm}\right)$ to mimic digestion in mouth. After 5 mins, $12 \mathrm{ml}$ prepared gastric fluid was added into sample and then digestion for another 2 hours to simulate the digestion in stomach. Eventually, $12 \mathrm{ml}$ of intestinal juice with $6 \mathrm{ml}$ of bile were added in sample, and $\mathrm{pH}$ value was adjusted to 6.8-7.0 using 1\% (w/v) KOH solution. The tube was shaken for another 2 hours to mimic intestinal digestion. Following these steps of digestion, the sample was centrifuged at $7000 \mathrm{rpm}$ for 10 minutes to separate the solution from the residual solids both of which were subject to MeHg analysis.

\subsubsection{Determination of MeHg content}

The MeHg levels in cereal, fish samples, residue and supernatant of digested samples were measured using a gas chromatography-atomic fluorescence spectrometry (GC-AFS) 
(Brooks Rand Automated MERX) MeHg System, following a modified extraction method reported previously. ${ }^{97}$ Briefly, $0.5 \mathrm{~g}$ of cereal or fish sample or $3 \mathrm{ml}$ supernatant or entire residue of digested samples was digested with $6 \mathrm{ml}$ of $\mathrm{KBr} / \mathrm{H}_{2} \mathrm{SO}_{4} / \mathrm{CuSO}_{4}$ solution and the $\mathrm{MeHg}$ present in the digest was extracted into $10 \mathrm{ml}$ of $\mathrm{CH}_{2} \mathrm{Cl}_{2}$. Then, 0.1 to $1 \mathrm{ml}$ of $\mathrm{CH}_{2} \mathrm{Cl}_{2}$ extract was pipetted into a 40-ml amber glass vial containing $30 \mathrm{ml}$ of ultrapure deionized water. The vial was purged with $\mathrm{N}_{2}$ to completely volatilize the $\mathrm{CH}_{2} \mathrm{Cl}_{2}$, leaving $\mathrm{MeHg}$ in the aqueous solution. $\mathrm{MeHg}$ in the aqueous solution was then derivatized with $150 \mu \mathrm{l}$ of $1 \%$ (w/v) NaBEt4 to convert MeHg to volatile methylethylmercury which was then purged and trapped on a Tenax trap followed by analysis on GC-CVAFS MeHg system.

\subsection{Results and discussion}

\subsubsection{Bioaccessibility of MeHg in rice cereals and possible affecting factors}

The concentrations of $\mathrm{THg}$ and $\mathrm{MeHg}$ in 21 infant cereal samples studied ranged from 2.0 to $15.9 \mu \mathrm{g} / \mathrm{kg}$ and 1.2 to $13.9 \mu \mathrm{g} / \mathrm{kg}$ with a mean value of $6.0 \pm 4.2 \mu \mathrm{g} / \mathrm{kg}$ and $4.5 \pm 3.7 \mu \mathrm{g} / \mathrm{kg}$, respectively. The 21 rice cereal samples involved in this study included various brands from different locations. The results obtained in this study were compared with the studies about $\mathrm{MeHg}$ in rice and our previous study on $\mathrm{MeHg}$ in rice-based cereals. To our best knowledge, there is no other group who has conducted the study on $\mathrm{MeHg}$ in rice-based baby cereals, except for our previous work in which we determined $\mathrm{THg}$ and $\mathrm{MeHg}$ in a large number of infant cereal samples commonly available in the main markets in China and USA. The range of $\mathrm{MeHg}$ concentration is comparable to the concentrations of $\mathrm{MeHg}$ in rice from unpolluted area and rice-based baby cereals

purchased in both China and USA. ${ }^{52}$ The results indicated that rice MeHg was transferred 
into infant cereals after cooking and packing process, while the concentration did not changed drastically.

To estimate the bioaccessibility of $\mathrm{MeHg}$ in rice cereal samples, the sum of $\mathrm{MeHg}$ extracted by artificial gastrointestinal fluid was compared to the total $\mathrm{MeHg}$ found through acidic $\mathrm{KBr}$ extraction. The $\mathrm{MeHg}$ was assumed to be dissolved in gastrointestinal fluid before it can be absorbed by the gastrointestinal track. Detailed sample information, including $\mathrm{Hg}$ concentration, bioaccessibilities of $\mathrm{MeHg}$ in rice cereals were summarized in Table 3.1.

Table 3.1. Hg concentrations and bioaccessibilities of infant rice cereals and fish

\begin{tabular}{|c|c|cc|}
\hline Sample ID & $\begin{array}{c}\text { MeHg concentration } \\
(\boldsymbol{\mu g} / \mathbf{k g}, \mathbf{n}=\mathbf{3})\end{array}$ & $\begin{array}{c}\text { THg concentration } \\
(\boldsymbol{\mu g} / \mathbf{k g}, \mathbf{n}=\mathbf{3})\end{array}$ & $\begin{array}{c}\text { Bioaccessibility } \\
(\boldsymbol{\%}, \mathbf{n}=\mathbf{3})\end{array}$ \\
\hline R54 & $1.24 \pm 0.08$ & $3.30 \pm 0.42$ & $74 \pm 23$ \\
\hline R18 & $2.39 \pm 0.34$ & $6.43 \pm 0.32$ & $70 \pm 3$ \\
\hline R8 & $9.23 \pm 1.43$ & $11.74 \pm 1.48$ & $67 \pm 33$ \\
\hline R34 & $2.43 \pm 0.62$ & $3.22 \pm 0.14$ & $65 \pm 14$ \\
\hline R47 & $4.24 \pm 0.03$ & $6.02 \pm 0.13$ & $62 \pm 0.2$ \\
\hline R23 & $13.9 \pm 2.02$ & $14.8 \pm 2.19$ & $59 \pm 19$ \\
\hline R32 & $1.84 \pm 0.46$ & $2.96 \pm 0.18$ & $57 \pm 10$ \\
\hline R38 & $3.58 \pm 0.42$ & $4.49 \pm 0.32$ & $54 \pm 12$ \\
\hline R49 & $2.92 \pm 0.53$ & $4.15 \pm 0.25$ & $52 \pm 7$ \\
\hline R50 & $3.01 \pm 0.17$ & $3.66 \pm 0.12$ & $52 \pm 17$ \\
\hline R19 & $2.68 \pm 0.53$ & $3.51 \pm 0.26$ & $49 \pm 7$ \\
\hline R58 & $1.83 \pm 0.05$ & $2.43 \pm 0.34$ & $48 \pm 9$ \\
\hline R22 & $13.4 \pm 1.88$ & $15.9 \pm 2.17$ & $47 \pm 5$ \\
\hline R2 & $2.13 \pm 0.09$ & $4.92 \pm 0.25$ & $44 \pm 7$ \\
\hline R55 & $2.35 \pm 0.19$ & $3.16 \pm 0.20$ & $44 \pm 8$ \\
\hline R6 & $3.95 \pm 0.22$ & $4.87 \pm 0.18$ & $43 \pm 7$ \\
\hline R9 & $1.78 \pm 0.38$ & $1.97 \pm 0.41$ & $40 \pm 4$ \\
\hline R57 & $4.22 \pm 1.09$ & $4.75 \pm 0.11$ & $35 \pm 5$ \\
\hline R51 & $3.87 \pm 0.41$ & $4.87 \pm 0.30$ & $32 \pm 14$ \\
\hline R42 & $3.30 \pm 0.12$ & $3.54 \pm 0.31$ & $27 \pm 3$ \\
\hline R8 & $9.23 \pm 1.43$ & $11.7 \pm 1.48$ & $25 \pm 2$ \\
\hline Tilapia & $14.3 \pm 4.50$ & $15.5 \pm 2.30$ & $68 \pm 15$ \\
\hline Salmon & $4.99 \pm 1.16$ & $5.59 \pm 0.87$ & $47 \pm 8$ \\
\hline Tuna & $131 \pm 5.76$ & $148 \pm 4.26$ & $70 \pm 20$ \\
\hline & & & \\
\hline
\end{tabular}


The results of $\mathrm{MeHg}$ analysis suggest that the bioaccessible portion of $\mathrm{MeHg}$ in 21 infant cereal samples ranged from 25 to $74 \%$, with a median of $49 \%$ and a mean of $50 \%$. And as shown in the Figure 3.1, the bioaccessibilities of MeHg in infant rice cereals ranged widely, while the same phenomenon was also observed in the previous studies on $\mathrm{MeHg}$ bioaccessibilities in fish. No correlation between the content, including protein, fat, carbohydrate, or $\mathrm{Hg}$ concentration, and $\mathrm{MeHg}$ bioaccesibility was found in this study. The other possible explanations proposed by other groups include the differences in properties of individual samples, digestion ability of enzyme used, and protein denaturation caused by storage of individual samples. However, samples in this study were kept under the same storage condition, and even bioaccessibility of $\mathrm{MeHg}$ in same samples made in different locations (same product with different lot number) showed significant differences. Furthermore, as shown in the previous studies, even protein denaturation occurred during the cooking of fish was unable to affect the $\mathrm{MeHg}$ speciation and concentrations, hence the protein denaturation mentioned above may not be considered as the major causes of varying bioaccessibilities of $\mathrm{MeHg}$ in rice cereal samples. The digestive abilities of enzymes used were suggested to be a possible reason that has caused varying $\mathrm{MeHg}$ bioaccessibilities in same type of fish. The reason was considered because $\mathrm{MeHg}$ in fish is mainly present as the form of $\mathrm{MeHg}$-thiol complex, ${ }^{81,85,123}$ and the proteins need to be broken down through the involvement of enzymes to release $\mathrm{MeHg}$ and make $\mathrm{MeHg}$ becoming bioaccessible. 

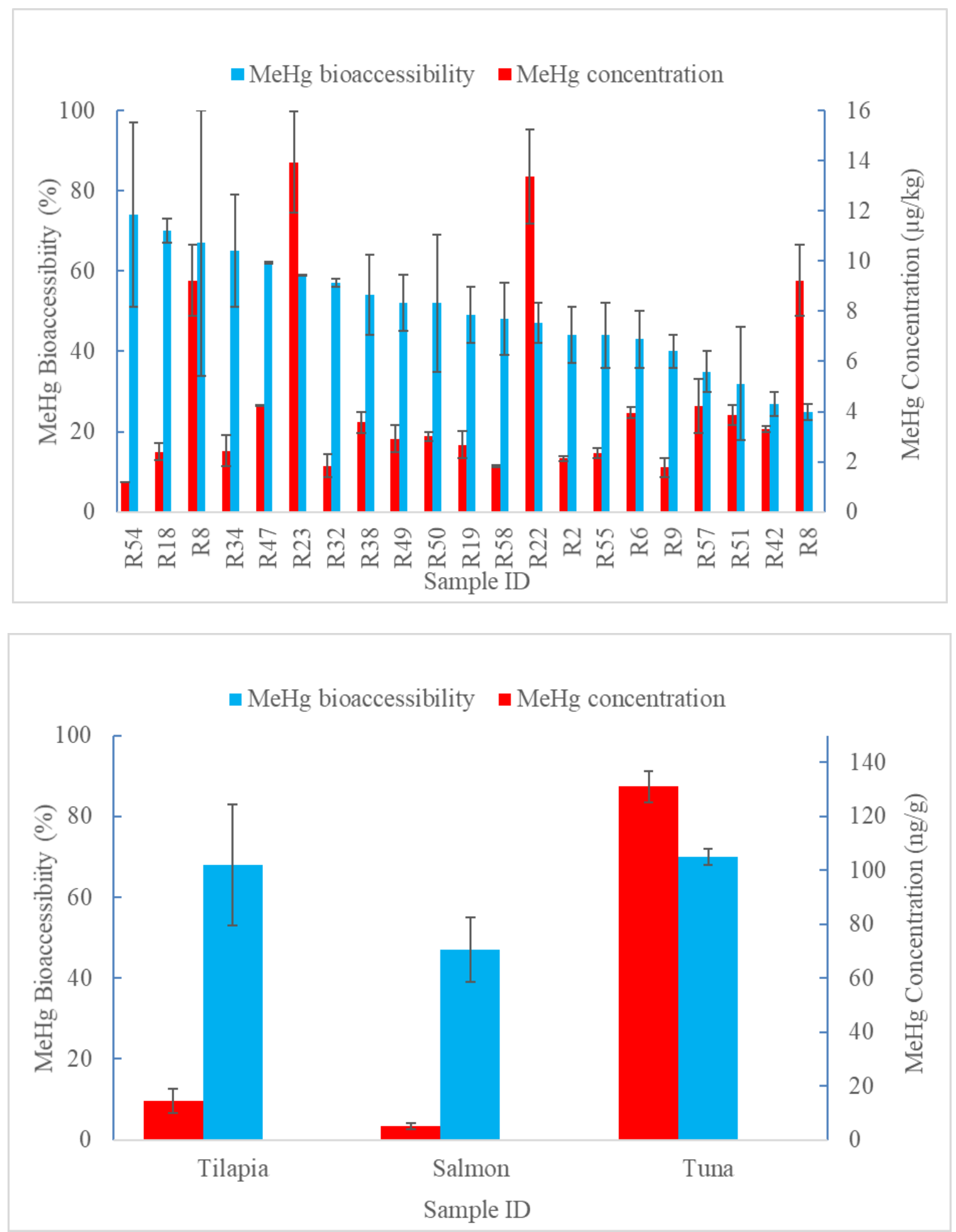

Figure 3.1. MeHg levels and bioaccessibilities in infant rice cereal and fish 
But even in the previous study on $\mathrm{MeHg}$ bioaccessibility in same type of fish using same enzyme, significant differences in $\mathrm{MeHg}$ bioaccessibilities were observed in individual samples, ${ }^{86}$ suggesting the limited influence of digestion abilities of enzyme on MeHg bioaccessibility in fish tissue.

More importantly, the bioaccessibility of $\mathrm{MeHg}$ in food samples were expected to raise if more enzymes were used and digestion times were increased, on the assumption that various enzymes used and longer digestion would both help with the protein digestion, which means more $\mathrm{MeHg}$ would be released. However, in this study, it has been observed that the bioaccessibility of $\mathrm{MeHg}$ in rice cereal samples under gastric digestion were higher than that under gastrointestinal conditions (where more types of enzymes were present in this dual-step digestion). These results indicated that no more $\mathrm{MeHg}$ was released after samples were further digested during intestinal digestive phase even when more enzymes were added (shown in Fig. 3.2).

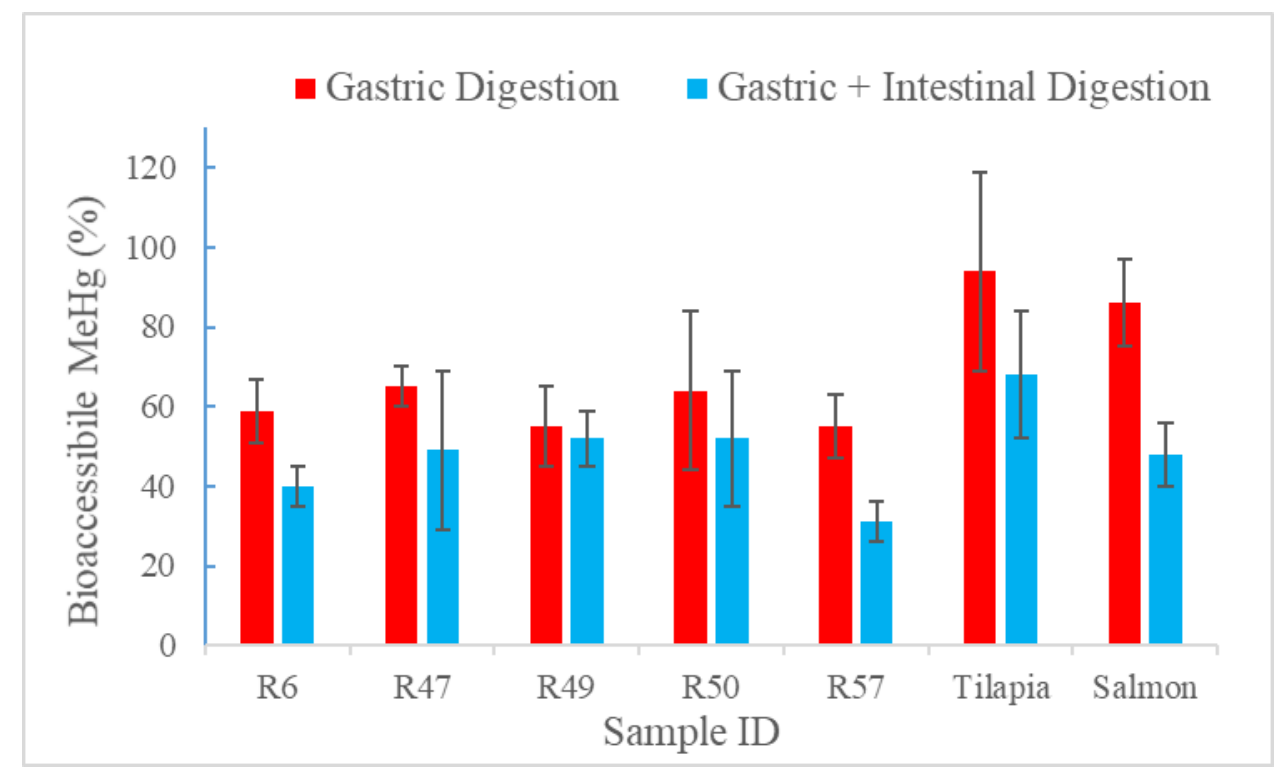

Figure 3.2. MeHg bioaccessibility in dual step digestion 
It is worth noting that in the study as we increased the total digestion time from $1 \mathrm{~h}$ ( $0.5 \mathrm{~h}$ gastric followed by $0.5 \mathrm{~h}$ intestinal digestion) to $8 \mathrm{~h}$ ( $4 \mathrm{~h}$ gastric followed by $4 \mathrm{~h}$ intestinal digestion), the bioaccessible MeHg showed a tendency to reduce. (Shown in Fig. 3.3)

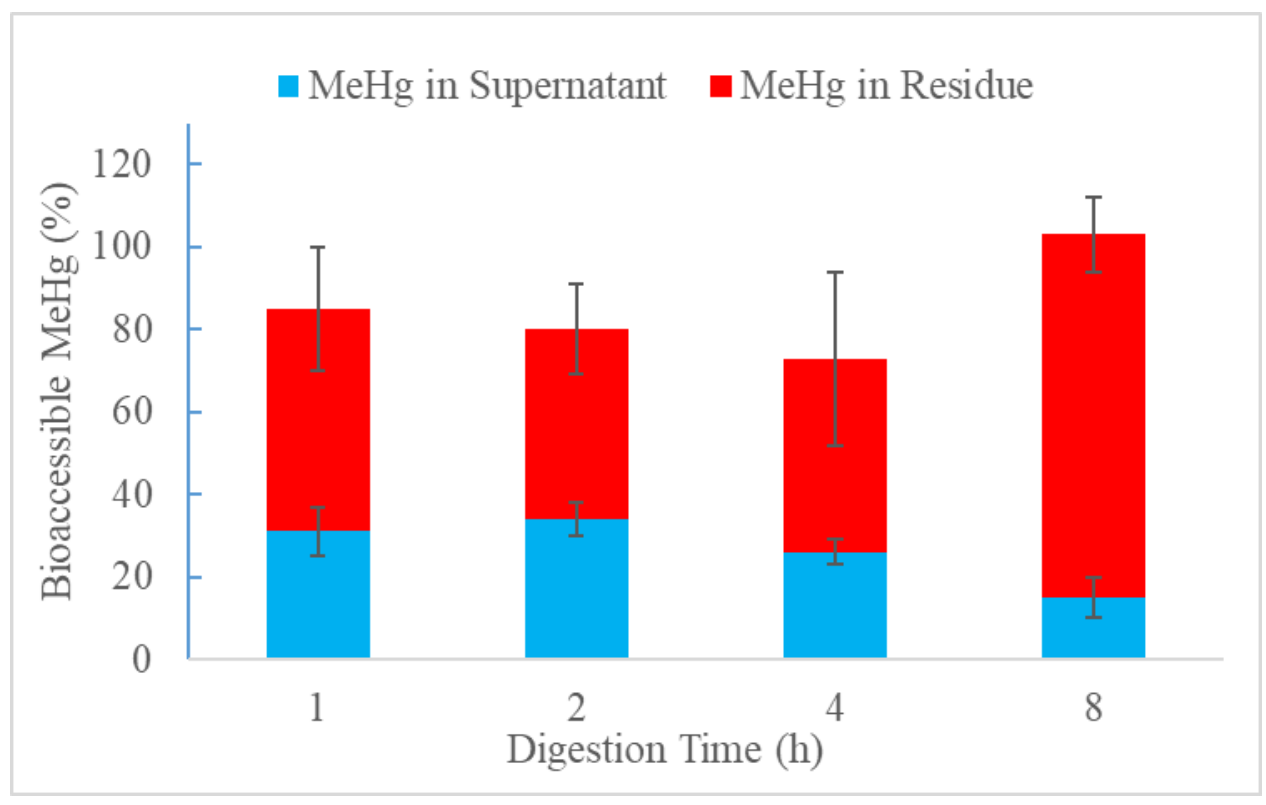

Figure 3.3. MeHg measured in supernatant and residue of rice cereal samples under different digestion time

For instance, the bioaccessibility of $\mathrm{MeHg}$ in sample R57 dropped from 35\% (30 min for both gastric and intestinal digestion) to $15 \%$ (240 min for both gastric and intestinal digestion). These results could suggest that during the digestion process, most of the $\mathrm{MeHg}$ in rice cereals have been released from food matrix into solution phase after gastric and intestinal digestion, but some of the released $\mathrm{MeHg}$ might be re-adsorbed on the residual solids resistive to the digestion. The result may be particularly the case for the differences in $\mathrm{MeHg}$ bioaccessibility between gastric and gastrointestinal digestions as a consequences of increased $\mathrm{pH}$ values (from 2 to 7 , from gastric to intestinal digestion 
phase), because previous studies have shown that the distribution of $\mathrm{MeHg}$ and $\mathrm{MeHg}$ complexion in solution strongly related to the $\mathrm{pH} .{ }^{124}$ As the $\mathrm{pH}$ of solution increased, the portion of MeHg and MeHg-protein complexion in liquid phase of solution rich in particles reduced, ${ }^{125}$ since the availability of HS- group on particles, which can be strongly bound with MeHg, decreased. Hence, in the case, the re-adsorption of bioaccessible $\mathrm{MeHg}$ on digestive residue may have occurred.

\subsubsection{Effect of re-adsorption on MeHg bioaccessibility}

To confirm the occurrence of re-adsorption of MeHg onto the residues post digestion, the proper amount of $\mathrm{MeHgCl}$ standard solution was spiked into the gastrointestinal digested rice cereal samples to examine the adsorption of the spiked MeHg. The results showed that around $64 \%$ of spiked $\mathrm{MeHg}$ standard was adsorbed on the digestion residue. Moreover, the results of multiple steps extraction experiments, where the digestion residue was repeatedly extracted, provided further evidence for the occurrence of $\mathrm{MeHg}$ adsorption. In the experiments, the residues of gastric and intestinal digestion were extracted using neutral intestinal fluid ( $\mathrm{pH}=7$, no enzyme) and acidic gastric fluid ( $\mathrm{pH}=2$, no enzyme) in sequence.

In Figure 3.4, the repetitive extraction results showed that only a small portion of $\mathrm{MeHg}$ on the residue was released under the neutral condition (intestinal fluid extraction), while a significantly larger portion of $\mathrm{MeHg}$ was eluted under acidic condition (gastric fluid extraction). In addition, there was still detectable portion of bioaccessible MeHg being eluted during the second acidic juice extraction of acidic fluid eluted residues. After combining all portions of dissolved $\mathrm{MeHg}$ in each extractant, the amount was close to the total $\mathrm{MeHg}$ present in rice-based baby cereal samples. The 
results of experiments could suggest that almost $100 \%$ of $\mathrm{MeHg}$ in rice-based baby cereals were probably bioaccessible, and the distribution of bioaccessible $\mathrm{MeHg}$ in liquid phase was strongly affected by $\mathrm{pH}$ of digestive juice. The adsorption of bioaccessible $\mathrm{MeHg}$ on residue occurred from $\mathrm{pH} 2$ to $\mathrm{pH} 7$, while a significantly larger fraction of bioaccessible $\mathrm{MeHg}$ was adsorbed under neutral condition than that under acidic condition. The reason was because, as mentioned above, the distribution of MeHg-thiol complex in liquid phase decreased as $\mathrm{pH}$ increased from 2 to 7 , hence resulting in occurrence of larger portion of released $\mathrm{MeHg}$-thiol complex being re-adsorbed on the surface of residue.

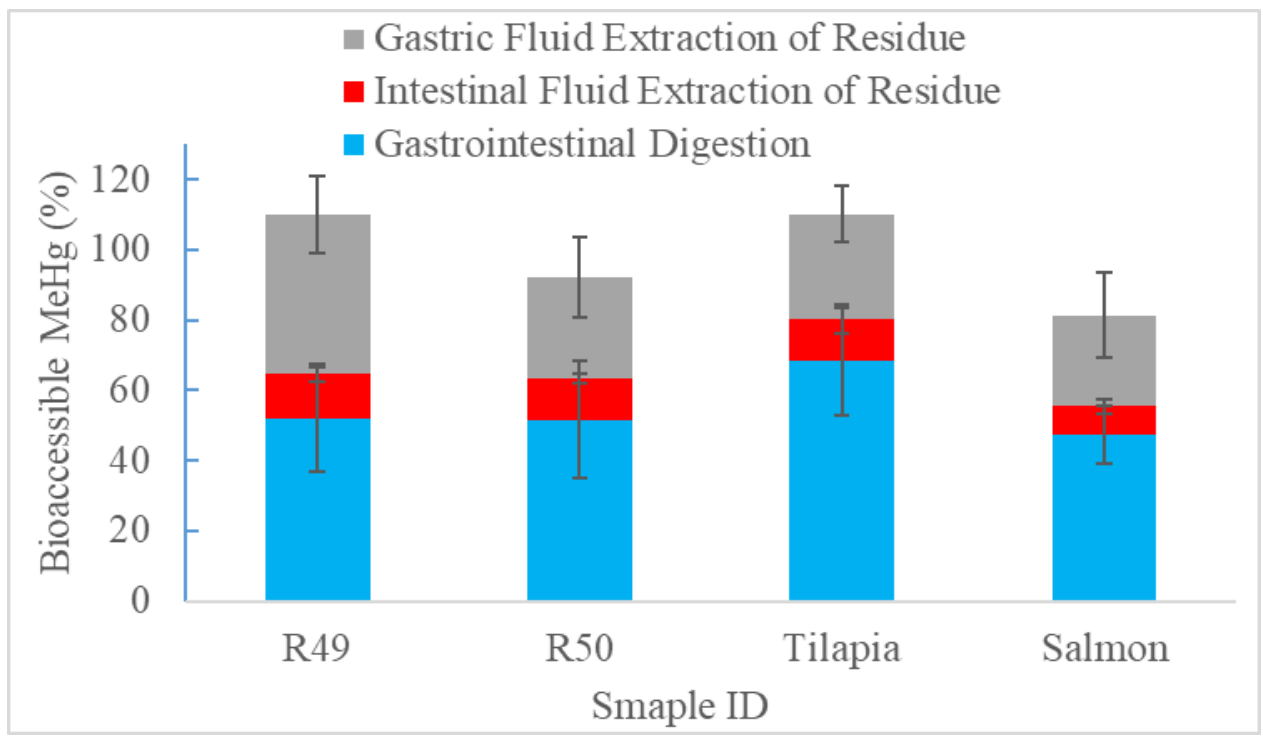

Figure 3.4. MeHg bioaccessibility determined using multiple steps extraction

In addition, $\mathrm{pH}$ changes may alter the binding of $\mathrm{MeHg}$ with the functional groups (thiol) in residue and thus affect $\mathrm{MeHg}$ re-adsorption on residue. The sulfur (thiol) containing residue under neutral condition may bind bioaccessible $\mathrm{MeHg}$, since the digestive residue of rice contains thiol containing peptides. The high $\mathrm{pH}$ value could 
promote the dissociation of thiol groups, ${ }^{126,127}$ resulting in the combination between $\mathrm{MeHg}^{+}$and thiolates. In fact, previous studies have shown that the adding of thiol containing reagent indeed affected the bioaccessibility of MeHg in fish and seafood. ${ }^{81,128}$ It also needs to be pointed out that the distribution of bioaccessible $\mathrm{MeHg}$ is a dynamic distribution process, hence the re-adsorbed $\mathrm{MeHg}$ should be considered as bioaccessible. Because the absorption of $\mathrm{MeHg}$ in gastrointestinal track is a dynamic process as well, the adsorbed MeHg and MeHg-thiol complex may be released back to digestive juice as the dissolved MeHg was absorbed by GI-track.

\subsubsection{Effect of speciation on MeHg bioaccessibility}

In the interpretation of possible mechanism about re-adsorption of bioaccessible $\mathrm{MeHg}$ released from rice cereals, the speciation of $\mathrm{MeHg}$ was found be related to how $\mathrm{MeHg}$ was adsorbed on the digestive residue. Hence the speciation of $\mathrm{MeHg}$ in rice cereal samples was expected to be correlated to the MeHg bioaccessibilities. The experiments were conducted to confirm the hypothesis. As shown in Fig. 3.5, in the most cases, extraction of un-digested rice cereal samples using only gastric juice containing no enzyme had a result with high MeHg bioaccessibility, which strongly suggested the facility of releasing of $\mathrm{MeHg}$ in rice cereal under acidic condition. The result was not surprising because of the presence of $\mathrm{Cl}^{-}$ions in the acidic gastric fluid that may promote the release of $\mathrm{MeHg}$ from $\mathrm{MeHg}$-protein complexation because of the relatively high concentration of $\mathrm{Cl}^{-}$and its high binding constant with MeHg.

As the MeHg bioaccessibility varies with samples, Figure 3.5 showed that the gastrointestinal digestion may increase the bioaccessibility of $\mathrm{MeHg}$ in some of cereal 
samples, such as sample R49. Part of MeHg in undigested R49 was released into digestion fluid after extraction using gastric fluid containing no enzyme.
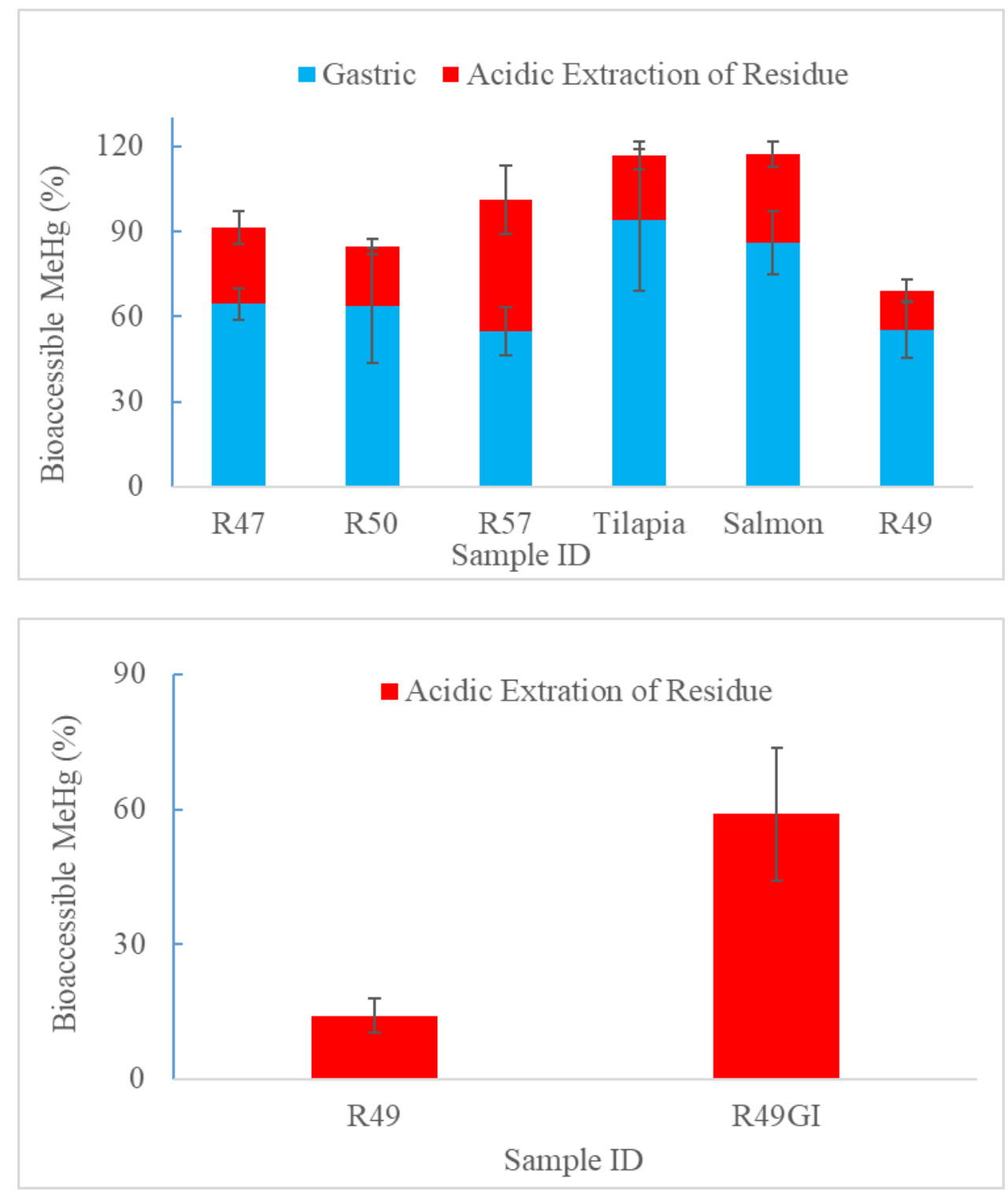

Figure 3.5. Bioaccessible MeHg in supernatant and residue of undigested samples

However, continually using gastric fluid without enzyme was not able to elute more $\mathrm{MeHg}$ from the residue, while large portion of $\mathrm{MeHg}$ in residue was eluted using gastric fluid without enzyme only after the sample going through entire gastrointestinal 
digestion. The results indicated that the presence of enzymes helped with the breakdown of proteins and the release of MeHg. The results also indicated that not only the adsorption of $\mathrm{MeHg}$ on residue, but also the speciation of $\mathrm{MeHg}$ in sample have an influence on the $\mathrm{MeHg}$ bioaccessibility, since only a portion of $\mathrm{MeHg}$ in rice cereal samples was bioaccessible while the rest portions were not until the contents were enzymatically digested.

\subsubsection{Effect of food matrix on MeHg bioaccessibility}

The finding of re-adsorption of bioaccessible $\mathrm{MeHg}$ in rice-based baby cereal samples during in vitro extraction procedures could also be used to explain the varying bioaccessibilities of MeHg in fish observed in previous studies where similar procedures were used. To verify our hypothesis, experiments were conducted to investigate the effect of re-adsorption on MeHg bioaccessibility in different food matrix. First, the concentrations of $\mathrm{MeHg}$ in fish were determined. Compared to rice cereals samples, the MeHg concentration in fish samples varied widely among individuals, and freshwater fish contain less MeHg than saltwater fish do, which matched previous data as well. ${ }^{129-131}$ Then the bioaccessible MeHg in the fish samples were determined, which ranged from $47 \%$ to $80 \%$ (shown in Table 3.1 and Fig. 3.1), using the gastrointestinal fluid extraction. The results were comparable with those observed in previous studies conducted by other

groups. ${ }^{80,82,83,131}$ At last, the multiple steps extraction experiments were conducted on the digested residues of fish samples. Compared to the rice cereal experiments, the similar results were obtained in the fish experiments. As shown in the Figure 3.4 and 3.5, a considerable portion of $\mathrm{MeHg}$ was eluted from the residues of digested and undigested fish samples, and bioaccessible $\mathrm{MeHg}$ in both fish samples were close to $100 \%$. The 
results were expected since the previous studies have pointed out that the $\mathrm{MeHg}$ in both

rice and fish mainly exists in the forms of $\mathrm{CH}_{3} \mathrm{HgCl}$ and $\mathrm{CH}_{3} \mathrm{Hg}$-thiol complex, ${ }^{50,85}$

therefore as both food could be completely digested, the amount of bioaccessible $\mathrm{MeHg}$ should expected to be the same.

\subsection{Conclusions}

The present study used an in vitro gastrointestinal extraction method to determine the bioaccessibility of $\mathrm{MeHg}$ in rice-based infant cereals and to examine the factors controlling the $\mathrm{MeHg}$ bioaccessibility. The fractions of bioaccessible $\mathrm{MeHg}$ in rice cereals varied from 25 to $74 \%$ following the conventional gastric and intestinal extractions. However, a further examination on the results when considering the effects of various factors on $\mathrm{MeHg}$ bioaccessibility suggests the occurrence of re-adsorption of the $\mathrm{MeHg}$ initially released into the solution phase. After taking the portion of readsorbed $\mathrm{MeHg}$ into account, the bioaccessibility of $\mathrm{MeHg}$ in all measured rice cereal and fish samples were close to $100 \%$. These results indicated that the amount of $\mathrm{MeHg}$ that can be released from food matrix into gastrointestinal track could be underestimated, if not considering carefully the extraction procedures used. Results of previous studies using in vitro digestion models indicated the bioaccessibilities of $\mathrm{MeHg}$ in fish varied widely and were relatively low in some cases, but this study suggests that the readsorption of $\mathrm{MeHg}$ on the residues should be taken into account when explaining these results. The assessment of potential health risk caused by $\mathrm{MeHg}$ exposure through fish and rice products consumption could be influenced by using underestimated data while calculating the daily intake of $\mathrm{MeHg}$ through diet. In addition, in this study, the digestive ability of enzymes was also suggested to be related to the $\mathrm{MeHg}$ bioaccessibility, 
providing important data for further studies on the factors affecting $\mathrm{MeHg}$ bioaccessibility in different types of foods. 
Chapter 4. Decadal Variations of Mercury in Mosquito Fish in the Everglades and Relation to Changes in Atmospheric Hg Deposition and Ecosystem Alteration 


\begin{abstract}
The finding of elevated methylmercury $(\mathrm{MeHg})$ in wildlife in the Florida Everglades in last nineteen eighties resulted in great concern about the impact of this highly toxic mercury $(\mathrm{Hg})$ species to this ecosystem. Since then, great efforts have been made to identify the source, fate, transport of $\mathrm{Hg}$, as well as the production and transformation of MeHg. However, a comprehensive analysis utilizing various databases has not been conducted. By performing the statistical analysis of data obtained from various data bases, the temporal trends of $\mathrm{Hg}$ contamination in the food web across different trophic levels over recent years were investigated. In this study, a clear decline of $\mathrm{Hg}$ in mosquitofish was observed while the similar trend has not been clearly observed for $\mathrm{Hg}$ in large fish at high trophic levels. Then the analysis on the data of $\mathrm{Hg}$ in environmental matrices including air, surface water, and periphyton was carried out. The result of data analysis suggested that the periphyton possibly play a dominant role in controlling $\mathrm{Hg}$ in mosquitofish by affecting the production of $\mathrm{MeHg}$, while the other parameters such as dissolved carbon (DOC) and sulfate in water may have influence on $\mathrm{Hg}$ in mosquitofish by affecting the $\mathrm{Hg}$ in periphyton. However, more work should be performed in this field in future for the purpose of resolving the $\mathrm{Hg}$ problem in the Everglades as well as the other similar systems.
\end{abstract}

\title{
4.1 Introduction
}

Mercury $(\mathrm{Hg})$ is a worldwide contaminant and it has drawn great public concerns because of its prevalent existence, widespread distribution via the atmospheric transport, high toxicity and biomagnified to high concentrations in organisms at high trophic levels. 
Mercury in the environment originates from both natural (e.g., volcanoes, ${ }^{45}$ forest fires, ${ }^{132-134}$ oceanic and terrestrial emission, and natural degassing of the earth's crust) and anthropogenic sources (e.g., mining, mineral processing, chlor-alkali production and combustion of fossil fuels). ${ }^{41}$ The major form of $\mathrm{Hg}$ emitted into the environment is inorganic $\mathrm{Hg}\left(\mathrm{Hg}^{0}\right.$ and $\left.\mathrm{Hg}^{2+}\right)$. After entering the aquatic environments, the inorganic $\mathrm{Hg}$ can be transformed into a more toxic form, methylmercury $(\mathrm{MeHg})$, which can be bioaccumulated and biomagnified through the food chain. With the increase in the anthropogenic emission of $\mathrm{Hg}$ in the past several centuries, elevated $\mathrm{Hg}$ has been frequently detected in the fish of a large number of aquatic ecosystems. ${ }^{135,136}$

Since the realization of the risk of $\mathrm{Hg}$ to human health, a variety of measures (e.g., closing the $\mathrm{Hg}$ mining, removal from many consumer items, and improving emission control) have been and are being implemented to minimize the use and release of mercury, reducing the emission of $\mathrm{Hg}$ into the environment around the world since 1980s. ${ }^{137}$ Accordingly, the decrease in the emission of $\mathrm{Hg}$ has been reported in some regions, especially in Europe and Northern America. ${ }^{138}$ Although fish could present a rapid response to $\mathrm{Hg}$ wet deposition ${ }^{139}$, debatable results have been observed on the variation of $\mathrm{Hg}$ in fish. Both increase and decrease in fish $\mathrm{Hg}$ have been found in the northern America and Europe lakes, where the input of $\mathrm{Hg}$ has decreased dramatically. ${ }^{140-}$ 147 These inconsistent findings could be caused by two reasons. Firstly, it is a complicated course for the inputted inorganic $\mathrm{Hg}$ finally being accumulated in fish as $\mathrm{MeHg}$, involving a number of transport and transformation processes (e.g., adsorption/desorption, methylation/demethylation, reduction/oxidation and bioaccumulation). As these processes are controlled by many environmental factors, e.g., 
natural organic matter, sulfate temperature. These factors, rather than $\mathrm{Hg}$ emission, may dominantly control the long-term variation of fish $\mathrm{Hg}$ in aquatic environments. In fact, climate changes (e.g., global warming) ${ }^{148,149}$ and ecosystem variations (e.g., fish body condition, ${ }^{150}$ eutrophication) has been deemed to result in the variation of fish $\mathrm{Hg}$ in a variety of aquatic ecosystems. Secondly, large uncertainties exist for the long-term trend of fish $\mathrm{Hg}$, in particularly for large fish, because of the limitations of fish amount per angler, sampling sites, and big individual differences. ${ }^{151}$ Small size fish could be a better indicator for studying the response of high trophic species to $\mathrm{Hg}$ emission and ecosystem alteration because of the virtues of less individual differences, ease of getting samples, and possibility of getting samples at more sites.

The Everglades is a subtropical wetland ecosystem located in the south of Florida. Elevated $\mathrm{Hg}$ has been frequently detected in fish, birds, and other animals of the Everglades since 1980s, ${ }^{152}$ promoting the long-term Hg studies in this system. Hg flux input into the Everglades (>90\% from atmospheric deposition) was much less than that in highly $\mathrm{Hg}$ contaminated system. ${ }^{138,153-155}$ However, $\mathrm{Hg}$ in fish were determined to be much higher in this ecosystem, which could be caused by the high natural organic matter (NOM) concentrations, ${ }^{156}$ quick methylation in the periphyton, water, and sediment, ${ }^{157}$ and slow photodegradation in water. ${ }^{158}$ Despite these studies on Hg distribution and cycling, there is a lack of knowledge on the long-term variation in fish $\mathrm{Hg}$ in the Everglades. A significant change in atmospheric deposition of $\mathrm{Hg}$ has been observed in many regions, including the United States, ${ }^{159}$ whose effects on Everglades should be clarified. In addition, Comprehensive Everglades Restoration Plan (CERP), the largest environmental restoration project in the world, was launched in 2000. This project has 
changed and is being changing the topography, water chemistry, and ecosystem of the Everglades. ${ }^{160}$ These changes in ecosystem may also alter Hg cycling in Florida Everglades.

Eastern mosquitofish (Gambusia Holbrooki) is a kind of small fish in the Everglades. In consideration of its ubiquitous existence and ease to get sufficient samples at each site, eastern mosquitofish could serve as a good indicator for studying the response of fish to external changes of $\mathrm{Hg}$. The objectives of this study were to elucidate the temporal trend in mosquitofish $\mathrm{Hg}$ in the past two decades, and to evaluate the contributions of atmospheric deposition, and ecosystem alteration to these changes.

\subsection{Materials and methods}

\subsubsection{Data source}

This major data base utilized in this study (mosquitofish $\mathrm{Hg}$ data and various environmental parameters) was obtained by the USEPA REMAP program (four phases, 1995-1996, 1999, 2005, and 2014). Wet atmospheric deposition of $\mathrm{Hg}$ into the Everglades was from the National Atmospheric Deposition Program. Mosquitofish Hg data at 12 sites from different programs collected by South Florida Water Management District (DBHYDRO database) were also included for the purpose of validation.

\subsubsection{Sampling and sample analysis}

Four phases of sampling with a large number of sampling sites (covering the entire

freshwater Everglades, including water conservation areas 1, 2, and 3 (WCA-1, WCA-2, and WCA-3), and Everglades National Park (ENP), from North to South) have been conducted in the Everglades (1995-96, 1999, 2005, and 2014), supported by the USEPA REMAP program. Detailed sampling procedures and analytical procedures for $\mathrm{MeHg}$, 
total $\mathrm{Hg}(\mathrm{THg})$ and other ancillary parameters and QA/QC of $\mathrm{Hg}$ analysis can be found in the report of USEPA REMAP program.

\subsubsection{Measurement of MeHg in the porewater of sediment/floc and absorbed water of periphyton}

$\mathrm{MeHg}$ concentrations in the porewater of sediment/floc and absorbed water of periphyton were collected at four sites and 6 sites of the Everglades in October 2010 and April 2012, respectively. Sediment and floc samples were centrifuged at $4000 \mathrm{rpm}$ to obtain the porewater. $\mathrm{MeHg}$ in periphyton adsorbed water was collected by gently handsqueezing the periphyton.

\subsubsection{Data analysis}

The Mann-Kendall test was performed to determine if there is a significant decreasing or increasing trend for a certain variable by JMP (SAS Institute, Inc., Version 10.0.0 for Windows). Spearman's correlation test was applied to determine the correlation between $\mathrm{Hg}$ in and environmental factors. PCA and CA analyses were performed by SPSS (Version 19 for Windows, SPSS Inc., Chicago, IL) to identify the factors controlling $\mathrm{Hg}$ in mosquitofish and $\mathrm{MeHg}$ in periphyton.

\subsection{Results and discussion}

\subsubsection{Decadal variation of mercury in Everglades mosquitofish from 1995 to 2014}

A long-term field monitoring program with a large number of sampling sites was conducted in the Everglades by the USEPA (USEPA-REMAP) since 1995. Mosquitofish $\mathrm{Hg}$ measured in this program was utilized as an indicator of the long-term trend of $\mathrm{Hg}$ in Everglades fish. As shown in Fig. 4.1, a decline in mosquitofish $\mathrm{Hg}$ was observed from 1996 to 2014 in dry season and from 1999-2014 in wet season (Mann Whitney test, $p<$ 
0.01), also indicated by the significant decrease in both mean and median values (Fig.

4.1).
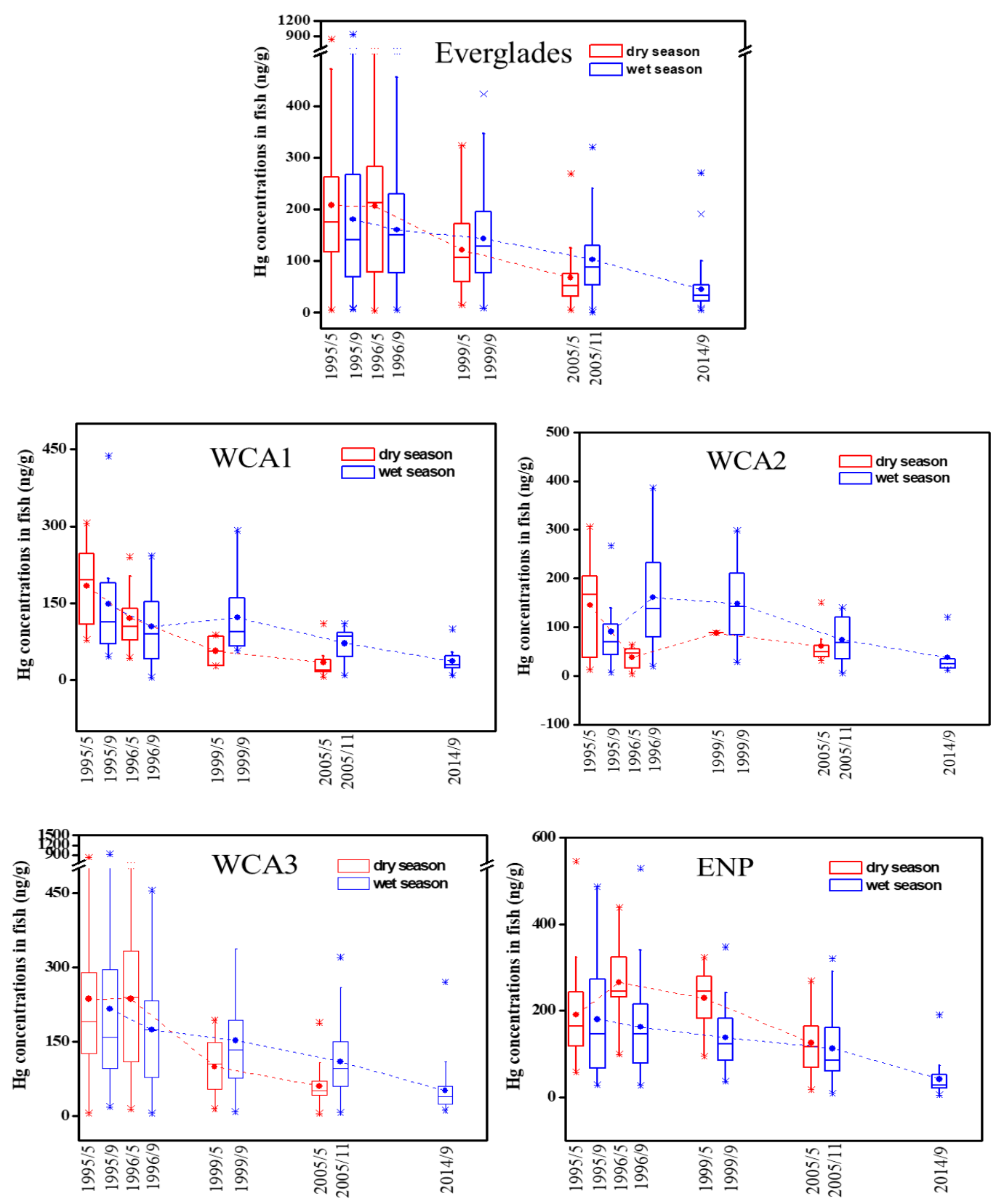

Figure 4.1. Long-term variation in the mosquito fish $\mathrm{Hg}$ in the Everglades, and WCA 1, WCA 2, WCA 3 and ENP parts of the Everglades from 1995-2014 
In addition, the decreasing rate in dry season ( $7 \% /$ year) was slightly higher than that in wet season ( 4\%/year). Significant decrease in mosquitofish $\mathrm{Hg}$ was observed at all the four parts of the Everglades. The decreasing rate in dry season and wet season was 8.5\%/year and 3.8\%/year, $4.1 \% /$ year and 3.6\%/year, $7.9 \% / y e a r$ and 3.8\%/year, 4.0 \%/year and $3.8 \% /$ year for WCA 1, WCA 2, WCA 3 and ENP, respectively. Similar decreasing trend was also observed at 8 of 13 sites monitored by other projects (data obtained from the DBHYDRO) (Fig. 4.2). All these results suggest that $\mathrm{Hg}$ in Everglades mosquitofish declined in the past two decades.

Compared to the result of $\mathrm{Hg}$ in mosquitofish, the $\mathrm{Hg}$ level in fish at higher trophic level didn't show the similar trend. As shown in Figure 4.3, the Hg concentration in both sunfish and LMB didn't change too much during the last two decades among all over the Everglades area. The results of Mann-Kendall test $(\mathrm{p}>0.05)$ performed on the Hg in both sunfish and LMB collected from all 11 sampling sites indicated that no significant decline in sunfish $\mathrm{Hg}$ or LMB Hg was observed. These inconsistent results could be due to several reasons. Firstly, duet to the difficulty of sampling, it is a big challenge to get sufficient large fish samples at a large number of sites, which is expected to result in large errors for analyzing the trend of $\mathrm{Hg}$ in large fish. Secondly, small fish are expected to response much quicker to ecosystem alteration in comparison to large fish due to their short generation time. In addition, as the mosquitofish only accounts for small part of sunfish and LMB diet, hence the change in mosquitofish $\mathrm{Hg}$ is not big enough to cause Hg level changes in sunfish and LMB. 

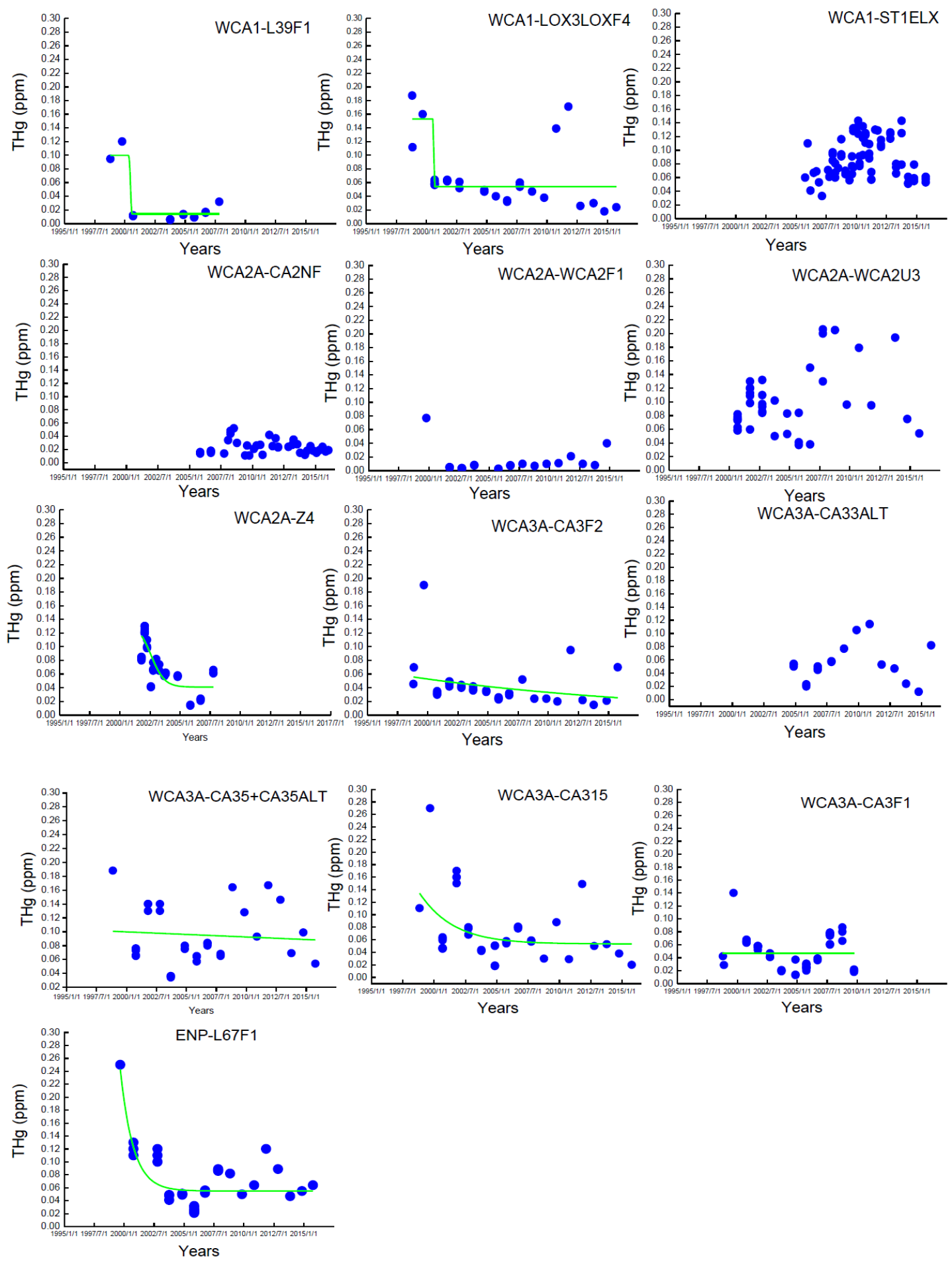

Figure 4.2. Long-term variation in the mosquito fish $\mathrm{Hg}$ from 1995-2014 (data obtained from SFWD DBHYDRO data) 

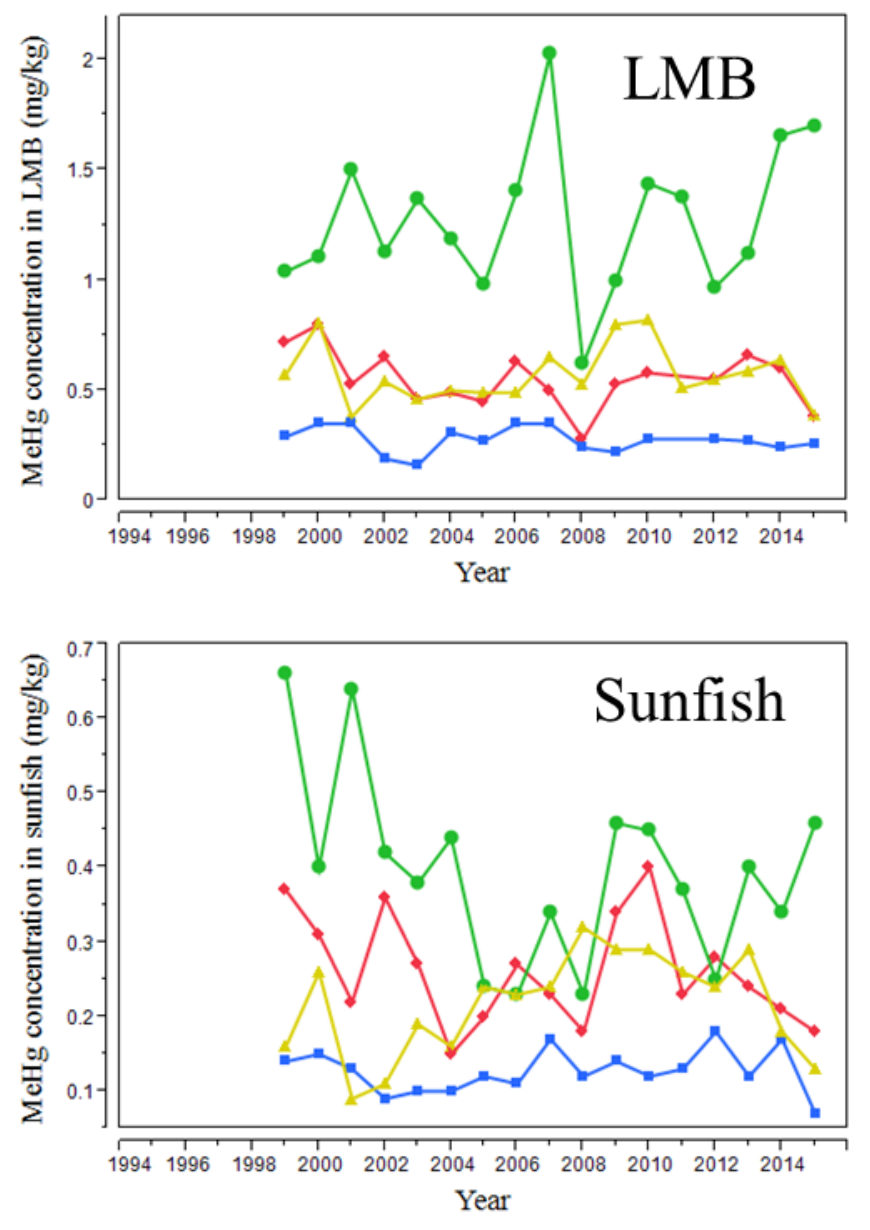

Sampling sites $\bullet-$ ENP $\bullet$ WCA3 $\$$ WCA2 $\because-$ WCA1

Figure 4.3 Long-term variation in the large bass and sunfish $\mathrm{Hg}$ from 1999-2015

Inorganic $\mathrm{Hg}$ is the major form of $\mathrm{Hg}$ inputted into aquatic environments, whereas most proportion of $\mathrm{Hg}$ in mosquitofish is in the form of $\mathrm{MeHg}(>95 \%) .{ }^{157}$ Mercury in fish are controlled by a variety of processes, including the input of $\mathrm{Hg}$, and a number of transport and transformation processes (e.g., adsorption/desorption, methylation/demethylation, reduction/oxidation and bioaccumulation). Decrease in fish $\mathrm{Hg}$ has been observed in a variety of ecosystems in the past few decades. Most of them 
were deemed to be caused by the decrease in $\mathrm{Hg}$ discharge, ${ }^{141}$ while climate changes (e.g., global warming) ${ }^{148,149}$ and ecosystem variations (e.g., fish body condition, ${ }^{150}$ eutrophication) were also thought to be potential reasons.

In the Everglades, atmospheric deposition is the major source of inorganic $\mathrm{Hg}$, accounting for $>95 \%$ of $\mathrm{Hg}$ inputted into the system. ${ }^{152}$ The decrease in mosquitofish $\mathrm{Hg}$ could be because of the change in atmospheric $\mathrm{Hg}$ deposition or ecosystem alteration in the Everglades. These possible explanations were further tested in later sections.

\subsubsection{Change in $\mathrm{Hg}$ atmospheric deposition into Everglades and its effects on mosquitofish $\mathrm{Hg}$}

Wet deposition of $\mathrm{Hg}$ was monitored at four sites of Everglades (NADP project data) since 1996. As shown in Figure 4.4, no significant change was observed on the input of $\mathrm{Hg}$ from wet deposition in both wet season and dry season in the past twenty years MannKendall test, $p>0.1$ ). Although there is lack of long-term monitoring of atmospheric $\mathrm{Hg}$ concentrations and $\mathrm{Hg}$ dry deposition in the Everglades and south Florida, atmospheric Hg concentrations in United States were observed to be relatively stable from 2008$2015,{ }^{159}$ indicating that dry deposition in the Everglades may be also stable during this period. In addition, no significant drop was observed in water and sediment $\mathrm{Hg}$ (MannKendall test, $p>0.1$ ), further proving that the atmospheric deposition of $\mathrm{Hg}$ changed insignificantly during the past twenty years. This indicates that the significant decrease in mosquitofish $\mathrm{Hg}$ in the past twenty years should not be because of the change in atmospheric deposition in the Everglades. 

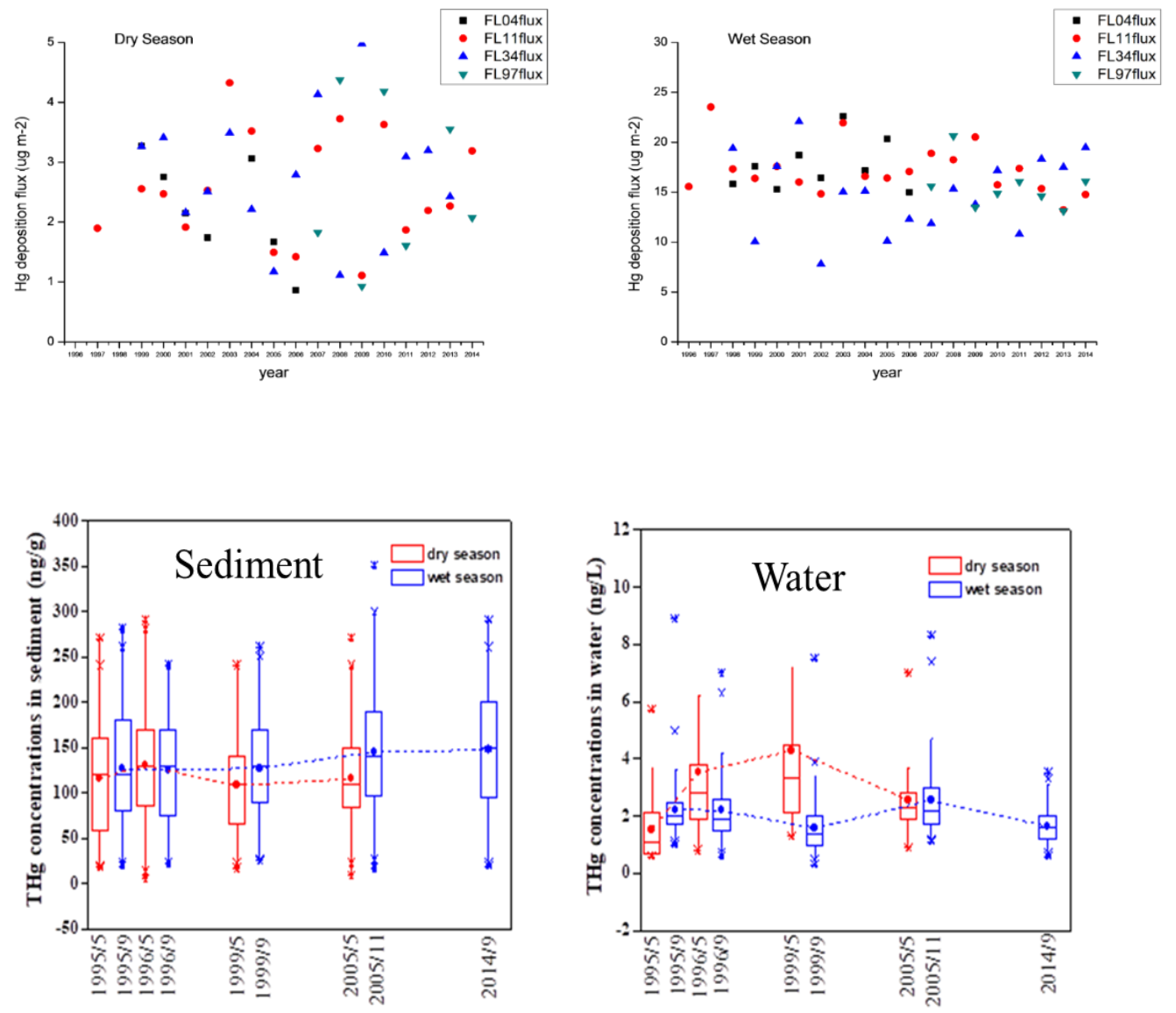

\section{Figure 4.4. Wet deposition of $\mathrm{Hg}$ into the Florida Everglades and $\mathrm{THg}$ in Everglades sediment and water}

Variation in atmospheric deposition of $\mathrm{Hg}$ has been deemed to be the major factor controlling Hg levels in fish in a number of aquatic ecosystems. ${ }^{141,161}$ Diverse trend has been observed on the atmospheric deposition flux of $\mathrm{Hg}$ in the world, owing to the complicated trend in $\mathrm{Hg}$ emission (e.g., increase in Asia and Africa, and decrease in Europe and North America) in the pasted several decades. ${ }^{159}$ Both local and regional sources contribute significantly to $\mathrm{Hg}$ in the South Florida. ${ }^{156}$ Since most local sources of $\mathrm{Hg}$ have been terminated before 1990s and a relative stable $\mathrm{Hg}$ concentration may exist in 
the atmosphere in the past two decades, it is reasonable to obtain a flat change in $\mathrm{Hg}$ atmospheric deposition in the Everglades.

By excluding the contribution of atmospheric deposition to the quick drop in mosquitofish $\mathrm{Hg}$, it is reasonable to assume that this phenomenon may be caused by the alteration in ecosystem (e.g., less production of $\mathrm{MeHg}$ in the Everglades).

\subsubsection{Ecosystem alteration in the Everglades and its effects on mosquitofish $\mathrm{Hg}$}

$\mathrm{MeHg}$ is the major form of $\mathrm{Hg}$ specie in mosquitofish ${ }^{157}$ and $\mathrm{MeHg}$ in fish is from other compartments (e.g., periphyton, floc, water), other than production in fish body. $\mathrm{MeHg}$ in the Everglades mainly produced in the soil and periphyton. As for the long-term variation of $\mathrm{MeHg}$ in soil and periphyton (Fig. 4.5), no significant change was detected in the soil MeHg of Everglades; however, $\mathrm{MeHg}$ in the water and periphyton decreased dramatically from 1995-2014, especially in the dry season. Periphyton and water $\mathrm{MeHg}$ decreased at a rate of $6.7 \%$ and $3.8 \%$ in dry season, and $0.7 \%$ and $2.8 \%$ in wet season, respectively. Periphyton and sediment are the major source of $\mathrm{MeHg}$ in the Everglades. ${ }^{160}$ As periphyton was one of the major sources of $\mathrm{MeHg}$ in Everglades water, it is reasonable to assume that the decline in mosquitofish $\mathrm{Hg}$ may be caused by the decrease in periphyton $\mathrm{MeHg}$. This opinion was further supported by analyzing the relations of mosquitofish $\mathrm{Hg}$ with $\mathrm{THg}$ and $\mathrm{MeHg}$ in water, soil, floc, and periphyton of the Everglades. As shown in Table 1, mosquitofish $\mathrm{Hg}$ exhibited a good relation with $\mathrm{MeHg}$ in periphyton $(\mathrm{R}=0.44, \mathrm{p}<0.01)$ and water $(\mathrm{R}=0.42, \mathrm{p}<0.01)$ and $\mathrm{THg}$ in periphyton $(\mathrm{R}=0.35, \mathrm{p}<0.01)$, while weak relation was observed on mosquitofish $\mathrm{Hg}$ and $\mathrm{THg}$ and $\mathrm{MeHg}$ in sediment and floc and $\mathrm{THg}$ in water. 

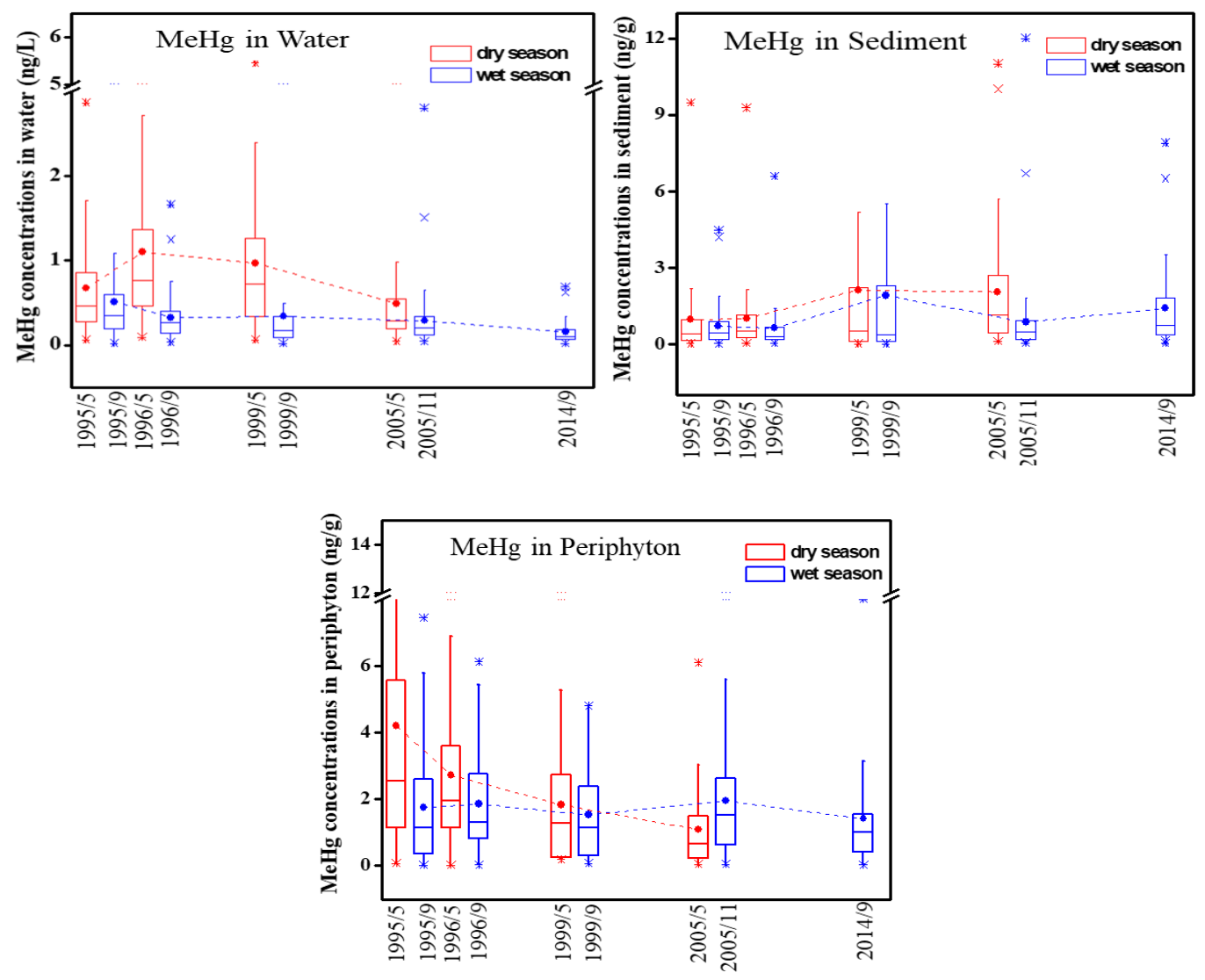

Figure 4.5. Long-term variation in MeHg in Everglades water, sediment, and periphyton from 1995-2014 (EPA-REMAP data).

Principal component analysis (PCA), and multiple regression analyses also showed that $\mathrm{Hg}$ in mosquitofish have the best correlation with $\mathrm{MeHg}$ and $\mathrm{THg}$ in periphyton, in comparison to $\mathrm{Hg}$ in the other matrices and related environmental parameters (Fig. 4.6). These results indicate that the decrease in periphyton (food source for mosquitofish and major sources of $\mathrm{MeHg}$ in Everglades water) $\mathrm{MeHg}$ may be the reason of dramatic decline in Everglades mosquitofish Hg.

Sediment methylation has been thought to be major source of $\mathrm{MeHg}$ in aquatic environments. Our pervious study160 found that both soil (sediment in other systems) 
and periphyton are the major source of $\mathrm{MeHg}$ in the Florida Everglades. The net production of $\mathrm{MeHg}$ in the soil was calculated to be much larger than that in periphyton. However, a large portion of produced $\mathrm{MeHg}$ may be adsorbed on solid phase which cannot be diffused into the water body.
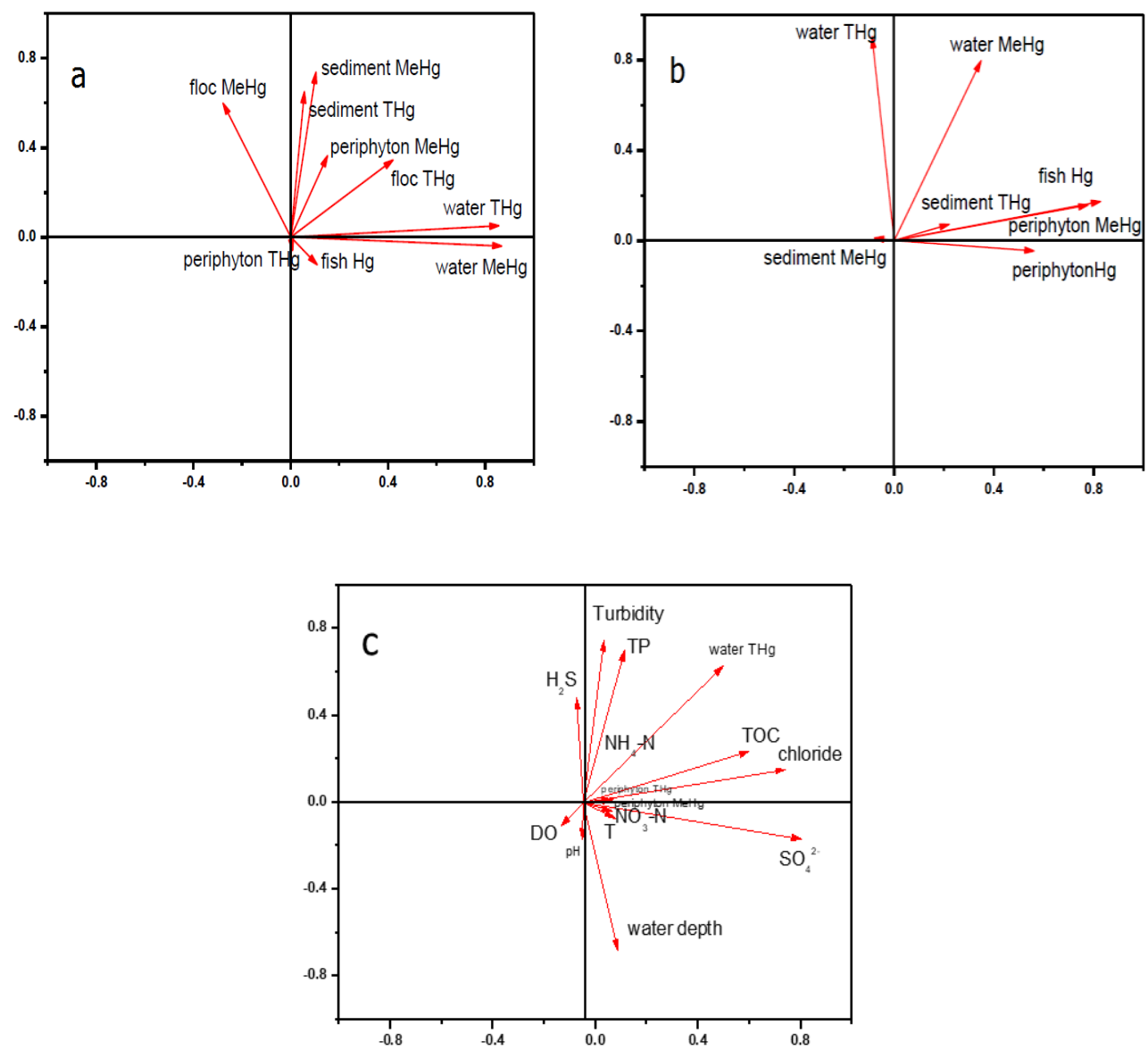

Figure 4.6. PCA of $\mathrm{Hg}$ in fish with $\mathrm{Hg}$ in other matrices (a, floc included, b, floc not included) and $\mathrm{MeHg}$ in periphyton with environmental factors (c).

This could be particularly true in the Everglades, where soil has a much higher content of organic matter and could sequester more $\mathrm{MeHg}$. To test this hypothesis, $\mathrm{MeHg}$ in porewater of soil/floc and surface water adsorbed by periphyton was measured and 
compared with $\mathrm{MeHg}$ in the water body. As shown in Fig. 4.7, MeHg in soil/floc porewater was comparable to or even lower than that in associated overlying water, indicating that most $\mathrm{MeHg}$ in surface water may not be from the sediment phase. $\mathrm{MeHg}$ adsorbed on periphyton was higher than that in surface water, indicating a significant diffusion of $\mathrm{MeHg}$ from periphyton to water body. These results suggest that periphyton may be a more important source for $\mathrm{MeHg}$ in comparison to soil/floc although the production of $\mathrm{MeHg}$ in soil was higher than that in periphyton. This was consistent with the statistical analysis on the basis of the monitoring data from 1995-2014, indicated by the better correlation of $\mathrm{MeHg}$ in water with $\mathrm{MeHg}$ in periphyton $(\mathrm{R}=0.53)$ in comparison to $\mathrm{MeHg}$ in the soil $(\mathrm{R}=0.13)$.
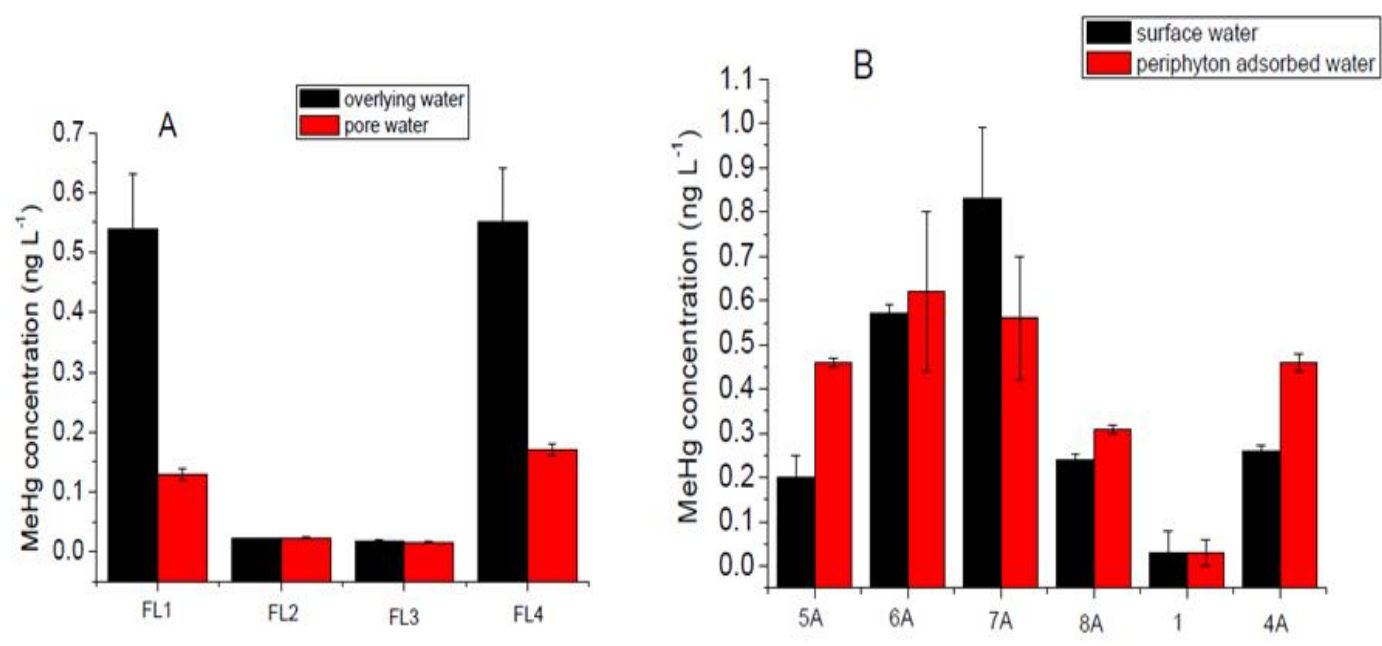

Figure 4.7. MeHg concentrations in Everglades soil/floc porewater, periphyton adsorbed water, surface water, and surface water.

A variety of processes could affect the level of $\mathrm{Hg}$ in fish in aquatic environment, including the deposition of $\mathrm{Hg}^{139}$, and changes in environmental factors that can 
significantly affect $\mathrm{MeHg}$ production or fish biomass or bioaccumulation of $\mathrm{Hg}$ via food chain. In this study, it was found that the decrease in MeHg periphyton may result in the dramatic drop in mosquitofish $\mathrm{Hg}$ since 1995. Most previous studies reported that $\mathrm{Hg}$ in fish was controlled by $\mathrm{Hg}$ atmospheric deposition, ${ }^{141}$ climate changes, ${ }^{148,149}$ fish body condition, ${ }^{150}$ etc. This finding gives a new insight on the factors controlling $\mathrm{Hg}$ in fish. Periphyton is the major primary producer in the Everglades. As a kind of important food for mosquitofish, the decrease in periphyton $\mathrm{MeHg}$ in periphyton would directly result in the decrease in fish MeHg. In addition, periphyton is a major source of MeHg in water. The decrease in $\mathrm{MeHg}$ production by periphyton can cause the decrease in water $\mathrm{MeHg}$ and cause the less acquisition of MeHg by mosquitofish through the bioaccumulation from water via the phytoplankton chain. The levels of $\mathrm{MeHg}$ in periphyton are affected by both net production of $\mathrm{MeHg}$ by periphyton, which are controlled by a variety of environmental factors that controls periphyton composition and $\mathrm{MeHg}$ methylation, e.g., THg levels, phosphorus, $\mathrm{pH}$, dissolved oxygen (DO), sulfate, etc. The changes in these environmental factors will be further investigated and their possible effects on periphyton MeHg levels were tested.

\subsubsection{Possible reasons of the decrease in periphyton MeHg from 1995 to 2014}

To elucidate the reason of the decrease in periphyton $\mathrm{MeHg}$ since 1995, in periphyton, relations of periphyton $\mathrm{MeHg}$ with a variety of environmental parameters, including $\mathrm{THg}$ in periphyton, $\mathrm{THg}$ in water and periphyton, $\mathrm{DO}, \mathrm{pH}$, Temperature, water depth, sulfate, $\mathrm{H}_{2} \mathrm{~S}$, Turbidity, total organic matter (TOC), total phosphorus ${ }^{58}, \mathrm{NO}_{3}^{-}, \mathrm{Cl}^{-}$, ash free dry weight (AFDW) of periphyton, and chlorophyll a (Chl-a), were first investigated to identify the major factors controlling MeHg levels in periphyton. 
Periphyton $\mathrm{MeHg}$ presented a positive relation with $\mathrm{THg}$ in water and periphyton, water depth, TP, TOC and $\mathrm{SO}_{4}^{2-}, \mathrm{H}_{2} \mathrm{~S}$, and $\mathrm{Cl}^{-}$, and a negative relation with DO, $\mathrm{pH}$, Temperature, and $\mathrm{NO}_{3}^{-}(\mathrm{p}<0.05)$ (Table 4.1). The other factors had an insignificant relation with $\mathrm{MeHg}$ in periphyton.

Table 4.1. Correlation analysis and multiple regression analysis of $\mathrm{Hg}$ in mosquitofish and MeHg periphyton with environmental parameters.

\begin{tabular}{|c|c|c|c|c|c|c|}
\hline & \multicolumn{2}{|c|}{$\begin{array}{l}\text { Spearman's } \\
\text { analysis(R) }\end{array}$} & \multicolumn{4}{|c|}{ Multiple regression $(\beta)$} \\
\hline & Fish $\mathrm{Hg}$ & $\begin{array}{l}\text { Periphyton } \\
\text { MeHg }\end{array}$ & & $\begin{array}{l}\text { Fish } \\
\mathrm{Hg}\end{array}$ & $\begin{array}{c}\text { Fish Hg } \\
\text { (w/o floc) }\end{array}$ & $\begin{array}{l}\text { Periphyton } \\
\text { MeHg }\end{array}$ \\
\hline Water THg & $0.09^{*}$ & $0.16^{* *}$ & & 0.04 & 0.03 & 0.03 \\
\hline Water $\mathrm{MeHg}$ & $0.42^{* *}$ & $0.53^{*}$ & & 0.07 & 0.1 & \\
\hline Sediment $\mathrm{THg}$ & $0.11^{* *}$ & $0.48^{* *}$ & & 0.07 & 0.03 & \\
\hline $\begin{array}{c}\text { Sediment } \\
\mathrm{MeHg}\end{array}$ & 0.01 & $0.30^{* *}$ & & -0.13 & -0.15 & \\
\hline $\begin{array}{l}\text { Periphyton } \\
\text { THg }\end{array}$ & $0.35^{* *}$ & $0.39^{* *}$ & & -0.01 & 0.13 & 0.25 \\
\hline $\begin{array}{l}\text { Periphyton } \\
\text { MeHg }\end{array}$ & $0.44^{* *}$ & -- & & 0.32 & 0.52 & \\
\hline Floc $\mathrm{THg}$ & $0.14^{*}$ & $0.17^{* *}$ & & -0.23 & -- & \\
\hline Floc MeHg & 0.05 & $0.26^{* *}$ & & -0.21 & -- & \\
\hline DO & 0.04 & $-0.20^{* *}$ & & & & 0.05 \\
\hline $\mathrm{pH}$ & 0.02 & $-0.27^{* * *}$ & & & & -0.1 \\
\hline $\mathrm{T}$ & 0.02 & $-0.12^{* *}$ & & & & -0.02 \\
\hline Water Depth & 0.06 & $0.22^{* *}$ & & & & 0.17 \\
\hline $\mathrm{SO}_{4}^{2-}$ & 0.03 & $0.24^{* * *}$ & & & & -0.33 \\
\hline $\mathrm{H}_{2} \mathrm{~S}$ & $0.35^{* *}$ & $0.20^{* *}$ & & & & -0.25 \\
\hline Turbidity & 0.06 & $0.15^{* *}$ & & & & -0.1 \\
\hline TOC & -0.02 & $0.36^{* *}$ & & & & 0.42 \\
\hline TP & 0.04 & $0.30^{* * *}$ & & & & 0.22 \\
\hline SRP & $-0.29^{* *}$ & 0.05 & & & & \\
\hline $\mathrm{NO}_{3}^{-}-\mathrm{N}$ & $-0.12^{*}$ & $-0.14^{*}$ & & & & 0.01 \\
\hline Chloride & 0.09 & $0.17^{* *}$ & & & & 0.04 \\
\hline AFDW & 0.08 & 0.01 & & & & \\
\hline Chl-a & $-0.21^{* *}$ & 0.1 & & & & \\
\hline & & & $\mathrm{r}^{2}$ & 0.13 & 0.37 & \\
\hline & & & $p$ & $<0.01$ & $<0.0001$ & \\
\hline
\end{tabular}


Several commonly used multivariate statistical analyses (PCA, CA, and multiple regression analysis) (Fig. 4.6 and Table 4.1) were then performed to estimate the relative importance of these factors in periphyton MeHg. These analyses showed that periphyton THg, TP, TOC, water depth, $\mathrm{H}_{2} \mathrm{~S}$, and $\mathrm{SO}_{4}^{2-}$ are the primary controlling factors for $\mathrm{MeHg}$ in periphyton.

For these important factors, $\mathrm{THg}$ decreased at a rate of $7.2 \%$ in dry season and $5.2 \%$ in wet season, (Fig. 4.8) in good consistence with the long-term change in mosquitofish Hg. TP concentrations were observed to decrease at a rate of $2.4 \%$ in wet season and $4.9 \%$ in dry season during this period. Sulfate in water decreased at a rate of $2.1 \%$ in dry season and $2.2 \%$ in wet season. Significant decrease was also observed on water depth. TOC presented a negligible change from 1995 to 2014, indicating that it may not be the reason of decrease in mosquitofish $\mathrm{Hg}$ during this period.

As the precursor of $\mathrm{Hg}$ methylation, the decrease in periphyton $\mathrm{THg}$ and sulfate is expected to inhibit the methylation of $\mathrm{Hg}$ in the periphyton, resulting in the decrease in periphyton MeHg. This was partially proved by the decrease in $\mathrm{H}_{2} \mathrm{~S}$ in surface water, which is the product of sulfate reduction. The decrease in TP is expected to change both the biomass and microbial community of periphyton, which may subsequently affect the uptake of inorganic $\mathrm{Hg}$ and production of methylmercury by periphyton. Water depth is another important parameter that would affect the periphyton as well as the ecosystem.

Comprehensive Everglades Restoration Plan (CERP), the largest environmental restoration project in the world, was launched in 2000. This project has changed and is changing the topography, water chemistry, and ecosystem of the Everglades. ${ }^{162}$ 

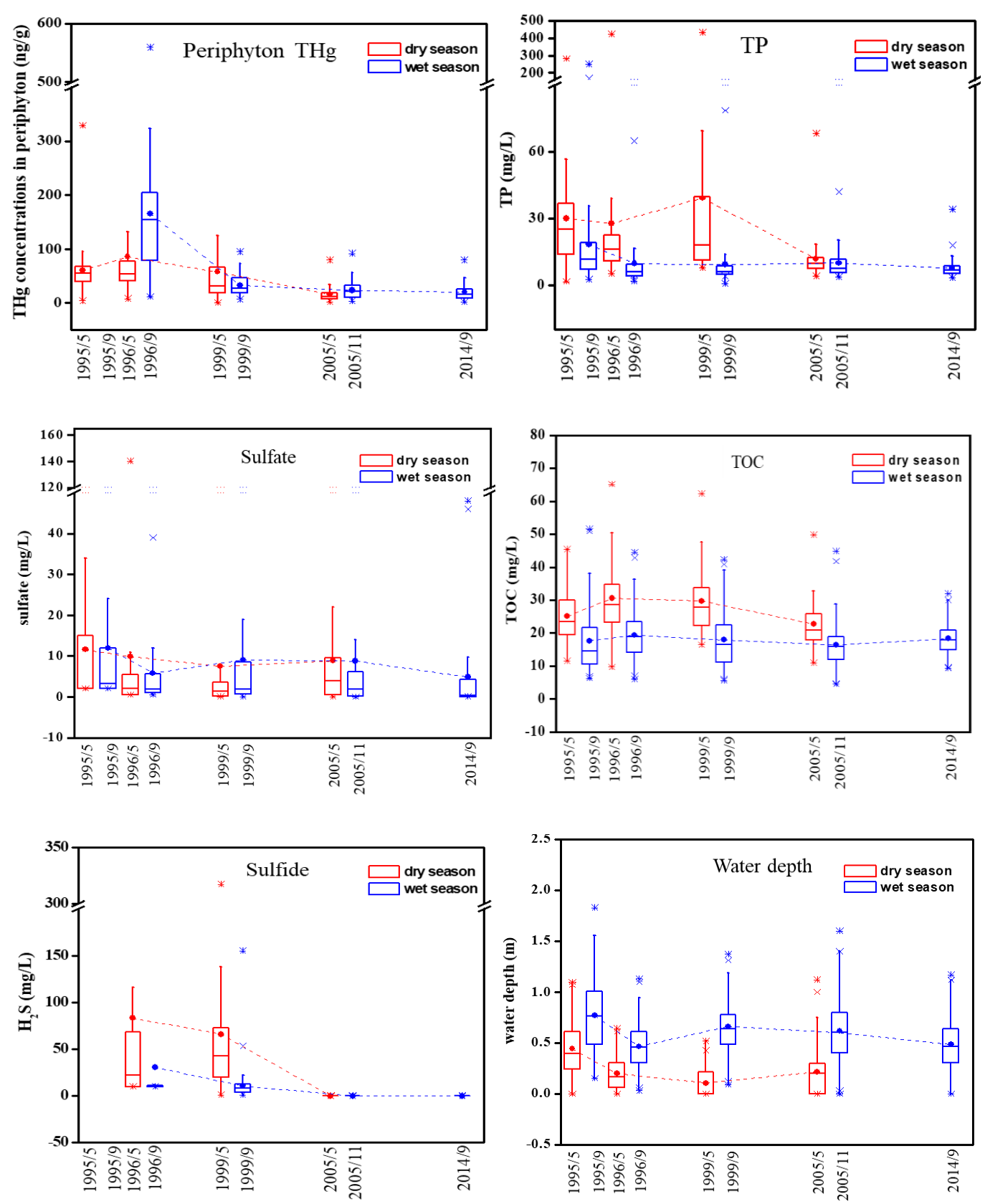

Figure 4.8. Long-term variation in Everglades periphyton THg, and TP, $\mathrm{SO}_{4}^{2-}$, TOC, $\mathrm{H}_{2} \mathrm{~S}$, water depth in Everglades water from 1995-2014 (EPA-REMAP data).

A variety of measures have been implemented in the northern farming area, reducing the discharge of phosphorus and sulfate into the Everglades. As a major biological 
nutrient for both plant and microorganisms, the decrease in TP would result in the change in periphyton biomass and periphyton composition and microbial structure in periphyton, which may further result in the decrease in $\mathrm{THg}$ uptake and $\mathrm{MeHg}$ production in periphyton. Sulfate is the necessary reactant for $\mathrm{Hg}$ methylation by SRB, the decrease in sulfate may affect the SRB in the periphyton. Hydrologic condition is another important factor for periphyton biomass and composition. The continuing getting drying since 1995 is expected to change periphyton significantly during this period. These changes in periphyton by ecosystem alteration could then affect the production of $\mathrm{MeHg}$ in periphyton, resulting in the decline in mosquitofish $\mathrm{Hg}$. It should be noted that the changes in periphyton, hydrologic condition, and environmental factors may also have significant influence on mosquitofish biomass. The biomass of mosquitofish as well as small fishes has been observed to significantly decrease from 1995 to 2014 (Joel Drexler, unpublished data). According to the biodilution theory, $\mathrm{Hg}$ in mosquitofish is expected to decrease accordingly. This suggests that the change in mosquitofish biomass should not be the dominant reason of the dramatic drop in mosquitofish $\mathrm{Hg}$.

\subsection{Conclusions}

In this study, a clear decreasing trend was observed on mosquitofish $\mathrm{Hg}$, implying a possible turning-good pattern for $\mathrm{Hg}$ problem in the Everglades. Periphyton was found to possibly play a dominant role in controlling $\mathrm{Hg}$ in mosquitofish by affecting the production of $\mathrm{MeHg}$. The results of statistical analyses performed on the data of $\mathrm{MeHg}$ in different matrices and environmental parameters supported the hypothesis. Besides, no clearly trend of $\mathrm{Hg}$ level in large fish at high trophic level was observed in this study. The observation was considered being related to the difficulty of sampling, which leads to the 
sampling on limited number of sites then further results in large errors for data analyzing the trend of $\mathrm{Hg}$ in large fish. In addition, the lag-effect caused by the relative long life of large fish may also contribute to the errors occurred in trend analysis. By performing the study, data from various databases were intergraded and the factors affecting $\mathrm{Hg}$ in fish were studied. However, as mosquitofish only account for part of small fish in the Everglades, there is a need to monitor the variation of other small fishes in the Everglades. In addition, efforts should be made on monitoring long-term variation in large fish $\mathrm{Hg}$ at sufficient sites for the purpose of a more accurate assessment of $\mathrm{Hg}$ in fish in the Everglades. 
Chapter 5. Summary and Future work 


\subsection{Summary}

In the study $\mathrm{MeHg}$ in rice cereal part, considerable levels of $\mathrm{MeHg}$ and $\mathrm{THg}$ were found in the studied infant cereal samples including commonly available cereals in the market of 8 major cities in US and China. The concentrations of $\mathrm{MeHg}$ in rice-based infant cereals were significantly higher than those in cereals containing no rice, suggesting that the source of $\mathrm{MeHg}$ in infant cereals could be the rice used to make cereals. The estimated daily intake of $\mathrm{MeHg}$ for infants through diet (including rice cereals and breast milk) could exceed or be close to RfD set by USEPA, but further studies are required for more precisely evaluate the effects of postnatal diet $\mathrm{MeHg}$ exposure during infancy and childhood. The results provide an important data towards the understanding and assessment of $\mathrm{MeHg}$ exposure and health risks caused by consumption of rice products for infants.

The results of bioaccessibility study indicated the amount of $\mathrm{MeHg}$ can be released from food matrix into gastrointestinal track was underestimated. After taking the portion of re-adsorbed $\mathrm{MeHg}$ into account, the bioaccessibility of $\mathrm{MeHg}$ in all measured rice cereal and fish samples were close to $100 \%$ instead of mean value approximately $50 \%$ reported by previous studies. Therefore, the assessment of potential health risk caused by $\mathrm{MeHg}$ exposure through fish and rice product consumption could be influenced by using underestimated data while calculating the daily intake of $\mathrm{MeHg}$ through diet. In addition, the presence of enzyme, as well as $\mathrm{MeHg}$ speciation in digested samples also have been proven to be related to the measured $\mathrm{MeHg}$ bioaccessibility, which also provided valuable data for a further study on the factors affecting $\mathrm{MeHg}$ bioaccessibility. 
In Chapter 4, Hg decline was observed in mosquitofish, while the similar trend has not been clearly observed for $\mathrm{Hg}$ in fish at high tropic level. The low frequency of sampling or the lagged response of fish at high trophic level to $\mathrm{Hg}$ variation in prey fish were proposed as the possible reason of the observation. Beyond that, by performing the statistical analysis on the data obtained during the last two decades, periphyton was found to possibly play a dominant role in controlling $\mathrm{Hg}$ in mosquitofish by affecting the production of MeHg in this study. However, it is obvious that data collected at more sites and higher frequency are still needed for a more accurate evaluation of importance of $\mathrm{Hg}$ in periphyton on $\mathrm{Hg}$ control in Everglades water.

\subsection{Future work}

In the second and third part of this dissertation, the concentrations of $\mathrm{MeHg}$ in ricebase infant cereals were determined and then the daily intake of MeHg through the consumption of rice-base infant cereals for babies was estimated. In addition, the bioaccessibility of MeHg in rice-base infant cereals was investigated to better estimate the risk of exposure to MeHg via food consumption. However, this assessment is on the basis of the assumption that all solubilized $\mathrm{MeHg}$ can eventually be absorbed, which could overestimate the risk. In future work, the absorption efficiency of bioaccessible $\mathrm{MeHg}$ should be determined to refine the results. In this study, we found that $\mathrm{MeHg}$ bioaccessibility in both rice and fish depended on the speciation of MeHg. However, due to the lack of a sufficient analyzing method, the speciation of $\mathrm{MeHg}$ in food samples was not determined, limiting our understanding on the speciation of $\mathrm{MeHg}$ bioaccessible and the transformation of $\mathrm{MeHg}$ species during cooking and digestion. MeHg speciation in raw fish and rice samples as well as in cooked and digested samples should be 
determined in future work to better understand the bioaccessibility and transformations of MeHg in foods.

For study on fish $\mathrm{Hg}$ variation in the Everglades, a clear decreasing trend was observed on mosquitofish $\mathrm{Hg}$, implying a possible turning-good pattern for $\mathrm{Hg}$ problem in the Everglades. However, similar trend has not been clearly observed for $\mathrm{Hg}$ in large fish and predators at high tropic level, e.g., largemouth bass, wading bird, etc. These inconsistent results could be due to several reasons. Firstly, duet to the difficulty of sampling, it is a big challenge to get sufficient large fish samples at a large number of sites, which is expected to result in large errors for analyzing the trend of $\mathrm{Hg}$ in large fish. Secondly, small fish are expected to response much quicker to ecosystem alteration in comparison to large fish due to their short generation time. Thus, there may be a lageffect for large fish. Efforts should be made on monitoring long-term variation in large fish $\mathrm{Hg}$ at sufficient sites in the Everglades. Besides, only mosquitofish $\mathrm{Hg}$ (as an indicator of small fishes) were monitored in previously performed EPA-REMAP project. As mosquitofish only account for part of small fish in the Everglades, there is a need to monitor the variation of other small fishes in the Everglades. As a system with a small quantity of local anthropogenic discharge of $\mathrm{Hg}$, it is almost an unrealistic mission to largely decrease the discharge of $\mathrm{Hg}$ into the Everglades at the near future. However, there is an urgent need to reduce Hg levels in Everglades fish for both the ecosystem and human health. This study indicates that ecosystem alteration could be an effective measure to conquer the problem of $\mathrm{Hg}$ pollution in the Everglades. However, it should be noted that this should be on the basis of clearly understanding the major processes of MeHg cycling in the Everglades (methylation/demethylation, benthic layer-water and 
periphyton-water diffusion fluxes, bioaccumulation, etc.). Otherwise, it will be impossible to sufficiently evaluate the effectiveness of implemented measures. More work should be performed on this field in future for the purpose of resolving the $\mathrm{Hg}$ problem in the Everglades as well as the other similar systems. 


\section{References}

(1) Morel, F. M.; Kraepiel, A. M.; Amyot, M., The chemical cycle and bioaccumulation of mercury. Annual Review of Ecology and Systematics 1998, 543-566.

(2) Pirrone, N.; Cinnirella, S.; Feng, X.; Finkelman, R.; Friedli, H.; Leaner, J.; Mason, R.; Mukherjee, A.; Stracher, G.; Streets, D., Global mercury emissions to the atmosphere from anthropogenic and natural sources. Atmospheric Chemistry and Physics 2010, 10, (13), 5951-5964.

(3) Pacyna, J. M.; Travnikov, O.; De Simone, F.; Hedgecock, I. M.; Sundseth, K.; Pacyna, E. G.; Steenhuisen, F.; Pirrone, N.; Munthe, J.; Kindbom, K., Current and future levels of mercury atmospheric pollution on a global scale. Atmospheric Chemistry and Physics 2016, 16, (19), 12495.

(4) Nriagu, J., The Biogeochemistry of mercury in the environment Elsevier/North Holland Biomedical Press: New York, 1979; p 696.

(5) Fitzgerald, W. F.; Lamborg, C. H.; Hammerschmidt, C. R., Marine biogeochemical cycling of mercury. Chemical Reviews 2007, 107, (2), 641-662.

(6) Pirrone, N.; Mason, R. P., Mercury fate and transport in the global atmosphere: Emissions, measurements and models. Springer: 2009.

(7) Fitzgerald, W. F.; Engstrom, D. R.; Lamborg, C. H.; Tseng, C. M.; Balcom, P. H.; Hammerschmidt, C. R., Modern and historic atmospheric mercury fluxes in northern Alaska: Global sources and arctic depletion. Environmental Science \& Technology 2005, $39,(2), 557-568$.

(8) Ebinghaus, R.; Jennings, S. G.; Schroeder, W. H.; Berg, T.; Donaghy, T.; Guentzel, J.; Kenny, C.; Kock, H. H.; Kvietkus, K.; Landing, W., International field intercomparison measurements of atmospheric mercury species at Mace Head, Ireland. Atmospheric Environment 1999, 33, (18), 3063-3073.

(9) Litman, R.; Williams, E. T.; Finston, H. L., Extraction of mercury by dithizone and stability of the extracted complex. Analytical Chemistry 1977, 49, (7), 983-987. 
(10) Ullrich, S. M.; Tanton, T. W.; Abdrashitova, S. A., Mercury in the aquatic environment: a review of factors affecting methylation. Critical Reviews in Environmental Science and Technology 2001, 31, (3), 241-293.

(11) Leermakers, M.; Baeyens, W.; Quevauviller, P.; Horvat, M., Mercury in environmental samples: Speciation, artifacts and validation. TrAC Trends in Analytical Chemistry 2005, 24, (5), 383-393.

(12) Liu, G.; Cai, Y.; O'driscoll, N.; Feng, Z.; Jiang, G., Overview of mercury in the environment. Environmental Chemistry and Toxicology of Mercury 2012, 1-12.

(13) UNEP Global mercury assessment; 2002.

(14) Krabbenhoft, D. P.; Wiener, J. G.; Brumbaugh, W. G.; Olson, M. L.; DeWild, J. F.; Sabin, T. J. In A national pilot study of mercury contamination of aquatic ecosystems along multiple gradients, US Geological Survey Toxic Substances Hydrology Program: Proceedings of the Technical Meeting, Charleston, South Carolina, March 8, 1999, pp $147-160$.

(15) Cai, Y.; Jaffé, R.; Jones, R., Ethylmercury in the soils and sediments of the Florida Everglades. Environmental Science \& Technology 1996, 31, (1), 302-305.

(16) Clarkson, T. W., The toxicology of mercury. Critical Reviews in Clinical Laboratory Sciences 1997, 34, (4), 369-403.

(17) Sweet, L. I.; Zelikoff, J. T., Toxicology and immunotoxicology of mercury: A comparative review in fish and humans. Journal of Toxicology and Environmental Health Part B: Critical Reviews 2001, 4, (2), 161-205.

(18) Tchounwou, P. B.; Ayensu, W. K.; Ninashvili, N.; Sutton, D., Review: Environmental exposure to mercury and its toxicopathologic implications for public health. Environmental Toxicology 2003, 18, (3), 149-175.

(19) Mergler, D.; Anderson, H. A.; Chan, L. H. M.; Mahaffey, K. R.; Murray, M.; Sakamoto, M.; Stern, A. H., Methylmercury exposure and health effects in humans: A worldwide concern. AMBIO: A Journal of the Human Environment 2007, 36, (1), 3-11. 
(20) Myers, G. J.; Davidson, P. W.; Cox, C.; Shamlaye, C. F.; Palumbo, D.; Cernichiari, E.; Sloane-Reeves, J.; Wilding, G. E.; Kost, J.; Huang, L.-S., Prenatal methylmercury exposure from ocean fish consumption in the Seychelles child development study. The Lancet 2003, 361, (9370), 1686-1692.

(21) Rustam, H.; Hamdi, T., Methyl mercury poisoning in Iraq a neurological study. Brain 1974, 97, (1), 499-510.

(22) Clarkson, T. W.; Amin-Zaki, L.; Al-Tikriti, S., An outbreak of methylmercury poisoning due to consumption of contaminated grain. Federation Proceedings 1976, 35, (12), 2395-2399.

(23) De Lacerda, L. D.; Salomons, W., Mercury from gold and silver mining: A chemical time bomb? Springer Science \& Business Media: 2012.

(24) Ekino, S.; Susa, M.; Ninomiya, T.; Imamura, K.; Kitamura, T., Minamata disease revisited: An update on the acute and chronic manifestations of methyl mercury poisoning. Journal of the Neurological Sciences 2007, 262, (1), 131-144.

(25) Kurland, T.; Faro, S. N.; Siedler, H., Minamata disease. The outbreak of a neurologic disorder in Minamata, Japan, and its relationship to the ingestion of seafood contaminated by mercuric compounds. World Neurology 1960, 1, (5), 370-95.

(26) Harada, M., Congenital Minamata disease: Intrauterine methylmercury poisoning. Teratology 1978, 18, (2), 285-288.

(27) Harada, M., Minamata disease: Methylmercury poisoning in Japan caused by environmental pollution. Critical Reviews in Toxicology 1995, 25, (1), 1-24.

(28) Salonen, J. T.; Seppänen, K.; Nyyssönen, K.; Korpela, H.; Kauhanen, J.; Kantola, M.; Tuomilehto, J.; Esterbauer, H.; Tatzber, F.; Salonen, R., Intake of mercury from fish, lipid peroxidation, and the risk of myocardial infarction and coronary, cardiovascular, and any death in eastern Finnish men. Circulation 1995, 91, (3), 645-655.

(29) USEPA Mercury study report to congress; Office of Air Quality Planning and Standards and Office of Research and Development, U.S. Environmental Protection Agency: 1997. 
(30) Clarkson, T.; Cox, C.; Davidson, P. W.; Myers, G. J., Mercury in fish. Science 1998, $279,(5350), 459-459$.

(31) WHO Mercury: Environmental aspects; 1989.

(32) USEPA How people are exposed to mercury. http://www.epa.gov/mercury/howpeople-are-exposed-mercury (1 March, 2016),

(33) USFDA Mercury levels in commercial fish and shellfish (1990-2012). https://www.fda.gov/food/foodborneillnesscontaminants/metals/ucm115644.htm (December 14, 2016),

(34) Malm, O., Gold mining as a source of mercury exposure in the Brazilian Amazon. Environmental Research 1998, 77, (2), 73-78.

(35) Cai, Y.; Bayona, J. M., Determination of methylmercury in fish and river water samples using in situ sodium tetraethylborate derivatization following by solid-phase microextraction and gas chromatography-mass spectrometry. Journal of Chromatography A 1995, 696, (1), 113-122.

(36) Cai, Y.; Rooker, J. R.; Gill, G. A.; Turner, J. P., Bioaccumulation of mercury in pelagic fishes from the northern Gulf of Mexico. Canadian Journal of Fisheries and Aquatic Sciences 2007, 64, (3), 458-469.

(37) Rudd, J.; Furutani, A.; Turner, M. A., Mercury methylation by fish intestinal contents. Applied and Environmental Microbiology 1980, 40, (4), 777-782.

(38) Gerbersmann, C.; Heisterkamp, M.; Adams, F. C.; Broekaert, J. C., Two methods for the speciation analysis of mercury in fish involving microwave-assisted digestion and gas chromatography-atomic emission spectrometry. Analytica Chimica Acta 1997, 350, (3), 273-285.

(39) Mahaffey, K. R.; Mergler, D., Blood levels of total and organic mercury in residents of the upper St. Lawrence River basin, Quebec: Association with age, gender, and fish consumption. Environmental Research 1998, 77, (2), 104-114. 
(40) Birke, G.; Johnels, A. G.; Plantin, L.-O.; Sjöstrand, B.; Skerfving, S.; Westermark, T., Studies on humans exposed to methyl mercury through fish consumption. Archives of Environmental Health: An International Journal 1972, 25, (2), 77-91.

(41) Renzoni, A.; Zino, F.; Franchi, E., Mercury levels along the food chain and risk for exposed populations. Environmental Research 1998, 77, (2), 68-72.

(42) Nakagawa, R.; Yumita, Y.; Hiromoto, M., Total mercury intake from fish and shellfish by Japanese people. Chemosphere 1997, 35, (12), 2909-2913.

(43) USEPA Reference dose for methylmercury 00-27781; 2000; pp 64702-64703.

(44) UNEP Global Mercury Assessment; United Nations Environment Programme Chemicals Branch: Geneva, 2002.

(45) Selin, N. E., Global biogeochemical cycling of mercury: A review. Annual review of environment and resources 2009, 34, (1), 43-63.

(46) Skyllberg, U., Distribution of mercury, methyl mercury and organic sulphur species in soil, soil solution and stream of a boreal forest catchment. Biogeochemistry 2003, 64, (1), 53-76.

(47) Rothenberg, S. E.; Mgutshini, N. L.; Bizimis, M.; Johnson-Beebout, S. E.; Ramanantsoanirina, A., Retrospective study of methylmercury and other metal (loid) $s$ in Madagascar unpolished rice (Oryza sativa L.). Environmental Pollution 2015, 196, 125133.

(48) Zhang, H.; Feng, X.; Larssen, T.; Qiu, G.; Vogt, R. D., In inland China, rice, rather than fish, is the major pathway for methylmercury exposure. Environmental Health Perspectives 2010, 118, (9), 1183 .

(49) Meng; Li, B.; Shao, J.-j.; Wang, T.; He, B.; Shi, J.-b.; Ye, Z.-h.; Jiang, G.-b., Accumulation of total mercury and methylmercury in rice plants collected from different mining areas in China. Environmental Pollution 2014, 184, 179-186.

(50) Meng; Feng, X.; Qiu, G.; Anderson, C. W.; Wang, J.; Zhao, L., Localization and speciation of mercury in brown rice with implications for pan-asian public health. Environmental Science \& Technology 2014, 48, (14), 7974-7981. 
(51) Li, P.; Feng, X.; Yuan, X.; Chan, H. M.; Qiu, G.; Sun, G.-X.; Zhu, Y.-G., Rice consumption contributes to low level methylmercury exposure in southern China. Environment International 2012, 49, 18-23.

(52) Rothenberg, S. E.; Windham-Myers, L.; Creswell, J. E., Rice methylmercury exposure and mitigation: A comprehensive review. Environmental Research 2014, 133, 407-423.

(53) Xu, X.; McGrath, S.; Meharg, A.; Zhao, F., Growing rice aerobically markedly decreases arsenic accumulation. Environmental Science \& Technology 2008, 42, (15), 5574-5579.

(54) Zhang, H.; Feng, X.; Larssen, T.; Shang, L.; Li, P., Bioaccumulation of methylmercury versus inorganic mercury in rice (Oryza sativa L.) grain. Environmental Science \& Technology 2010, 44, (12), 4499-4504.

(55) Krisnayanti, B. D.; Anderson, C. W.; Utomo, W. H.; Feng, X.; Handayanto, E.; Mudarisna, N.; Ikram, H., Assessment of environmental mercury discharge at a four-yearold artisanal gold mining area on Lombok Island, Indonesia. Journal of Environmental Monitoring 2012, 14, (10), 2598-2607.

(56) Windham-Myers, L.; Marvin-DiPasquale, M.; Kakouros, E.; Agee, J. L.; Kieu, L. H.; Stricker, C. A.; Fleck, J. A.; Ackerman, J. T., Mercury cycling in agricultural and managed wetlands of California, USA: Seasonal influences of vegetation on mercury methylation, storage, and transport. Science of the Total Environment 2014, 484, 308-318.

(57) Meng, B.; Feng, X.; Qiu, G.; Liang, P.; Li, P.; Chen, C.; Shang, L., The process of methylmercury accumulation in rice (Oryza sativa L.). Environmental Science \& Technology 2011, 45, (7), 2711-2717.

(58) Bouman, B.; Barker, R.; Humphreys, E.; Tuong, T.; Atlin, G.; Bennett, J.; Dawe, D.; Dittert, K.; Dobermann, A.; Facon, T. Rice: Feeding the billions; International Water Management Institute: 2007.

(59) Miller, M. D.; Marty, M. A.; Arcus, A.; Brown, J.; Morry, D.; Sandy, M., Differences between children and adults: Implications for risk assessment at California EPA. International Journal of Toxicology 2002, 21, (5), 403-418. 
(60) Bose-O'Reilly, S.; McCarty, K. M.; Steckling, N.; Lettmeier, B., Mercury exposure and children's health. Current Problems in Pediatric and Adolescent Health Care 2010, $40,(8), 186-215$.

(61) Gilbert, S. G.; Grant-Webster, K. S., Neurobehavioral effects of developmental methylmercury exposure. Environmental Health Perspectives 1995, 103, (Suppl 6), 135.

(62) Sakamoto, M.; Yasutake, A.; Domingo, J. L.; Chan, H. M.; Kubota, M.; Murata, K., Relationships between trace element concentrations in chorionic tissue of placenta and umbilical cord tissue: Potential use as indicators for prenatal exposure. Environment International 2013, 60, 106-111.

(63) Iwai-Shimada, M.; Satoh, H.; Nakai, K.; Tatsuta, N.; Murata, K.; Akagi, H., Methylmercury in the breast milk of Japanese mothers and lactational exposure of their infants. Chemosphere 2015, 126, 67-72.

(64) Miklavčič, A.; Cuderman, P.; Mazej, D.; Tratnik, J. S.; Krsnik, M.; Planinšek, P.; Osredkar, J.; Horvat, M., Biomarkers of low-level mercury exposure through fish consumption in pregnant and lactating Slovenian women. Environmental Research 2011, $111,(8), 1201-1207$.

(65) Valent, F.; Horvat, M.; Sofianou-Katsoulis, A.; Spiric, Z.; Mazej, D.; Little, D. A.; Prasouli, A.; Mariuz, M.; Tamburlini, G.; Nakou, S., Neurodevelopmental effects of lowlevel prenatal mercury exposure from maternal fish consumption in a Mediterranean cohort: Study rationale and design. Journal of Epidemiology 2013, 23, (2), 146-152.

(66) Grandjean, P.; Jørgensen, P. J.; Weihe, P., Human milk as a source of methylmercury exposure in infants. Environmental Health Perspectives 1994, 102, (1), 74.

(67) Sakamoto, M.; Kubota, M.; Matsumoto, S.-i.; Nakano, A.; Akagi, H., Declining risk of methylmercury exposure to infants during lactation. Environmental Research 2002, 90, (3), 185-189.

(68) Mania, M.; Wojciechowska-Mazurek, M.; Starska, K.; Rebeniak, M.; Szynal, T.; Strzelecka, A.; Postupolski, J., Toxic elements in commercial infant food, estimated dietary intake, and risk assessment in Poland. Polish Journal of Environmental Studies 2015, 24, (6). 
(69) Martins, C.; Vasco, E.; Paixão, E.; Alvito, P., Total mercury in infant food, occurrence and exposure assessment in Portugal. Food Additives \& Contaminants: Part B 2013, 6, (3), 151-157.

(70) Hernández-Martínez, R.; Navarro-Blasco, I., Survey of total mercury and arsenic content in infant cereals marketed in Spain and estimated dietary intake. Food Control 2013, 30, (2), 423-432.

(71) Kadan, R.; Robinson, M.; Thibodeaux, D.; Pepperman, A., Texture and other physicochemical properties of whole rice bread. Journal of Food Science 2001, 66, (7), 940-944.

(72) Poole, J. A.; Barriga, K.; Leung, D. Y.; Hoffman, M.; Eisenbarth, G. S.; Rewers, M.; Norris, J. M., Timing of initial exposure to cereal grains and the risk of wheat allergy. Pediatrics 2006, 117, (6), 2175-2182.

(73) Wachter, K., Rice cereal can wait, let them eat meat dirst AAP committee has changes in mind. Pediatric News 2009, pp 1-5.

(74) Rubio-Tapia, A.; Ludvigsson, J. F.; Brantner, T. L.; Murray, J. A.; Everhart, J. E., The prevalence of celiac disease in the United States. The American Journal of Gastroenterology 2012, 107, (10), 1538-1544.

(75) Fox, M. K.; Reidy, K.; Karwe, V.; Ziegler, P., Average portions of foods commonly eaten by infants and toddlers in the United States. Journal of the American Dietetic Association 2006, 106, (1), 66-76.

(76) Griffin, J. P., The textbook of pharmaceutical medicine. John Wiley \& Sons: 2009.

(77) Ruby, M. V.; Schoof, R.; Brattin, W.; Goldade, M.; Post, G.; Harnois, M.; Mosby, D.; Casteel, S.; Berti, W.; Carpenter, M., Advances in evaluating the oral bioavailability of inorganics in soil for use in human health risk assessment. Environmental Science \& Technology 1999, 33, (21), 3697-3705.

(78) Siedlikowski, M.; Bradley, M.; Kubow, S.; Goodrich, J. M.; Franzblau, A.; Basu, N., Bioaccessibility and bioavailability of methylmercury from seafood commonly consumed in North America: In vitro and epidemiological studies. Environmental Research 2016, $149,266-273$. 
(79) Ouédraogo, O.; Amyot, M., Effects of various cooking methods and food components on bioaccessibility of mercury from fish. Environmental Research 2011, 111, (8), 1064-1069.

(80) Laird, B. D.; Shade, C.; Gantner, N.; Chan, H. M.; Siciliano, S. D., Bioaccessibility of mercury from traditional northern country foods measured using an in vitro gastrointestinal model is independent of mercury. Science of the Total Environment 2009, 407, (23), 6003-6008.

(81) He, M.; Wang, W.-X., Factors affecting the bioaccessibility of methylmercury in several marine fish species. Journal of Agricultural and Food Chemistry 2011, 59, (13), 7155-7162.

(82) Wang, H.-S.; Xu, W.-F.; Chen, Z.-J.; Cheng, Z.; Ge, L.-C.; Man, Y.-B.; Giesy, J. P.; Du, J.; Wong, C. K.; Wong, M.-H., In vitro estimation of exposure of Hong Kong residents to mercury and methylmercury via consumption of market fishes. Journal of Hazardous Materials 2013, 248, 387-393.

(83) Maulvault, A. L.; Machado, R.; Afonso, C.; Lourenço, H. M.; Nunes, M. L.; Coelho, I.; Langerholc, T.; Marques, A., Bioaccessibility of $\mathrm{Hg}, \mathrm{Cd}$ and $\mathrm{As}$ in cooked black scabbard fish and edible crab. Food and Chemical Toxicology 2011, 49, (11), 2808-2815.

(84) Gundacker, C.; Pietschnig, B.; Wittmann, K. J.; Lischka, A.; Salzer, H.; Hohenauer, L.; Schuster, E., Lead and mercury in breast milk. Pediatrics 2002, 110, (5), 873-878.

(85) Lemes, M.; Wang, F., Methylmercury speciation in fish muscle by HPLC-ICP-MS following enzymatic hydrolysis. Journal of Analytical Atomic Spectrometry 2009, 24, (5), 663-668.

(86) Torres-Escribano, S.; Vélez, D.; Montoro, R., Mercury and methylmercury bioaccessibility in swordfish. Food Additives and Contaminants 2010, 27, (3), 327-337.

(87) Kathiresan, K.; Bingham, B. L., Biology of mangroves and mangrove ecosystems. Advances in Marine Biology 2001, 40, 81-251.

(88) Horvat, M.; Sakamoto, M.; Chan, L.; Faganeli, J., Mercury in contaminated sites: Identification, characterisation, impacts, and remediation. Environmental Research 2013, 125,1 . 
(89) Sakamoto, M.; Murata, K.; Katita, A.; Sasaki, M., A review of mercury toxicity with special reference to methylmercury. In Environmental Chemistry and Toxicology of Mercury, Liu, G.; Cai, Y.; O’driscoll, N., Eds. John Wiley \& Sons: 2012; pp 501-516.

(90) Hall, B.; Bodaly, R.; Fudge, R.; Rudd, J.; Rosenberg, D., Food as the dominant pathway of methylmercury uptake by fish. Water, Air, and Soil Pollution 1997, 100, (1-2), $13-24$

(91) Kehrig, H. d. A.; Howard, B. M.; Malm, O., Methylmercury in a predatory fish (Cichla spp.) inhabiting the Brazilian Amazon. Environmental Pollution 2008, 154, (1), 68-76.

(92) Choi, A. L.; Grandjean, P., Human health significance of dietary exposures to methylmercury. In Environmental Chemistry and Toxicology of Mercury, Liu, G.; Cai, Y.; O’driscoll, N., Eds. John Wiley \& Sons: 2012; pp 545-568.

(93) Feng, X.; Li, P.; Qiu, G.; Wang, S.; Li, G.; Shang, L.; Meng, B.; Jiang, H.; Bai, W.; $\mathrm{Li}, \mathrm{Z}$., Human exposure to methylmercury through rice intake in mercury mining areas, Guizhou Province, China. Environmental Science \& Technology 2007, 42, (1), 326-332.

(94) Windham-Myers, L.; Fleck, J. A.; Ackerman, J. T.; Marvin-DiPasquale, M.; Stricker, C. A.; Heim, W. A.; Bachand, P. A.; Eagles-Smith, C. A.; Gill, G.; Stephenson, M., Mercury cycling in agricultural and managed wetlands: A synthesis of methylmercury production, hydrologic export, and bioaccumulation from an integrated field study. Science of the Total Environment 2014, 484, 221-231.

(95) Brombach, C.-C.; Manorut, P.; Kolambage-Dona, P. P. P.; Ezzeldin, M. F.; Chen, B.; Corns, W. T.; Feldmann, J.; Krupp, E. M., Methylmercury varies more than one order of magnitude in commercial European rice. Food Chemistry 2017, 214, 360-365.

(96) Horvat, M.; Nolde, N.; Fajon, V.; Jereb, V.; Logar, M.; Lojen, S.; Jacimovic, R.; Falnoga, I.; Liya, Q.; Faganeli, J., Total mercury, methylmercury and selenium in mercury polluted areas in the province Guizhou, China. Science of the Total Environment 2003, 304, (1), 231-256.

(97) Cai, Y.; Tang, G.; Jaffe, R.; Jones, R., Evaluation of some isolation methods for organomercury determination in soil and fish samples by capillary gas chromatographyatomic fluorescence spectrometry. International Journal of Environmental Analytical Chemistry 1997, 68, (3), 331-345. 
(98) De Onis, M., WHO child growth standards: Length/height-for-age, weight-for-age, weight-for-length, weight-for-height and body mass index-for-age. World Health Organization: 2006.

(99) Charalampopoulos, D.; Wang, R.; Pandiella, S.; Webb, C., Application of cereals and cereal components in functional foods: A review. International Journal of Food Microbiology 2002, 79, (1), 131-141.

(100) Patra, M.; Sharma, A., Mercury toxicity in plants. The Botanical Review 2000, 66, (3), 379-422.

(101) Ren, J.-H.; Sun, H.-J.; Wang, S.-F.; Luo, J.; Ma, L. Q., Interactive effects of mercury and arsenic on their uptake, speciation and toxicity in rice seedling. Chemosphere 2014, 117, 737-744.

(102) Hang, X.; Gan, F.; Wang, J.; Chen, X.; Chen, Y.; Wang, H.; Zhou, J.; Du, C., Soil mercury accumulation and transference to different crop grains. Human and Ecological Risk Assessment: An International Journal 2016, 22, (5), 1242-1252.

(103) Yang, W.; ShuLai, X.; Yu, Z.; Rong, R.; FengXia, G.; FengHai, W., Development status, problems and countermeasures of the infant rice cereal in China. Journal of Food Safety and Food Quality 2014, 5, (2), 607-612.

(104) Chen, V., The evolution of the baby food industry, 2000-2008. Journal of Competition Law \& Economics 2010, 6, (2), 423-442.

(105) USEPA Exposure factors handbook: 2011 edition (final); EPA/600/R-09/052F; Washington, DC, 2011.

(106) Rice, D. C.; Schoeny, R.; Mahaffey, K., Methods and rationale for derivation of a reference dose for methylmercury by the US EPA. Risk Analysis 2003, 23, (1), 107-115.

(107) Zia, M. H.; Codling, E. E.; Scheckel, K. G.; Chaney, R. L., In vitro and in vivo approaches for the measurement of oral bioavailability of lead $(\mathrm{Pb})$ in contaminated soils: A review. Environmental Pollution 2011, 159, (10), 2320-2327. 
(108) Hashemi, R.; Young, J., The prediction of methylmercury elimination half-life in humans using animal data: A neural network/rough sets analysis. Journal of Toxicology and Environmental Health Part A 2003, 66, (23), 2227-2252.

(109) Hillman, B., Role of gut bacteria in human toxicology and pharmacology. CRC Press: 2004.

(110) Karagas, M. R.; Choi, A. L.; Oken, E.; Horvat, M.; Schoeny, R.; Kamai, E.; Cowell, W.; Grandjean, P.; Korrick, S., Evidence on the human health effects of low-level methylmercury exposure. Environmental Health Perspectives 2012, 120, (6), 799-806.

(111) Cao, Y.; Chen, A.; Jones, R. L.; Radcliffe, J.; Caldwell, K. L.; Dietrich, K. N.; Rogan, W. J., Does background postnatal methyl mercury exposure in toddlers affect cognition and behavior? NeuroToxicology 2010, 31, (1), 1-9.

(112) Burbacher, T. M.; Rodier, P. M.; Weiss, B., Methylmercury developmental neurotoxicity: A comparison of effects in humans and animals. Neurotoxicology and Teratology 1990, 12, (3), 191-202.

(113) Gilbert, S. G.; Grant-Webster, K. S., Neurobehavioral effects of developmental methylmercury exposure. Environmental Health Perspectives 1995, 103, (Suppl 6), 135142.

(114) Rice, D. C., Sensory and cognitive effects of developmental methylmercury exposure in monkeys, and a comparison to effects in rodents. NeuroToxicology 1996, 17, (1), 139-154.

(115) Rice, D. C., Age-related increase in auditory impairment in monkeys exposed in utero plus postnatally to methylmercury. Toxicological Sciences 1998, 44, (2), 191-196.

(116) National Research Council, Toxicological effects of methylmercury. National Academies Press: 2000.

(117) Counter, S. A.; Buchanan, L. H., Mercury exposure in children: A review. Toxicology and Applied Pharmacology 2004, 198, (2), 209-230. 
(118) Cheng, Z.; Wang, H.-S.; Du, J.; Sthiannopkao, S.; Xing, G.-H.; Kim, K.-W.; Yasin, M. S. M.; Hashim, J. H.; Wong, M.-H., Dietary exposure and risk assessment of mercury via total diet study in Cambodia. Chemosphere 2013, 92, (1), 143-149.

(119) Chaiwanon, P.; Puwastien, P.; Nitithamyong, A.; Sirichakwal, P. P., Calcium fortification in soybean milk and in vitro bioavailability. Journal of Food Composition and Analysis 2000, 13, (4), 319-327.

(120) Miller, D.; Berner, L., Is solubility in vitro a reliable predictor of iron bioavailability? Biological Trace Element Research 1989, 19, (1), 11-24.

(121) Rodriguez, R. R.; Basta, N. T.; Casteel, S. W.; Pace, L. W., An in vitro gastrointestinal method to estimate bioavailable arsenic in contaminated soils and solid media. Environmental Science \& Technology 1999, 33, (4), 642-649.

(122) Versantvoort, C. H.; Oomen, A. G.; Van de Kamp, E.; Rompelberg, C. J.; Sips, A. J., Applicability of an in vitro digestion model in assessing the bioaccessibility of mycotoxins from food. Food and Chemical Toxicology 2005, 43, (1), 31-40.

(123) Harris, H. H.; Pickering, I. J.; George, G. N., The chemical form of mercury in fish. Science 2003, 301, (5637), 1203-1203.

(124) Morel, F. M.; Kraepiel, A. M.; Amyot, M., The chemical cycle and bioaccumulation of mercury. Annual Review of Ecology and Systematics 1998, 29, (1), 543-566.

(125) Miller, D.; Akagi, H., pH affects mercury distribution, not methylation. Ecotoxicology and Environmental Safety 1979, 3, (1), 36-38.

(126) Juliano, B. O., Rice in human nutrition. International Rice Research Institute: 1993.

(127) Benesch, R.; Benesch, R. E., Reactions of thiols with organic mercury compounds. Archives of Biochemistry and Biophysics 1952, 38, (1), 425-441.

(128) Shim, S.-M.; Ferruzzi, M. G.; Kim, Y.-C.; Janle, E. M.; Santerre, C. R., Impact of phytochemical-rich foods on bioaccessibility of mercury from fish. Food Chemistry 2009, 112, (1), 46-50. 
(129) Hsi, H.-C.; Hsu, Y.-W.; Chang, T.-C.; Chien, L.-C., Methylmercury concentration in fish and risk-benefit assessment of fish intake among pregnant versus infertile women in Taiwan. PloS ONE 2016, 11, (5), e0155704.

(130) Carrington, C. D.; Bolger, M. P., An exposure assessment for methylmercury from seafood for consumers in the United States. Risk Analysis 2002, 22, (4), 689-699.

(131) Bradley, M. A.; Barst, B. D.; Basu, N., A review of mercury bioavailability in humans and fish. International Journal of Environmental Research and Public Health 2017, 14, (2), 169.

(132) Friedli, H., Initial estimates of mercury emissions to the atmosphere from global biomass burning. Environmental Science \& Technology 2009, 43, (10), 3507.

(133) Sigler, J. M., Emission and long-range transport of gaseous mercury from a largescale Canadian boreal forest fire. Environmental Science \& Technology 2003, 37, (19), 4343-4347.

(134) Ericksen, J. A., Accumulation of atmospheric mercury in forest foliage. Atmospheric Environment 2003, 37, (12), 1613-1622.

(135) Davis, J. A.; Ross, J. R. M.; Bezalel, S.; Sim, L.; Bonnema, A.; Ichikawa, G.; Heim, W. A.; Schiff, K.; Eagles-Smith, C. A.; Ackerman, J. T., Hg concentrations in fish from coastal waters of California and Western North America. Science of the Total Environment 2016, 568, 1146-1156.

(136) Eagles-Smith, C. A.; Ackerman, J. T.; Willacker, J. J.; Tate, M. T.; Lutz, M. A.; Fleck, J. A.; Stewart, A. R.; Wiener, J. G.; Evers, D. C.; Lepak, J. M.; Davis, J. A.; Pritz, C. F., Spatial and temporal patterns of mercury concentrations in freshwater fish across the Western United States and Canada. Science of the Total Environment 2016, 568, 1171-1184.

(137) Mohapatra, S. P.; Nikolova, I.; Mitchell, A., Managing mercury in the great lakes: An analytical review of abatement policies. Journal of Environmental Management 2007, $83,(1), 80-92$.

(138) AMAP/UNEP Global mercury modelling: Update of modelling results in the global mercury assessment 2013; Arctic monitoring and assessment programme/UNEP Chemicals Branch: Oslo, Norway/Geneva, Switzerland, 2015. 
(139) Harris, R. C.; Rudd, J. W. M.; Amyot, M.; Babiarz, C. L.; Beaty, K. G.; Blanchfield, P. J.; Bodaly, R. A.; Branfireun, B. A.; Gilmour, C. C.; Graydon, J. A.; Heyes, A.; Hintelmann, H.; Hurley, J. P.; Kelly, C. A.; Krabbenhoft, D. P.; Lindberg, S. E.; Mason, R. P.; Paterson, M. J.; Podemski, C. L.; Robinson, A.; Sandilands, K. A.; Southworth, G. R.; Louis, V. L. S.; Tate, M. T., Whole-ecosystem study shows rapid fishmercury response to changes in mercury deposition. Proceedings of the National Academy of Sciences of the United States of America 2007, 104, (42), 16586-16591.

(140) Bhavsar, S. P.; Gewurtz, S. B.; McGoldrick, D. J.; Keir, M. J.; Backus, S. M., Changes in mercury levels in Great Lakes fish between 1970s and 2007. Environmental Science \& Technology 2010, 44, (9), 3273-3279.

(141) Cross, F. A.; Evans, D. W.; Barber, R. T., Decadal declines of mercury in adult bluefish (1972-2011) from the Mid-Atlantic coast of the USA. Environmental Science \& Technology 2015, 49, (15), 9064-9072.

(142) Azim, M. E.; Kumarappah, A.; Bhavsar, S. P.; Backus, S. M.; Arhonditsis, G., Detection of the spatiotemporal trends of mercury in Lake Erie fish communities: A bayesian approach. Environmental Science \& Technology 2011, 45, (6), 2217-2226.

(143) Gandhi, N.; Tang, R. W. K.; Bhavsar, S. P.; Arhonditsis, G. B., Fish mercury levels appear to be increasing lately: A report from 40 years of monitoring in the province of Ontario, Canada. Environmental Science \& Technology 2014, 48, (10), 5404-5414.

(144) Drevnick, P. E.; Lamborg, C. H.; Horgan, M. J., Increase in mercury in Pacific yellowfin tuna. Environmental Toxicology and Chemistry 2015, 34, (4), 931-934.

(145) Wyn, B.; Kidd, K. A.; Burgess, N. M.; Curry, R. A.; Munkittrick, K. R., Increasing mercury in yellow perch at a hotspot in Atlantic Canada, Kejimkujik National Park. Environmental Science \& Technology 2010, 44, (23), 9176-9181.

(146) Brigham, M. E.; Sandheinrich, M. B.; Gay, D. A.; Maki, R. P.; Krabbenhoft, D. P.; Wiener, J. G., Lacustrine responses to decreasing wet mercury deposition rates-results from a case study in northern Minnesota. Environmental Science \& Technology 2014, 48, (11), 6115-6123.

(147) Hutcheson, M. S.; Smith, C. M.; Rose, J.; Batdorf, C.; Pancorbo, O.; West, C. R.; Strube, J.; Francis, C., Temporal and spatial trends in freshwater fish tissue mercury 
concentrations associated with mercury emissions reductions. Environmental Science \& Technology 2014, 48, (4), 2193-2202.

(148) Lucotte, M.; Paquet, S.; Moingt, M., Climate and physiography predict mercury concentrations in game fish species in Quebec lakes better than anthropogenic disturbances. Archives of Environmental Contamination and Toxicology 2016, 70, (4), 710-723.

(149) Evans, M.; Muir, D.; Brua, R. B.; Keating, J.; Wang, X. W., Mercury trends in predatory fish in great slave lake: The influence of temperature and other climate drivers. Environmental Science \& Technology 2013, 47, (22), 12793-12801.

(150) Dittman, J. A.; Driscoll, C. T., Factors influencing changes in mercury concentrations in lake water and yellow perch (Perca flavescens) in Adirondack lakes. Biogeochemistry 2009, 93, (3), 179-196.

(151) Jenkins, D. G., A critical analysis of Illinois' fish mercury monitoring program, 1974-1998. Environmental Monitoring and Assessment 2007, 131, (1-3), 177-184.

(152) Stober, Q. J.; Thornton, K.; Jones, R.; Richards, J.; Ivey, C.; Welch, R.; Madden, M.; Trexler, J.; Gaiser, E.; Scheidt, D.; Rathbun, S. South Florida ecosystem assessment: Phase I/II(technical report)-Everglades stressor interactions: Hydropatterns, eutrophication, habitat alteration, and mercury contamination; USEPA Region 4: Athens, GA, 2001.

(153) USEPA South Florida ecosystem assessment interim report; Region 4 SESD and ORD: 1996.

(154) Guentzel, J. L.; Landing, W. M.; Gill, G. A.; Pollman, C. D., Mercury and major ions in rainfall, throughfall, and foliage from the Florida Everglades. Science of the Total Environment 1998, 213, (1), 43-51.

(155) Guentzel, J.; Landing, W.; Gill, G.; Pollman, C., Atmospheric deposition of mercury in Florida: The FAMS project (1992-1994). Water, Air, and Soil Pollution 1995, $80,(1-4), 393-402$.

(156) Pollman, C.; Gill, G.; Landing, W.; Guentzel, J.; Bare, D.; Porcella, D.; Zillioux, E.; Atkeson, T., Overview of the Florida atmospheric mercury study (FAMS). Water, Air, and Soil Pollution 1995, 80, (1), 285-290. 
(157) Stober, J., D. Scheidt, R. Jones, K. Thornton, L. Gandy, D. Stevens, J. Trexler, S. Rathbun South Florida ecosystem assessment: Monitoring for ecosystem restoration. Final technical report-phase I. EPA 904-R-98-002.; Athens, Georgia, 1998.

(158) Pyke, G. H., A review of the biology of Gambusia affinis and G. holbrooki. Reviews in Fish Biology and Fisheries 2005, 15, (4), 339-365.

(159) Zhang, Y.; Jacob, D. J.; Horowitz, H. M.; Chen, L.; Amos, H. M.; Krabbenhoft, D. P.; Slemr, F.; Louis, V. L. S.; Sunderland, E. M., Observed decrease in atmospheric mercury explained by global decline in anthropogenic emissions. Proceedings of the National Academy of Sciences 2016, 113, (3), 526-531.

(160) Li, Y.; Yin, Y.; Liu, G.; Tachiev, G.; Roelant, D.; Jiang, G.; Cai, Y., Estimation of the major source and sink of methylmercury in the Florida Everglades. Environmental Science \& Technology 2012, 46, (11), 5885-5893.

(161) Sunderland, E. M.; Dalziel, J.; Heyes, A.; Branfireun, B. A.; Krabbenhoft, D. P.; Gobas, F., Response of a macrotidal estuary to changes in anthropogenic mercury loading between 1850 and 2000. Environmental Science \& Technology 2010, 44, (5), 1698-1704.

(162) Perry, W., Elements of south Florida's comprehensive Everglades restoration plan. Ecotoxicology 2004, 13, (3), 185-193. 
VITA

\title{
WENBIN CUI
}

Born, Qingdao, Shandong, China

\author{
$2006-2010$ B.S., Chemistry \\ Nanjing University of Science and Technology \\ Nanjing, Jiangsu, China \\ 2012 - 2016 Research Assistant \\ Florida International University \\ Miami, FL, USA. \\ 2016 M.S., Chemistry \\ Florida International University \\ Miami, FL, USA \\ 2015 - 2017 Doctoral. Candidate in Chemistry \\ Florida International University \\ Miami, FL, USA. \\ Teaching Assistant \\ Florida International University \\ Miami, FL, USA.
}

\section{PUBLICATIONS AND PRESENTATIONS}

Wenbin Cui, Guangliang Liu, Mayara Bezerra, et al. Occurrence of Methylmercury in Rice-base Infant Cereals and Estimation of Daily Dietary Intake of Methylmercury for Infants. (submitted)

Wenbin Cui, Michael Ojeda, Guangliang Liu, et al. Determination of Bioaccessibility of Methylmercury in Rice-based Infant Cereals using In vitro Digestion Model. (to be submitted) 
Yanbin Li, Wenbin Cui, Guangliang Liu, et al. Decadal Variations of Mercury in Mosquito Fish in the Everglades and Relation to Changes in Atmospheric Mercury Deposition and Ecosystem Alteration. (to be submitted)

Wenbin Cui, Guangliang Liu, Ping Jiang, et al. Methylmercury in Food Webs in the Everglades: Temporal Variations over the Last Two Decades. The Greater Everglades Ecosystem Restoration (GEER) Science Conference. Coral Springs, FL; April 21-23, 2015. (Poster)

Guangliang Liu, Yong Cai, Ping Jiang, Wenbin Cui. Distribution of Mercury in Ecosystem Components in the Everglades: A Mass Budget Perspective. The Greater Everglades Ecosystem Restoration (GEER) Science Conference. Coral Springs, FL; April 21-23, 2015. (Oral)

Wenbin Cui, Guangliang Liu, Yong Cai. Occurrence of Methylmercury in Rice-base Infant Cereals and Estimation of Daily Dietary Intake of Methylmercury for Infants. $92^{\text {nd }}$ Florida Annual Meeting and Exposition (FAME), Tampa, FL, May 4-6, 2016. (Poster)

Wenbin Cui, Guangliang Liu, Yong Cai. Occurrence of Methylmercury in Rice-base Infant Cereals and Estimation of Daily Dietary Intake of Methylmercury for Infants. $252^{\text {nd }}$ National ACS meeting, Philadelphia, PA, August 21-25, 2016. (Poster)

Genique Nicholas, Wenbin Cui, Yong Cai. Bioavailability of Methylmercury in Rice Cereal and Fish. Emerging Research National Conference in STEM, Washington, D.C., March 24, 2017. (Poster)

Wenbin Cui, Michael Ojeda, Guangliang Liu, et al. Determination of Methylmercury Bioaccessibility in Rice Products and Fish using In vitro Digestion Model. Florida International University Graduate Student Appreciation Week Scholarly Forum, Miami, FL, March 27-31, 2017. (Oral)

Guangliang Liu, Ping Jiang, Wenbin Cui, et al. Distribution of Mercury Species in the Everglades: A Geochemical Perspective and Implications on Mercury Bioaccumulation. The Greater Everglades Ecosystem Restoration (GEER) Science Conference. Coral Springs, FL; April 17-20, 2017. (Oral)

Guangliang Liu, Wenbin Cui, Yong Cai, et al. Methylmercury (MeHg) in Rice-based Infant Cereals. $13^{\text {th }}$ International Conference on Mercury as a Global Pollutant, Providence, RI, July 16-21, 2017. (Oral) 